\title{
Attention dysfunction and ADHD in adults : determinants and interventions
}

Citation for published version (APA):

Scholtissen-In de Braek, D. M. J. M. (2009). Attention dysfunction and ADHD in adults : determinants and interventions. [Doctoral Thesis, Maastricht University]. NeuroPsych Publishers. https://doi.org/10.26481/dis.20090917ds

Document status and date:

Published: 01/01/2009

DOI:

10.26481/dis.20090917ds

Document Version:

Publisher's PDF, also known as Version of record

\section{Please check the document version of this publication:}

- A submitted manuscript is the version of the article upon submission and before peer-review. There can be important differences between the submitted version and the official published version of record.

People interested in the research are advised to contact the author for the final version of the publication, or visit the DOI to the publisher's website.

- The final author version and the galley proof are versions of the publication after peer review.

- The final published version features the final layout of the paper including the volume, issue and page numbers.

Link to publication

\footnotetext{
General rights rights.

- You may freely distribute the URL identifying the publication in the public portal. please follow below link for the End User Agreement:

www.umlib.nl/taverne-license

Take down policy

If you believe that this document breaches copyright please contact us at:

repository@maastrichtuniversity.nl

providing details and we will investigate your claim.
}

Copyright and moral rights for the publications made accessible in the public portal are retained by the authors and/or other copyright owners and it is a condition of accessing publications that users recognise and abide by the legal requirements associated with these

- Users may download and print one copy of any publication from the public portal for the purpose of private study or research.

- You may not further distribute the material or use it for any profit-making activity or commercial gain

If the publication is distributed under the terms of Article $25 \mathrm{fa}$ of the Dutch Copyright Act, indicated by the "Taverne" license above, 


\section{Attention dysfunction and ADHD in adults}

determinants and interventions 
๑ D.M.J.M. Scholtissen-In de Braek, Maastricht 2009

LAYOUT | Anita Kaemingk, Maastricht

COVER IMAGE | painting Let's face it (2)! by Ghislaine In de Braek

PRINT | Drukkerij Gijsemberg

PUBLISHER | NeuroPsych Publishers

ISBN | 978-90-75579-40-6

NeuroPsych Publishers is a non-profit organisation, which aims at promoting the science of 'Brain and Behaviour' and improving the application of the products of this science in health care and education. NeuroPsych Publishers accomplishes these aims by publishing books, dissertations and other products of scientific activity, by disseminating educational material and publication of tests, assessment scales and other psychometric instruments in the field of Neuropsychology, Neuropsychiatry and other areas within the domain of Brain and Behaviour.

NeuroPsych Publishers, Department of Psychiatry \& Neuropsychology

Maastricht University, P.O. Box 616, NL-6200 MD Maastricht

www.np.unimaas.nl

All rights are reserved. No part of this book may be reproduced or transmitted in any form or by any means, without written permission from the author or, when appropriate, the publisher of the article. 


\section{Attention dysfunction and ADHD in adults}

determinants and interventions

\section{Proefschrift}

Ter verkrijging van de graad van doctor aan de Universiteit Maastricht, op gezag van de Rector Magnificus, Prof. mr. G. P. M. F. Mols, volgens het besluit van het College van Decanen, in het openbaar te verdedigen op donderdag 17 september 2009 om 12.00 uur

door

Dymphie Mathilde Joseph Maria Scholtissen-In de Braek Geboren op 23 september 1977 in Maastricht 
Promotor

Prof. Dr. J. Jolles

\section{Copromotor}

Dr. J. Dijkstra

\section{Beoordelingscommissie}

Prof. Dr. F. R. J. Verhey (voorzitter)

Dr. M. Jelicic

Prof. Dr. H. Merkelbach

Prof. Dr. J. Oosterlaan (VU Amsterdam)

Prof. Dr. H. Swaab-Barneveld (Universiteit Leiden)

The research presented in this thesis was performed at Mondriaan Zorg Groep, location Maastricht (Vijverdal), MHenS and the Department of Psychiatry \& Psychology, Maastricht University. 


\section{Contents}

$\begin{array}{lll}\text { Chapter } 1 & \text { Introduction } & 9\end{array}$

Chapter 2 Attention complaints in the general population:

the identification and effect on Quality of Life $\quad 21$

Chapter 3 Characteristics of Attention-Deficit/Hyperactivity Disorder (ADHD) in healthy adults are related to depression, anxiety and reduced Quality of Life: results in 912 subjects from the Maastricht Aging Study (MAAS)

Chapter 4 The role of the clinical neuropsychologist in Attention-Deficit/ Hyperactivity Disorder (ADHD) in adults: an overview

Chapter 5 Cognitive complaints and neuropsychological functioning in adults with and without Attention-Deficit/Hyperactivity Disorder (ADHD) referred for multidisciplinary assessment

Chapter 6 Diagnostic assessment of adults with Attention-Deficit/ Hyperactivity Disorder (ADHD): the role of childhood factors

Chapter 7 Goal Management Training in adults with Attention-Deficit/ Hyperactivity Disorder (ADHD): an intervention study

Chapter 8 Concluding Remarks

Summary

Samenvatting

Dankwoord

Curriculum Vitae 



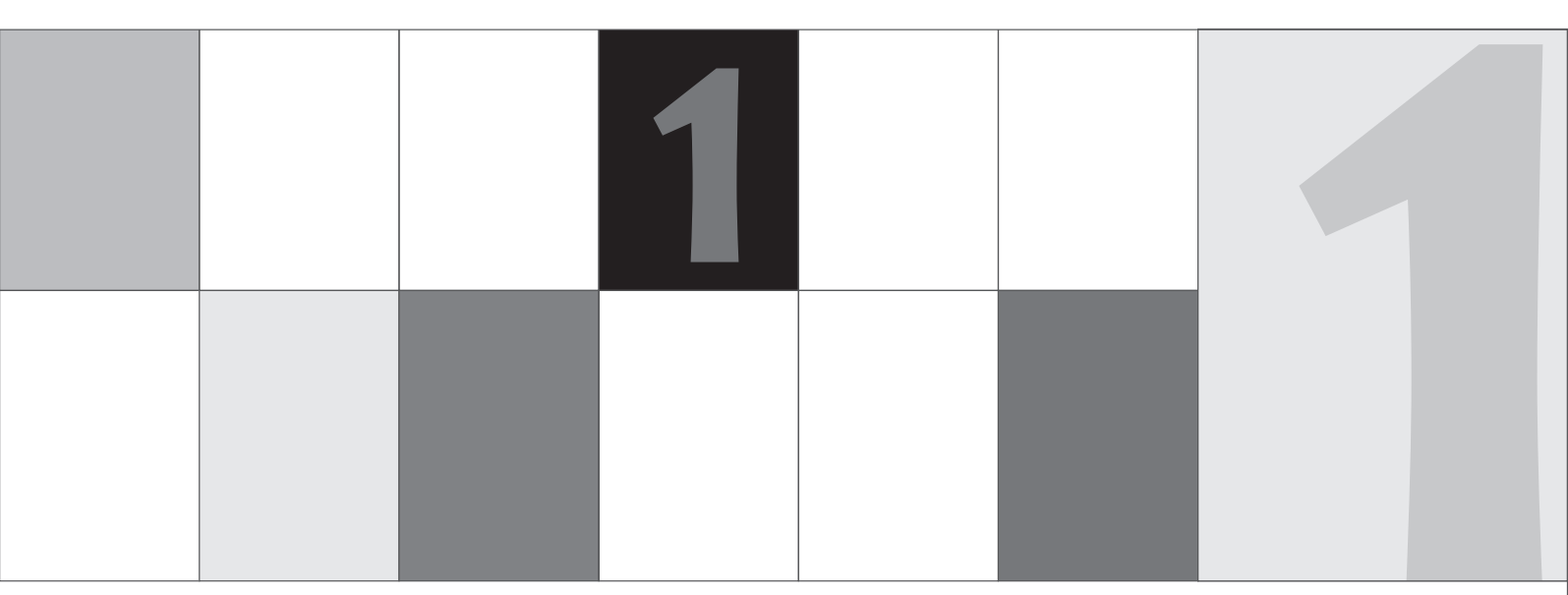





\section{Chapter One}

\section{Introduction}

Attention problems are more prevalent than has been recognized ten to fifteen years ago, especially in adults. Dysfunction in the domain of attention in children and adolescents had been noted and described in terms of AttentionDeficit/Hyperactivity Disorder (ADHD). During the past decades, there has been increasing evidence that ADHD can persistent into adulthood. Until then, it was thought that 'the child with ADHD' would grow over its cognitive and/or learning difficulties. However, symptoms of ADHD, such as inattentiveness, restlessness and impulsivity, often persist into adolescence and adulthood. Estimations of the prevalence of ADHD in adults vary from approximately $1 \%$ to $4.4 \%$ of adults all over the world (Faraone \& Biederman, 2005; Kessler et al., 2006; Kooij et al., 2005). ADHD symptoms can have serious consequences for education, occupational outcome, and relationships (Barkley, 2002). In addition, adults with ADHD typically have poorer academic results, more occupational difficulties and lower self-esteem (Faraone et al., 2000).

Apart from adult ADHD, subjective attentional problems as well as objective attentional impairments are also frequently found in several clinical samples, like Parkinson's Disease (PD), Fibromyalgia, Mild Cognitive Impairment (MCl) and Chronic Fatigue (CF) (Bronnick et al., 2006; Leavitt \& Katz, 2006; Ribeiro, de Mendonca, \& Guerreiro, 2006). Since prevalence figures show that approximately one in five people in the Dutch population will suffer from one of these disorders during their lifetime, the problem of attention disorders requires more consideration (Hersenstichting Nederland, 2002).

Attention dysfunction has serious consequences for the individual and society in general. Evidently, clear and early assessment of attention dysfunction in adulthood is imperative in order to develop more tools and adequate treatment programmes for these adults. Research into the frequency and consequences of attention problems in the general as well as clinical adult population, more specifically in ADHD, is therefore essential. Our current research was intended to contribute knowledge of the consequences of attentional problems in general and to gain insight into the clinical picture of adults with ADHD. Before describing the aims of this study and the ones that have been conducted before, some background information is presented below. 


\section{Background}

\section{Attention complaints in general}

Relatively little research has been carried out on attentional complaints within a general population. There are indications that healthy persons have complaints regarding cognitive functions which, upon consideration, are more accurately classified as belonging to the domain of attentional problems. They complain, for instance, about problems with multitasking and various studies also indicate that they are easily distracted during the performance of such tasks (Andres \& Fernandes, 2006; Melzer \& Oddsson, 2004). Moreover, attentional problems and attention deficits may underlie many of the cognitive failures of every day life (Broadbent, Cooper, FitzGerald, \& Parkes, 1982; Pollina, Greene, Tunick, \& Puckett, 1992). Even in healthy young adults, distraction may underlie many of the slips of action commonly encountered in everyday life (Pollina, Greene, Tunick, \& Puckett, 1992). Attention problems can be temporary and caused by factors like fatigue, sleep problems, illness, pain or depression (Burdick et al., 2009; Dickson, Toft, \& O'Carroll, 2009; Sharpe, Dear, \& Schrieber, 2009). On the other hand, there seems to be variation in attention capacities among individuals. This would suggest also a trait-vulnerability for attention problems. However, in current scientific literature, this idea has not been investigated yet.

Everybody has trouble with concentrating sometimes. This is probably also the reason that attention problems are considered to be normal. It is hard to distinguish between normal attention difficulties and 'a disorder', like ADHD. The difference is that persons with ADHD are always confronted with their attention problems in many settings. In the case of ADHD, one speaks of serious dysfunction.

\section{Attention Deficit-Hyperactivity Disorder (ADHD) in adults}

As said earlier, ADHD refers to a complex highly prevalent neurodevelopmental disorder with a substantial impact on society (Barkley, 2002; Biederman et al., 1993). In adults with ADHD 60-80 per cent also display comorbid disorders, like depression, anxiety, substance abuse or personality problems occur (Biederman, 2005). Studies have shown that symptoms of ADHD have far-reaching consequences which often persist through adolescence into adulthood (Biederman et al., 1993). ADHD also leads to increased health costs, over and above those associated with psychiatric treatment (Barkley, 2002). This high level of comorbidity complicates the diagnostic process of ADHD. Several symptoms of ADHD, like impulsive behaviour, are also recognised in other psychiatric conditions. Furthermore, there is some discussion whether these cognitive complaints/defects are related to ADHD or to comorbidity. 
Several biological factors contribute to the development of ADHD and can thus be considered as 'risk factors'. The evidence for the relevant biological and biopsychological factors comes from genetic research, brain imaging studies, and behavioural observations. Apart from genetics and neurology, other biological factors have been proposed as contributors to ADHD. These include pre-, peri-, and early postnatal problems (Biederman, 2005). There is no evidence that diet or food additives cause ADHD (Banerjee, Middleton, \& Faraone, 2007), which is relevant as such claims have been made. In addition, family and socioenvironmental factors must be considered in the diagnostic process of ADHD. The symptoms of ADHD at a given time vary and are influenced by several factors (Sagvolden, Johansen, Aase, \& Russell, 2005). The abovementioned findings suggest that ADHD is the result of a combination of genetic, biological, social, and psychological factors.

\section{ADHD: important issues}

\section{Problems with the diagnostic assessment of adult ADHD}

The most widely used classification system to describe the characteristics of ADHD is the DSM-IV-TR (APA, 2000). There are several problems with the diagnostic assessment of ADHD. To begin with, the DSM-IV-TR criteria are based on children. Longitudinal studies show that symptoms of hyperactivity and impulsivity decline over the years, while symptoms of inattention remain present (Biederman, Mick, \& Faraone, 2000). It is likely that the profile of problems/dysfunction in adults differs from that of children. Several authors suggest that the threshold originally set for children is too strict for adults and suggest the use of four or five out of nine DSM-IV-TR criteria (instead of six out of nine) (Barkley, 1998; Kooij et al., 2005). Also, three different subtypes can be distinguished, namely, the combined subtype (with symptoms of inattention and hyperactivity/impulsivity), the predominantly inattentive subtype (with primarily symptoms of inattention), and the predominantly hyperactive/impulsive subtype (with primarily hyperactive/impulsive symptoms) (APA, 2000). Secondly, the diagnosis of ADHD in adults is based on retrospective information about childhood symptoms. Because of the fact that adults with ADHD have problems with self-reflection and self-evaluation, this way of assessment may lead to under-diagnosis (Barkley, 1997). It is highly important to consult several sources of information such as parents and teachers and other 'significant others' such as brothers/sisters in the diagnostic assessment of adult ADHD (Roy-Byrne et al., 1997). However, it is not exactly clear what the contribution of informant scales in the diagnostic process of adult $A D H D$ is. 


\section{Neuropsychology and adult ADHD: diagnosis and treatment}

The cognitive functions that are often found to be impaired in adults with ADHD are the more complex higher-order processes also called the 'executive functions' (Barkley, 1998; Boonstra, Oosterlaan, Sergeant, \& Buitelaar, 2005; Woods, Lovejoy, \& Ball, 2002). The term executive functions is an 'umbrella term' which includes complex cognitive processes including goal-directed and contextappropriate behaviour (Lezak, 1995; Pennington \& Ozonoff, 1996). Adults with ADHD frequently experience problems with planning, prioritizing and goal setting. Adults with ADHD are ruled by their impulses when faced with a problem to solve, leading to reduced planning activity (Young, Morris, Toone, \& Tyson, 2007).

Most authors consider executive dysfunction to be the primary deficit in ADHD. Neuropsychological studies of adults with ADHD also have shown subtle impairments on tests of verbal memory and executive functioning (Marchetta, Hurks, Krabbendam, \& Jolles, 2008; Schoechlin \& Engel, 2005; Woods, Lovejoy, \& Ball, 2002). One of the leading theoretical cognitive models is the 'inhibition model' (Barkley, 1997). In this model, behavioural inhibition is considered to be the core deficit in ADHD, that secondarily leads to executive deficits including working memory, self-regulation of affect-motivation-arousal, internalisation of speech, and reconstitution of internally represented information (Barkley, 1997, 1998). Apart from executive dysfunction, also delay-aversion, cognitive-energetic problems or working memory have been proposed as important contributors to ADHD (Barkley, 1997; Castellanos \& Tannock, 2002; Sergeant, 2000; SonugaBarke, Taylor, \& Heptinstall, 1992; Sonuga-Barke, Taylor, Sembi, \& Smith, 1992). All available models are reviewed in this thesis.

The treatment of choice in adult ADHD is the pharmacological treatment (Adler, 2008; Kooij et al., 2004; Lerner \& Wigal, 2008; Stein, 2008). Unfortunately, research on (neuro-)psychological treatments is virtually absent. Although there is abundant neuropsychological knowledge on ADHD, this knowledge is not used on a regular basis in current treatment programmes. There are several neuropsychological models that consider ADHD as a primary deficit in inhibitory control, which is an aspect of executive dysfunction. Barkley (1997) also suggests that ADHD is primarily a deficit in inhibitory processes, involving executive function (Barkley, 1997).

On the basis of this information, we developed a neuropsychological intervention for adults with ADHD. We examined whether adults with ADHD would benefit from a structured course based on Goal Management Training (GMT). The aim of the GMT is to teach patients a strategy to stop their behaviour, improve 
planning activities and to structure intentions. The comprehensive course also included psycho-education on the important aspects of executive functioning as well as counselling with respect to coping behaviours. We expected that the neuropsychologist who was part of the programme would be able to make a contribution by teaching specific skills to deal with executive problems.

\section{Aims and outline of the thesis}

The research described in this thesis has three main objectives. The first aim is to study attention problems and their relationship with mental health and Quality of life in the general adult population. The second objective is to gain insight in the clinical picture of adult ADHD by examining the differences between an ADHD group and a non-ADHD group, in order to develop tools for diagnostic assessment. The final and third objective was to examine the effect of a specific intervention programme based on Goal Management Training (GMT) and psycho-education for adults with ADHD.

The first objective was part of a large longitudinal study, entitled Maastricht Aging Study (MAAS) (Jolles, 1995). The second and third were carried out at the out-patient centre for adult ADHD at the Mondriaan Zorg Groep, location Maastricht.

\section{The Outline of this Thesis}

Chapter 2 | Attention complaints in the general population: identification and effect on Quality of Life An important issue is to investigate prevalence figures regarding attention complaints, especially as attention dysfunction is frequently found in several clinical samples. Prevalence figures on attention problems are important as these may lead to more psychiatric and emotional complaints and a lower life satisfaction. This chapter describes a study aimed at gaining insight into the frequency of attention complaints in the general population. It also investigates whether subjective attention difficulties are related to aspects of mood, Quality of Life (QoL) and objective test performance.

Chapter 3 | Characteristics of Attention-Deficit/Hyperactivity Disorder (ADHD) in healthy adults are associated with reduced Quality of Life: results of a study of 912 subjects from the Maastricht Aging Study (MAAS)

Even though "healthy" persons often report complaints regarding attention, planning and organization of behaviour, research has paid little attention to these aspects of cognition. The aim of this study was to gain insight into the fre- 
quency of ADHD characteristics in the general population and to investigate the relationship between ADHD characteristics, depression, anxiety and Quality of Life (QoL). It is of high importance to investigate ADHD characteristics in the general population, because these can cause problems in several domains, including mental health, social, and occupational functioning. In addition, these problems could be a risk factor for development of psychopathology, such as depression and anxiety. In this chapter cognitive complaints were investigated by examining the Maastricht Cognitive Questionnaire (MCQ), Quality of Life (QoL) and complaints of depression and anxiety as measured by standard questionnaires in a cross-sectional sample drawn from a large-scale longitudinal study

Chapter 4 | The role of the clinical neuropsychologist in Attention-Deficit/ Hyperactivity Disorder (ADHD) in adults: an overview

A number of theoretical models have been proposed to explain ADHD. Some of the cognitive models may be able to contribute to a better understanding of ADHD and are presented in Chapter 4. The chapter is illustrated by two cases. These cognitive models and cases provide some tools for the clinical neuropsychologist in the diagnostic process for adults with ADHD.

Chapter 5 | Cognitive complaints and neuropsychological functioning in adults with and without Attention-Deficit/Hyperactivity Disorder (ADHD) referred for multidisciplinary assessment

The diagnostic process of adult ADHD is very complex. It depends for an important part on the recollection of childhood events. Furthermore, a high level of comorbidity is found in adult ADHD. Insight into the clinical presentation of adults referred for ADHD diagnosis is wanted. The study described in this chapter describes group differences between an ADHD and a non-ADHD sample, all of which had been clinically referred for multidisciplinary assessment of ADHD.

Chapter 6 | Diagnostic assessment of adults with Attention-Deficit/Hyperactivity Disorder (ADHD): the role of childhood factors

The diagnosis of ADHD in adults is based on detailed history-taking and uses DSM-IV-TR standards by retroactively looking for ADHD symptoms in childhood and adulthood. For a diagnosis of adult ADHD, the persistence of symptoms into adulthood is required. Therefore, information about childhood is essential in the diagnostic process of ADHD. The study described in chapter 6 investigated whether specific characteristics in childhood predict adult ADHD, by using a dedicated parent rating scale which retrospectively assesses childhood functioning. 
Chapter 7 | Goal Management Training in adults with Attention-Deficit/Hyperactivity Disorder (ADHD): an intervention study The current neuropsychological knowledge on ADHD is not used on a regular basis in current treatment programs. There are several neuropsychological models that consider ADHD as a primary deficit in inhibitory control, which is an aspect of executive dysfunction. We examined whether adults with ADHD would benefit from an intervention directed at executive functions, notably organization and planning of activities in daily life. The aim of the study described in chapter 7 was to investigate the efficacy of cognitive strategy training in adults with ADHD.

\section{Chapter 8 | Concluding remarks}

In this final chapter, the findings of the studies are summarised and discussed in the context of this thesis and recent literature. In addition, theoretical implications for future research, as well as recommendations for clinical practice are presented. 


\section{References}

Adler, L. A. (2008). Neurobiology, pharmacology, and emerging treatment. CNS Spectrum, 13(9 Suppl 13), 4, 1.

Andres, A. J., \& Fernandes, M. A. (2006). Effect of short and long exposure duration and dual-tasking on a global-local task. Acta Psychologica, 122(3), 247-266.

APA. (2000). Diagnostic and Statistical Manual of Mental Disorders (4th Edition-Text Revision). Washington D.C.: American Psychiatric Association.

Banerjee, T. D., Middleton, F., \& Faraone, S. V. (2007). Environmental risk factors for attention-deficit hyperactivity disorder. Acta Paediatrica, 96(9), 1269-1274.

Barkley, R. A. (1997). Behavioral inhibition, sustained attention, and executive functions: constructing a unifying theory of ADHD. Psychological Bulletin, 121(1), 65-94.

Barkley, R. A. (1998). Attention Deficit Hyperactivity Disorder- A handbook for Diagnosis and Treatment. New York: The Guilford Press.

Barkley, R. A. (2002). Major life activity and health outcomes associated with attention-deficit/hyperactivity disorder. Journal of Clinical Psychiatry, 63 Suppl 12, 10-15.

Biederman, J. (2005). Attention-deficit/hyperactivity disorder: a selective overview. Biological Psychiatry, 57(11), 1215-1220.

Biederman, J., Faraone, S. V., Spencer, T., Wilens, T., Norman, D., Lapey, K. A., et al. (1993). Patterns of psychiatric comorbidity, cognition, and psychosocial functioning in adults with attention deficit hyperactivity disorder. American Journal of Psychiatry, 150(12), 17921798.

Biederman, J., Mick, E., \& Faraone, S. V. (2000). Age-dependent decline of symptoms of attention deficit hyperactivity disorder: impact of remission definition and symptom type. American Journal of Psychiatry, 157(5), 816-818.

Boonstra, A. M., Oosterlaan, J., Sergeant, J. A., \& Buitelaar, J. K. (2005). Executive functioning in adult ADHD: a meta-analytic review. Psychological Medicine, 35(8), 1097-1108.

Broadbent, D. E., Cooper, P. F., FitzGerald, P., \& Parkes, K. R. (1982). The Cognitive Failures Questionnaire (CFQ) and its correlates. British Journal of Clinical Psychology, 21 (Pt 1), 1-16.

Bronnick, K., Ehrt, U., Emre, M., De Deyn, P. P., Wesnes, K., Tekin, S., et al. (2006). Attentional deficits affect activities of daily living in dementia associated with PD. Journal of Neurology, Neurosurgery and Psychiatry, 77, 1136-1142.

Burdick, K. E., Gunawardane, N., Goldberg, J. F., Halperin, J. M., Garno, J. L., \& Malhotra, A. K. (2009). Attention and psychomotor functioning in bipolar depression. Psychiatry Research, 166(2-3), 192-200.

Castellanos, F. X., \& Tannock, R. (2002). Neuroscience of attention-deficit/hyperactivity disorder: the search for endophenotypes. Nature Reviews Neuroscience, 3(8), 617-628.

Dickson, A., Toft, A., \& O'Carroll, R. E. (2009). Neuropsychological functioning, illness perception, mood and quality of life in chronic fatigue syndrome, autoimmune thyroid disease and healthy participants. Psychological Medicine, 1-10.

Faraone, S. V., \& Biederman, J. (2005). What is the prevalence of adult ADHD? Results of a population screen of 966 adults. Journal of Attention Disorders, 9(2), 384-391.

Faraone, S. V., Biederman, J., Spencer, T., Wilens, T., Seidman, L. J., Mick, E., et al. (2000). 
Attention-deficit/hyperactivity disorder in adults: an overview. Biological Psychiatry, 48(1), 9-20.

Hersenstichting Nederland. (2002). Tien jaar Nederlands Hersendecennium (Hersenwerk 2002).

Jolles, J., Houx, P.J., van Boxtel, M.P.J. \& Ponds, R.W.H.M. (Eds.). (1995). Maastricht Aging Study: determinants of cognitive aging. Maastricht: Neuropsych Publishers.

Kessler, R. C., Adler, L., Barkley, R., Biederman, J., Conners, C. K., Demler, O., et al. (2006). The prevalence and correlates of adult ADHD in the United States: results from the National Comorbidity Survey Replication. American Journal of Psychiatry, 163(4), 716-723.

Kooij, J. J., Buitelaar, J. K., van den Oord, E. J., Furer, J. W., Rijnders, C. A., \& Hodiamont, P. P. (2005). Internal and external validity of attention-deficit hyperactivity disorder in a population-based sample of adults. Psychological Medicine, 35(6), 817-827.

Kooij, J. J., Burger, H., Boonstra, A. M., Van der Linden, P. D., Kalma, L. E., \& Buitelaar, J. K. (2004). Efficacy and safety of methylphenidate in 45 adults with attention-deficit/hyperactivity disorder. A randomized placebo-controlled double-blind cross-over trial. Psychological Medicine, 34(6), 973-982.

Leavitt, F., \& Katz, R. S. (2006). Distraction as a key determinant of impaired memory in patients with fibromyalgia. Journal of Rheumatology, 33(1), 127-132.

Lerner, M., \& Wigal, T. (2008). Long-term safety of stimulant medications used to treat children with ADHD. Journal of psychosocial nursing and mental health services, 46(8), 38-48.

Lezak, M. D. (1995). Neuropsychological Assessment (3rd ed. ed.). New York: University Press.

Marchetta, N. D., Hurks, P. P., Krabbendam, L., \& Jolles, J. (2008). Interference control, working memory, concept shifting, and verbal fluency in adults with attention-deficit/ hyperactivity disorder (ADHD). Neurospsychology, 22(1), 74-84.

Melzer, I., \& Oddsson, L. I. (2004). The effect of a cognitive task on voluntary step execution in healthy elderly and young individuals. Journal of the American Geriatric Society, 52(8), 1255-1262.

Pennington, B. F., \& Ozonoff, S. (1996). Executive functions and developmental psychopathology. Journal of Child Psychology and Psychiatry, 37(1), 51-87.

Pollina, L. K., Greene, A. L., Tunick, R. H., \& Puckett, J. M. (1992). Dimensions of everyday memory in young adulthood. British Journal of Psychology, 83 (Pt 3), 305-321.

Ribeiro, F., de Mendonca, A., \& Guerreiro, M. (2006). Mild cognitive impairment: deficits in cognitive domains other than memory. Dementia and Geriatric Cognitive Disorders, 21(56), 284-290.

Roy-Byrne, P., Scheele, L., Brinkley, J., Ward, N., Wiatrak, C., Russo, J., et al. (1997). Adult attention-deficit hyperactivity disorder: assessment guidelines based on clinical presentation to a specialty clinic. Comprehensive Psychiatry, 38(3), 133-140.

Sagvolden, T., Johansen, E. B., Aase, H., \& Russell, V. A. (2005). A dynamic developmental theory of attention-deficit/hyperactivity disorder (ADHD) predominantly hyperactive/ impulsive and combined subtypes. Behavioural and Brain Sciences, 28(3), 397-419; discussion 419-368. 
Schoechlin, C., \& Engel, R. R. (2005). Neuropsychological performance in adult attentiondeficit hyperactivity disorder: meta-analysis of empirical data. Archives of Clinical Neuropsychology, 20(6), 727-744.

Sergeant, J. (2000). The cognitive-energetic model: an empirical approach to attention-deficit hyperactivity disorder. Neuroscience and Biobehavioral Reviews, 24(1), 7-12.

Sharpe, L., Dear, B. F., \& Schrieber, L. (2009). Attentional biases in chronic pain associated with rheumatoid arthritis: hypervigilance or difficulties disengaging? Journal of Pain, 10(3), 329-335.

Sonuga-Barke, E. J., Taylor, E., \& Heptinstall, E. (1992). Hyperactivity and delay aversion--II. The effect of self versus externally imposed stimulus presentation periods on memory. Journal of Child Psychology and Psychiatry, 33(2), 399-409.

Sonuga-Barke, E. J., Taylor, E., Sembi, S., \& Smith, J. (1992). Hyperactivity and delay aversion--I. The effect of delay on choice. Journal of Child Psychology and Psychiatry, 33(2), 387-398.

Stein, M. A. (2008). Treating adult ADHD with stimulants. CNS Spectrum, 13(9 Suppl 13), 8-11, 11.

Woods, S. P., Lovejoy, D. W., \& Ball, J. D. (2002). Neuropsychological characteristics of adults with ADHD: a comprehensive review of initial studies. Clinical Neuropsychology, 16(1), 1234 .

Young, S., Morris, R., Toone, B., \& Tyson, C. (2007). Planning ability in adults with attentiondeficit/hyperactivity disorder. Neuropsychology, 21(5), 581-589. 



\section{Attention complaints in the general population: the identification and effect on Quality of Life}

ACCEPTED IN JOURNAL OF ATTENTION DISORDERS

Dymphie Scholtissen-In de Braek, Petra Hurks, Martin van Boxtel, Jeanette Dijkstra \& Jelle Jolles

\section{Abstract}

Objective: The aim of this study was to provide more insight into subjective attention complaints in a healthy adult and elderly population and the consequences for Quality of Life (QoL).

Methods: A group of 1550 healthy Dutch participants completed a postal questionnaire, including the Maastricht Attention and memory Checklist (MAC). The influence of attention complaints on Quality of Life (QoL) was investigated in a sub sample of 499 participants.

Results: Factor analyses ( $n=1550)$ revealed two factors: 'attention' and 'memory'. Attention complaints were related to depressed mood, anxiety, vitality and sleep problems which can have serious consequences for daily life functioning and QoL $(n=499)$. Memory complaints, were related to other aspects of health, such as pain and changes in health.

Conclusion: Attention complaints in the healthy population are common and related to depression, anxiety and sleep and several aspects of QoL, such as problems with social functioning, emotional problems and vitality. 


\section{Introduction}

It is well-known that forgetfulness is common in the healthy adult and elderly population (Commissaris, 1998; McDougall, Becker, \& Arheart, 2006; Mol, van Boxtel, Willems \& Jolles, 2006; Ponds, Commissaris, \& Jolles, 1997). Other cognitive complaints, like attention and concentration, might be equally important, but are less investigated within the predefined population. It is essential to investigate attention complaints, especially since attention complaints as well as objective impairment, in terms of cognitive performance on attention tasks, are frequently found in several clinical samples like Parkinson's Disease (PD), Fibromyalgia, Chronic Fatigue (CF), Mild Cognitive Impairment (MCI) \& Attention-Deficit/ Hyperactivity Disorder (ADHD) (Bronnick et al., 2006; Leavitt \& Katz, 2006; Ribeiro, de Mendonca, \& Guerreiro, 2006).

ADHD is one of the most common neurodevelopmental disorders in childhood and adulthood which is also characterized by attention problems. ADHD in adults has gained more attention in the last decade. The estimated prevalence of ADHD in adults is between 2- 4.4\% (Kessler et al., 2006). These prevalence rates are much higher than expected, as is the level of comorbid disorders, like depression, anxiety and substance abuse (Biederman, Wilens, Spencer, \& Adler, 2007; Kessler et al., 2006; Kooij et al., 2005). Furthermore, ADHD can result in a heavy burden and serious consequences for the affected individuals, their families, mental health care and society in general (Barkley, 2002). Until now, most research on attention complaints has focused on clinical populations and no large-scale research has focused on the healthy population. Family-genetic studies in the field of ADHD show that functions like attentional control and mental flexibility may be suitable endophenotypes of ADHD, since problems in these areas exist among family members of persons with ADHD. In addition, in 1997 Levy suggested that ADHD is best viewed as the extreme of a behaviour that varies genetically throughout the entire population on the basis data from a large-scale twin sample (Levy, Hay, McStephen, Wood, \& Waldman, 1997). Our study wants to investigate the impact of attention complaints as a dimensional construct in the general population.

Prevalence figures on attention complaints are important, since attention complaints may lead to more psychiatric and emotional complaints and a lower life satisfaction, at least this is suggested in students (Gudjonsson, Sigurdsson, Eyjolfsdottir, Smari, \& Young, 2008). This then would indicate that there is a relative large group of adults with attention complaints and sub clinical mental health problems, who may seek help in the future. Insight into the prevalence and character of attention complaints can lead to better understanding, and if necessary adequate prevention and specific treatment. 
The first aim of this study is to gain insight into the frequency of attention complaints in the general population. There are indications that healthy persons may have memory complaints which, upon closer inspection, should be more accurately classified as belonging to the domain of attention problems. Moreover, attention difficulties and attention deficits may underlie many of the cognitive failures of every day life (Broadbent, Cooper, FitzGerald, \& Parkes, 1982; Pollina, Greene, Tunick, \& Puckett, 1992).

The current study also investigates whether subjective attention difficulties are related to Quality of Life (QoL). On the basis of the literature on ADHD, we expect to find that subjective attention complaints are related to the subjects' quality of life, and to more psychiatric and emotional complaints and to a lower life satisfaction (Barkley, Fischer, Smallish, \& Fletcher, 2006; Biederman et al., 1993). In the case of disorders such as chronic fatigue, depression, $\mathrm{MCl}$ and ADHD it has already been noted that attention problems reduce the quality of life of individuals (Bronnick et al., 2006; Leavitt \& Katz, 2006; Ribeiro, de Mendonca, \& Guerreiro, 2006). Therefore, the second aim of this study is to test to what extent attention complaints exist in a healthy population sample, and to investigate the relationship with daily life functioning and mental health.

Finally, it is important to know whether subjective cognitive complaints can be confirmed by neuropsychological test performance, since it is suggested that an attention complaint is the reflection of an underlying neuropsychological problem. However, the literature is inconclusive on this point and an association between for example a memory complaint and memory performance is not always found (Bolla, Lindgren, Bonaccorsy, \& Bleecker, 1991). Our hypothesis is that subjective cognitive complaints are related to objective cognitive test performance, since neuropsychological measures are designed to tap specific brain functions.

To test abovementioned hypotheses, the relationship of attention complaints with quality of life was assessed. Unfortunately, in the literature, no checklist for general attention complaints exists. Only disease-specific instruments for memory complaints like dementia and electroconvulsive therapy (ECT) are described (Meguro et al., 2004; Prudic, Peyser, \& Sackeim, 2000). Therefore, in order to achieve the aims of this study, we developed a checklist of memory and attention complaints in the general population, the Maastricht Attention and memory Checklist (MAC). Memory items were included in this checklist because we wanted to investigate the possible differences between attention and memory complaints. The research conducted in this study is based on the Maastricht Aging Study (MAAS). This is a large prospective study into the determinants 
of cognitive aging conducted at Maastricht University in the Netherlands. This study has made it possible to compare data on cognitive performance, age and level of education (Van der Elst, Van Boxtel, Van Breukelen, \& Jolles, 2006a, 2006b; Van der Elst, van Boxtel, van Breukelen, \& Jolles, 2006, 2007).

\section{Methods}

\section{Subjects}

Data used for this research were taken from the Maastricht Aging Study (MAAS), a large-scale longitudinal study on the determinants of cognitive aging (Jolles, Verhey, Riedel, \& Houx, 1995; van Boxtel et al., 1998). In the MAAS, a range of experimental and standardized instruments of health and psychological functioning were used to collect data at baseline and on three follow-up occasions, each separated by a 3-year interval (Jolles, Verhey, Riedel, \& Houx, 1995; van Boxtel et al., 1998). Participants were recruited by postal questionnaire from 15 family practices in the southern region of the Netherlands, all of which participated in the Registration Network of Family Practices (Metsemakers, Hoppener, Knottnerus, Kocken, \& Limonard, 1992). Participants were aged 24 to 81, and, at the moment of inclusion, were without medical conditions known to interfere with normal cognitive functioning such as neurodegenerative disease, mental retardation, and cerebrovascular disease. Overt visual and auditory handicaps also led to exclusion at baseline. The MAAS-sample was stratified by age (5-year age group; $25 \pm 1,30 \pm 1$, etc.), sex, and general ability level. For this study, age was used as a continuous variable. Education level was measured on an eight-point scale in accordance with a Dutch scoring system that ranges from primary to university education (De Bie, 1987). Data from those participants who had completed the postal questionnaire prior to the sample selection for the MAAS study but were not seen at follow-up ( $n=1550)$ were used to validate a new attention checklist: the MAC (see below). Furthermore, cognitive test data were used of participants who had received a full neuropsychological examination at baseline and who agreed with follow-up testing $(\mathrm{n}=499)$. The study was approved by the local ethics committee. All participants gave their informed consent.

\section{Maastricht Attention and memory Checklist (MAC)}

Relevant questions about subjective attention complaints that were included in the postal questionnaire used to select participants for the MAAS study were selected by using the DSMI-IV-TR Criteria for Attention-Deficit Hyperactivity Disorder (APA, 2000). This led to a screening instrument of subjective attention dif- 
Table 1. Factor analysis on the items of the Maastricht Attention and memory Checklist (MAC) $(n=1550)$.

\begin{tabular}{|c|c|c|}
\hline & Factor 1 & Factor 2 \\
\hline MAC1 & 0.465 & 0.209 \\
\hline MAC2 & -0.002 & 0.769 \\
\hline MAC3 & 0.137 & 0.721 \\
\hline MAC4 & 0.416 & 0.009 \\
\hline MAC5 & 0.662 & 0.167 \\
\hline MAC6 & 0.705 & 0.003 \\
\hline MAC7 & 0.387 & 0.017 \\
\hline MAC8 & 0.672 & -0.031 \\
\hline MAC9b & 0.410 & 0.272 \\
\hline MAC10a & 0.645 & 0.155 \\
\hline MAC10b & 0.675 & 0.228 \\
\hline & & 1.101 \\
\hline Eigenvalues & 3.215 & 10.010 \\
\hline \% of Variance & 29.230 & \\
\hline
\end{tabular}

Note: Factor loadings and communalities of the MAC-items.

Factor 1 = "attention" and Factor 2 = "memory"

ficulties that consisted of 11 items (including 9b, 10a and 10b, See Appendix 1). Item 9 was scored as "present", if one of the first three reasons for forgetfulness mentioned was "concentration problems". Answers to other questions were also recoded as "present" or "not present". Thus, if a participant answered the following item: "In comparison with other people of my age, I have ... problems concentrating on more than one task (e.g. driving a car and having a conversation; prepare a meal and listen to the radio)", with "far less", "less", or "the same", the answer would be recoded as "not present" (i.e., value o). In a similar manner, if a participant answered this item with "more" or "far more", it would be recoded as "present" (i.e., value 1). After recoding, reliability analyses were conducted.

The Cronbach's alpha of the MAC-items was subsequently calculated for the participants who were not selected for the follow-up study $(n=1550)$. This revealed a satisfactory reliability coefficient of 0.72 , which did not increase by leaving out single items. Next, a correlation matrix of the MAC-items was generated. It displayed no significant correlation among items higher than 0.60 . To detect underlying factors of the MAC, we performed a principal component anal- 
ysis on the MAC items by using an orthogonal rotational procedure (Varimax). The following criteria were used to determine the most appropriate number of factors to retain: (a) minimum eigenvalues of 1 , (b) minimum factor loadings of 0.30 and (c) meaningful interpretation of the factor. The results of the factor analyses indicated that the most comprehensive model meeting the criteria was a 2-factor model containing the factors "attention" (factor 1) and "memory" (factor 2). Together, both factors explained $39.2 \%$ of the variance in the items. Table 1 shows factor loadings and communalities. These two factors were used as independent variables for further analyses. Bivariate correlation coefficients between MAC items showed positive small and medium effects.

\section{Quality of Life}

The Satisfaction With Life Scale (SWLS) measures the cognitive component of subjective wellbeing (Pavot, Diener, Colvin, \& Sandvik, 1991). This 5-item selfreported scale assesses the individual's satisfaction with life as a whole using a 7-point Likert scale. Internal consistency and temporal stability of this scale are believed to be satisfactory (Pavot, Diener, Colvin, \& Sandvik, 1991). In the present study, we used the SWLS total score as the dependent variable. The range of the scale is 5-35, with a higher score indicating a better satisfaction with life.

The SF-36 is a validated, self-administered questionnaire used to measure health status with respect to several dimensions including physical functioning (score range 10-30), social functioning (score range 2-10), role limitations due to physical problems (score range 4-8) and emotional problems (score range 5-25), pain (score range 11-60), mental health (score range 5-30), vitality (score range 424) and general health perception (score range 5-25) (Aaronson et al., 1998; Ware \& Sherbourne, 1992; Zee, 1993). The dimensional scores were treated as dependent variables. A higher score indicates better health within each domain.

Finally, feelings of depression, anxiety and sleep were measured with three subscales of the Symptom Check List (SCL-90) to gain insight into recent subjective complaints. The SCL-90 is a multidimensional self-reported inventory of psychopathology (Derogatis, Rickels, \& Rock, 1976). The subscales were used as dependent variables with a higher score indicating more symptoms in these domains. The scores for the anxiety, depression and sleep subscales ranged from 0-50, 0-80, and 0-15, respectively.

\section{Cognitive tests}

The Letter Digit Substitution Test (LDST) is a modification of the conceptually identical Symbol-Digits Modalities Test (SDMT) (Smith, 1968; Van der Elst, van 
Boxtel, van Breukelen, \& Jolles, 2006). On a sheet of paper, a box is presented with nine numbers uniquely coupled to nine letters. Below the box, the letters are presented without the corresponding numbers. The participant is asked to fill in as many corresponding numbers as possible in ninety seconds. Some cognitive processes involved are visual scanning, working memory, visuoconstruction and motor functions (e.g. Lezak, 1995). This test is a commonly used neuropsychological measure of information processing speed. The dependent variable was the total number of correctly copied digits after 90 seconds.

The Stroop Colour Word Test (SCWT) involves three cards with 100 stimuli each (Stroop, 1935; Van der Elst, Van Boxtel, Van Breukelen, \& Jolles, 2006b). The first card contains colour words printed in black ink, which have to be read. The second card displays contains coloured patches, which have to be named. The third card displays colour names printed in incongruously coloured ink. Individuals are instructed to name the ink colour of the printed words. By subtracting the time needed for the last part from the mean score of the first and second part, an interference score can be calculated. This interference score is regarded as a measure of habitual response, which depends on adequate levels of attention and executive functioning (Hanninen et al., 1997). The variables of interest for this study were the total time needed to read part 1 (reading), the total time needed to read part 2 (colour naming), the total time needed to complete part 3 and the interference score.

The Concept Shifting Task (CST) is a modified version of the Trail Making Test (TMT) and is used to measure simple speed and cognitive flexibility (Van der Elst, van Boxtel, van Breukelen, \& Jolles, 2007; Vink, 1985). The test consists of three stimulus cards. On each test sheet, 16 small circles are grouped in one larger circle. In the smaller circles, the test items appear in a fixed random order. On the first card, the smaller circles contain numbers in a fixed random order and participants are asked to cross out the numbers in the right order as quickly and accurately as possible. In the second part of the test, the circles contain letters, which have to be crossed out in alphabetical order. In the third part of the test, the circles display both numbers and letters, and participants are requested to alternate between numbers and letters. The scores correspond to the time needed to complete each card. The mean Reaction Time (RT) of the first two cards are used as a reflection of simple speed and attention (CSTA + CSTB). The difference between the RT for the last card and the mean RT of the two previous cards is considered to reflect the extra time needed to shift between two sets of stimuli. This serves as a measure of cognitive flexibility.

The Verbal Learning Test (VLT) was used to evaluate learning capacity and 
retrieval from memory (Brand \& Jolles, 1985). In this test, 15 words are presented in a fixed order on a computer screen, one after another. Participants are asked to recall as many words in whatever order suits them best. This procedure is repeated five times. After 20 minutes, delayed recall was tested. Dependent variables were the total number of words in five trials (range: 0-45) as a measure of learning capacity, and the delayed recall score (range: 0-15) after 20 minutes as an estimate of delayed recall.

\section{Statistical methods}

Descriptives on the MAC were calculated using the data of participants who completed the postal questionnaire $(n=1550)$. Participants were aged 24.2 to 88.1 years old. The total score on the MAC was calculated. For further statistical analyses on the MAC only data derived from participants who were recruited for follow-up ( $\mathrm{n}=499$ ) were used.

Explorative, the influence of age (as a continuous variable) and education on the separate MAC items and MAC total score were calculated by means of ANOVA. The effect of sex on MAC items was determined with a Chi-square test. A small negative correlation was found between the MAC-total score and education $(r=-0.146)$.

Multiple linear regression analyses were used to investigate the nature of the specific relationships between the two factors of the MAC and the earlier mentioned dependent variables of QoL and cognition. Age (as a continuous variable), education and sex were also included in the statistical analyses, because of the known effects of these factors on cognitive functioning (Van der Elst, Van Boxtel, Van Breukelen, \& Jolles, 2006b; Van der Elst, van Boxtel, van Breukelen, \& Jolles, 2006).

The Statistical Package for the Social Sciences (SPSS) for Windows was used for all statistical analyses (Version 12, SPSS inc., USA). P<0.05 was considered statistically significant.

\section{Results}

The descriptives of the MAC total score are shown in Figure 1. At least $57.3 \%$ of all participants reported one attention complaint. In total $26.8 \%$ of the participants reported at least three complaints on the MAC. It should be noted that the 'memory' items (items 2 and 3) were excluded from these calculations, since we were primarily interested in attention complaints. ANOVA further revealed a significant relation between age and $M A C$ total score $(F=3.853, p=0.05)$. A significant 
relationship between education and MAC total score was also found $(F=7.264$, $p=0.007)$. In particular, a higher education reflected less attention complaints. Sex did not have any effect on MAC total score $(F=0.473, p=0.492)$ but did have an effect on MAC item 10a ('trouble concentrating'). Specifically, more women scored positively on this item ( $X 2$-trend $=7.587, p=0.006)$.

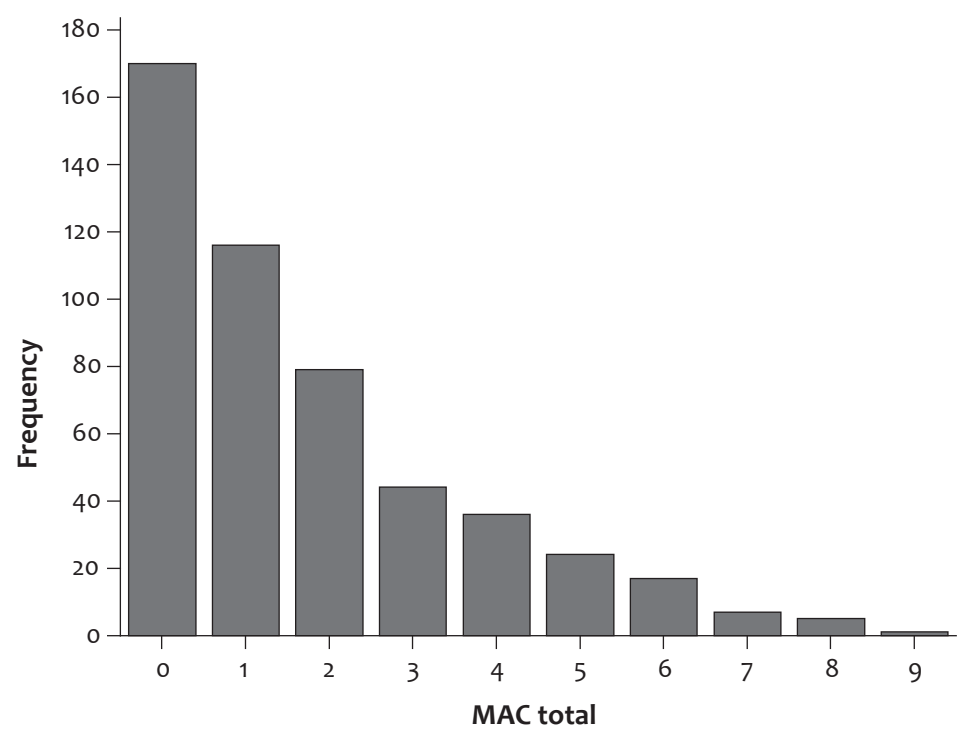

Figure 1. Frequency of the MAC total score from the participants who were included in the follow-up examination $(n=470)$.

Table 2 presents the results of the regression analyses.

Linear regression analyses revealed a significant relationship between "Attention" (Factor 1) and the Satisfaction with Life total score (SWLS), social functioning, emotional problems, vitality and general health perception, as measured by the SF-36. "Attention" (Factor 1) was also related to depression, anxiety and sleep, as measured by the SCL-90. "Memory" (Factor 2) was significantly related to the Satisfaction with Life total score (SWLS), pain and changes in health, both of which were measured by the SF-36. No association with psychiatric symptoms (SCL-90) was found.

"Attention" (Factor 1) was not related to any of the neuropsychological test measures. "Memory" (Factor 2) was only related to Stroop Part 1 (colour word reading, a measure of general speed of information processing; $\beta=-0.014, p=$ 0.031). 
Table 2. Linear Regression analysis with Beta values for the MAC factors and 'age', 'education' and 'sex' included in the model.

\begin{tabular}{|c|c|c|c|c|c|c|}
\hline & $\begin{array}{c}\text { Factor } 1 \\
\text { Attention }\end{array}$ & $\begin{array}{l}\text { Factor } 2 \\
\text { Memory }\end{array}$ & Age & Education & Sex & $\begin{array}{c}\text { R-square } \\
\text { change }\end{array}$ \\
\hline SWLS tot & $-0.12 * *$ & $-0.18 *$ & 0.45n.s. & 0.05n.s. & $-0.26 n . s$ & 0.06 \\
\hline PHF & $-0.25 n . s$. & $-0.04 \mathrm{n} . \mathrm{s}$ & $-0.33^{* * *}$ & $0.17^{* *}$ & -o.10n.s. & 0.20 \\
\hline SOCF & $-0.16 * *$ & -0.05n.s. & -o.ogn.s. & o.01n.s. & $-0.02 * *$ & 0.04 \\
\hline RLPH & -0.05n.s. & $-0.041 \mathrm{n} . \mathrm{s}$ & -o.10n.s. & 0.07n.s. & -0.06n.s. & 0.03 \\
\hline RLEM & $-0.14^{*}$ & $-0.05 n . s$. & -0.08n.s. & o.oon.s. & -0.04 n.s. & 0.03 \\
\hline PAIN & -0.04n.s. & $-0.063^{*}$ & o.01n.s. & $0.15^{* *}$ & $-0.19 * * *$ & 0.09 \\
\hline MH & -0.06n.s. & o.05n.s. & -0.04n.s. & -0.02n.s. & -0.05n.s. & 0.01 \\
\hline VIT & $-0.25 * * *$ & o.06n.s. & o.01n.s. & $0.13^{*}$ & $-0.19 * * *$ & 0.12 \\
\hline GHP & $-0.18 * * *$ & -0.04n.s. & $-0.25 * * *$ & 0.06n.s. & -0.03n.s. & 0.12 \\
\hline $\mathrm{HC}$ & -0.02n.s. & $-0.15 *$ & -0.12n.s. & -0.02n.s. & o.oon.s. & 0.04 \\
\hline SCLANG & $0.26^{* * *}$ & -0.03n.s. & $0.15^{* *}$ & -0.05 n.s. & $0.13^{*}$ & 0.11 \\
\hline SCLDEP & $0.25^{* * *}$ & o.01n.s. & $0.13 *$ & -0.03n.s. & $0.11 *$ & 0.10 \\
\hline SCLSLA & $0.14^{*}$ & o.ogn.s. & $0.23^{* * *}$ & -0.04n.s. & o.10n.s. & 0.11 \\
\hline
\end{tabular}

SWLS tot $=$ SWLS total score, PHF = Physical Functioning (SF-36), SOCF = Social Functioning (SF-36), RLPH = role limitations due to physical problem (SF-36), RLEM = role limitations due to emotional problem (SF-36), PAIN (SF-36), MH = Mental Health (SF-36), VIT = Vitality (SF36), GHP = General Health Perception (SF-36), HC = Health Change (SF-36), SCLANG = Anxiety (SCL-90), SCLDEP = Depression (SCL-90), SCLSLA = Sleep (SCL-90)

${ }^{*} p<0.05,{ }^{* *} p<0.01,{ }^{* *} p<0.001, n . s .=$ not significant

\section{Discussion}

The aim of the present study was to gain insight into the frequency and relationship of attention complaints with daily life functioning in the general population, by using a dedicated sample from a large-scale longitudinal study (MAAS) (Jolles, Houx, van Boxtel \& Ponds (Eds.). 1995). In our sample 57.3\% reported at least one attention complaint and more than one quarter of the participants reported several (three or more) attention complaints. This suggests that attention complaints are common in the general adult population.

Furthermore, factor analysis on the MAC items revealed two factors of difficulties: 'attention' and 'memory'. This is an important finding and suggests that in a healthy population, attention and memory complaints are different and may 
refer to different underlying mechanisms. Hence, the evaluation of cognitive complaints must be thorough.

In the present sample a higher level of education was related to less attention complaints. Education may be a protective factor, in the sense that cognitive complaints less easily come to light in well educated persons. Perhaps, persons with a high level of education are able to use more or different compensation strategies. Our finding also corresponds with the idea of 'brain reserve capacity', which suggests that a higher level of education leads to more cognitive reserve, which provides a higher threshold before clinical deficit are reached (Katzman, 1993; Kesler, Adams, Blasey, \& Bigler, 2003; Satz et al., 1993; Timiras, 1995). On the other hand, the reverse explanation is also feasible: persons with attention problems might not be able to finish their education.

The present study showed that the factor "attention" was related to symptoms of depression, anxiety and sleep, but that the factor "memory" was not. It is still unclear how this discrepancy can be explained. One explanation is that the selection of MAC-items was done with the ADHD-criteria in mind. Our approach was to investigate attention complaints in the general population based on the DSM-IV criteria of ADHD (APA, 2000). This can possibly account for differences which are also described in the literature. Earlier research found evidence for a strong relationship between memory complaints and symptoms of depression (Comijs, Deeg, Dik, Twisk, \& Jonker, 2002; Lautenschlager, Flicker, Vasikaran, Leedman, \& Almeida, 2005). Previous research also found that complaints of depression are common in middle-aged and elderly persons and are related to cognitive functioning (Baune, Suslow, Arolt, \& Berger, 2006). The discrepancy found in this study is, however, important. Previous studies did not look at specific cognitive complaints. Our findings show that it is useful to investigate attention complaints in the general population. More research into specific cognitive difficulties, such as attention, is necessary to explain the discrepancy found in this study. Our study suggests that there is a difference between cognitive complaints related to 'attention' versus those related to 'memory' in their contribution to different aspects of mental health. As by far the majority of studies performed until now has been devoted to memory, our findings provide new vistas with respect to the relationship of attention complaints and Quality of Life. An elaboration on these findings is given below.

"Attention" was related to aspects of QoL, such as problems with social functioning, emotional problems and vitality. "Memory", on the other hand, was related to other aspects of QoL, namely pain and changes in health. In the healthy population, different subsets of cognitive complaints (attention and memory) 
are related to different aspects of QoL, again indicating different underlying mechanisms. In the present study attention complaints were primarily related to several aspects of mental wellbeing, like symptoms of depression and anxiety, whereas difficulties in memory were not. The current study suggests that attention complaints are related to mental health problems and diminished daily life functioning. These findings have several implications for the clinician. A thorough examination of subjective cognitive complaints, including attention complaints, is necessary. Furthermore, subjective cognitive complaints are equally important as objective test measures, because of their relationship with several aspects of mental health. Since, attention complaints are different from memory complaints, management of these problems asks for a different approach. For instance, memory training might not be useful in the management of primarily difficulties in attention but dedicated interventions in the domain of Goal Management might be (Robertson, 2001; van Hooren et al., 2007). It is of interest that van Hooren et al (2007) found effects of their Goal Management Training in relatively healthy women (aged 55 years and older) who were characterized by complaints on the domain of attention and planning (van Hooren et al., 2007).

Another finding of the present study was that -overall- the two factors of the MAC were not related to neuropsychological test measures of speed of information processing, attention and memory. This is in agreement with previous studies suggesting the weak or non-existing relationship between subjective and objective cognitive measures (Bolla, Lindgren, Bonaccorsy, \& Bleecker, 1991; Smith, Petersen, Ivnik, Malec, \& Tangalos, 1996). One explanation is that cognitive complaints are situated on the level of health/QoL, whereas cognitive test performance is situated more on the level of functioning (WHO, 2001). For example, a person who reports problems with multitasking, may show a good score on Stroop part 3. In a structured setting, where neuropsychological testing is done, this person can 'function' very well. However, in more complex work situations, where demands are high, problems may arise. It is likely that higherorder attention dysfunction arises mainly in complex, unstructured situations, whereas neuropsychological testing is done in relatively structured settings.

In this study cognitive complaints as measured by the MAC were collected before neuropsychological testing. An interesting hypothesis is that cognitive complaints in the general population are not only related to actual mental health problems, but may also predict mental health problems later in time. More research is required in this area. Because of the cross-sectional design of the study no conclusion about causality could be discerned. Another point to consider in the present study is that we used clinical criteria in the general pop- 
ulation. The MAC explained relatively a small proportion of variance, perhaps because of the large number of zero scores on the MAC or highly skewed distribution of scores. However, the aim of this study was to examine whether symptoms of ADHD exist in the general population. This seems to be the case, since more than half of the participants reported at least one attention complaints which corresponds with one ADHD symptom, and more than one quarter of the participants reported several (three or more) attention complaints. Finally, our study has not considered the role of personality or insight as a mediating factor between cognitive complaints and objective test measures. One can envisage for instance lower objective test scores in more neurotic participants (Reid \& Maclullich, 2006).

This study suggests that it is very relevant to recognize attention complaints in the healthy population, because these complaints are common and related to depression, anxiety and sleep and several aspects of QoL, such as problems with social functioning, emotional problems and vitality. Insight into (factors contributing to) specific cognitive complaints in the current sample can lead to a better understanding of cognitive problems and, in turn, to adequate prevention and specific treatment. 


\section{References}

Aaronson, N. K., Muller, M., Cohen, P. D., Essink-Bot, M. L., Fekkes, M., Sanderman, R., et al. (1998). Translation, validation, and norming of the Dutch language version of the SF36 Health Survey in community and chronic disease populations. Journal of Clinical and Experimental Neuropsychology, 51(11), 1055-1068.

APA. (2000). Diagnostic and Statistical Manual of Mental Disorders (4th Edition-Text Revision). Washington D.C.: American Psychiatric Association.

Barkley, R. A. (2002). Major life activity and health outcomes associated with attentiondeficit/hyperactivity disorder. Journal of Clinical Psychiatry, 63 Suppl 12, 10-15.

Barkley, R. A., Fischer, M., Smallish, L., \& Fletcher, K. (2006). Young adult outcome of hyperactive children: adaptive functioning in major life activities. Journal of American and Academic Child and Adolescent Psychiatry, 45(2), 192-202.

Baune, B. T., Suslow, T., Arolt, V., \& Berger, K. (2006). The relationship between psychological dimensions of depressive symptoms and cognitive functioning in the elderly - The MEMO-Study. Journal of Psychiatry Research, 41(3-4), 247-54.

Biederman, J., Faraone, S. V., Spencer, T., Wilens, T., Norman, D., Lapey, K. A., et al. (1993). Patterns of psychiatric comorbidity, cognition, and psychosocial functioning in adults with attention deficit hyperactivity disorder. American Journal of Psychiatry, 150(12), 1792-1798.

Biederman, J., Wilens, T. E., Spencer, T. J., \& Adler, L. A. (2007). Diagnosis and treatment of adults with attention-deficit/hyperactivity disorder. CNS Spectrum, 12(4 Suppl 6), 1-15.

Bolla, K. I., Lindgren, K. N., Bonaccorsy, C., \& Bleecker, M. L. (1991). Memory complaints in older adults. Fact or fiction? Archives of Neurology 48(1), 61-64.

Brand, N., \& Jolles, J. (1985). Learning and retrieval rate of words presented auditorily and visually. Journal of General Psychology, 112(2), 201-210.

Broadbent, D. E., Cooper, P. F., FitzGerald, P., \& Parkes, K. R. (1982). The Cognitive Failures Questionnaire (CFQ) and its correlates. Britisch Journal of Clinical Psychology, 21 (Pt 1), 1-16.

Bronnick, K., Ehrt, U., Emre, M., De Deyn, P. P., Wesnes, K., Tekin, S., et al. (2006). Attentional deficits affect activities of daily living in dementia associated with PD. Journal of Neurology, Neurosurgery and Psychiatry, 77, 1136-1142.

Comijs, H. C., Deeg, D. J., Dik, M. G., Twisk, J. W., \& Jonker, C. (2002). Memory complaints; the association with psycho-affective and health problems and the role of personality characteristics. A 6-year follow-up study. Journal of Affective Disorders, 72(2), 157-165.

Commissaris, C. J. A. M., Ponds, R.W.H.M. \& Jolles, J. (1998). Subjective forgetfulness in a normal dutch population: Possibilities for health education and other interventions. Patient Education and Counseling, 34, 25-32.

De Bie, S. E. (1987). Standaardvragen 1987: Voorstellen voor uniformering van vraagstellingen naar achtergrondkenmerken en interviews [Standard questions 1987: Proposal for uniformisation of questions regarding background variables]. (2nd ed. ed.). Leiden, The Netherlands: Leiden University Press.

Derogatis, L. R., Rickels, K., \& Rock, A. F. (1976). The SCL-90 and the MMPI: a step in the 
validation of a new self-report scale. British Journal of Psychiatry, 128, 280-289.

Gudjonsson, G. H., Sigurdsson, J. F., Eyjolfsdottir, G. A., Smari, J., \& Young, S. (2008). The Relationship Between Satisfaction With Life, ADHD Symptoms, and Associated Problems Among University Students. Journal of Attention Disorders, 20 (Aug).

Hanninen, T., Hallikainen, M., Koivisto, K., Partanen, K., Laakso, M. P., Riekkinen, P. J., Sr., et al. (1997). Decline of frontal lobe functions in subjects with age-associated memory impairment. Neurology, 48(1), 148-153.

Jolles, J., Houx, P.J., van Boxtel, M.P.J. \& Ponds, R.W.H.M. (Eds.). (1995). Maastricht Aging Study: determinants of cognitive aging. Maastricht: Neuropsych Publishers.

Jolles, J., Verhey, F. R., Riedel, W. J., \& Houx, P. J. (1995). Cognitive impairment in elderly people. Predisposing factors and implications for experimental drug studies. Drugs \& Aging, 7(6), 459-479.

Katzman, R. (1993). Education and the prevalence of dementia and Alzheimer's disease. Neurology, 43(1), 13-20.

Kesler, S. R., Adams, H. F., Blasey, C. M., \& Bigler, E. D. (2003). Premorbid intellectual functioning, education, and brain size in traumatic brain injury: an investigation of the cognitive reserve hypothesis. Applied Neuropsychology, 10(3), 153-162.

Kessler, R. C., Adler, L., Barkley, R., Biederman, J., Conners, C. K., Demler, O., et al. (2006). The prevalence and correlates of adult ADHD in the United States: results from the National Comorbidity Survey Replication. 163(4), 716-723.

Kooij, J. J., Buitelaar, J. K., van den Oord, E. J., Furer, J. W., Rijnders, C. A., \& Hodiamont, P. P. (2005). Internal and external validity of attention-deficit hyperactivity disorder in a population-based sample of adults. Psychological Medicine, 35(6), 817-827.

Lautenschlager, N. T., Flicker, L., Vasikaran, S., Leedman, P., \& Almeida, O. P. (2005). Subjective memory complaints with and without objective memory impairment: relationship with risk factors for dementia. American Journal of Geriatric Psychiatry, 13(8), 731-734.

Leavitt, F., \& Katz, R. S. (2006). Distraction as a key determinant of impaired memory in patients with fibromyalgia. Journal of Rheumatology, 33(1), 127-132.

Levy, F., Hay, D. A., McStephen, M., Wood, C., \& Waldman, I. (1997). Attention-deficit hyperactivity disorder: a category or a continuum? Genetic analysis of a large-scale twin study. Journal of American Academic Child Adolescent Psychiatry, 36(6), 737-744.

Lezak, M. D. (1995). Neuropsychological Assessment (3rd ed. ed.). New York: University Press.

McDougall, G. J., Jr., Becker, H., \& Arheart, K. L. (2006). Older Adults in the SeniorWISE Study At Risk for Mild Cognitive Impairment. Archives of Psychiatric Nursing, 20(3), 126134.

Meguro, K., Ishii, H., Yamaguchi, S., Ishizaki, J., Sato, M., Hashimoto, R., et al. (2004). Prevalence and cognitive performances of clinical dementia rating 0.5 and mild cognitive impairment in Japan. The Tajiri project. Alzheimer Disease and Associated Disorders, 18(1), 3-10.

Metsemakers, J. F., Hoppener, P., Knottnerus, J. A., Kocken, R. J., \& Limonard, C. B. (1992). Computerized health information in The Netherlands: a registration network of family practices. British Journal of General Practice, 42(356), 102-106. 
Mol, M. E., van Boxtel, M. P., Willems, D., \& Jolles, J. (2006). Do subjective memory complaints predict cognitive dysfunction over time? A six-year follow-up of the Maastricht Aging Study. International Journal of Geriatric Psychiatry, 21(5), 432-441.

Pavot, W., Diener, E., Colvin, C. R., \& Sandvik, E. (1991). Further validation of the Satisfaction with Life Scale: evidence for the cross-method convergence of well-being measures. Journal of Personality Assessment, 57(1), 149-161.

Pollina, L. K., Greene, A. L., Tunick, R. H., \& Puckett, J. M. (1992). Dimensions of everyday memory in young adulthood. British Journal of Psychology, 83 ( Pt 3), 305-321.

Ponds, R. W., Commissaris, K. J., \& Jolles, J. (1997). Prevalence and covariates of subjective forgetfulness in a normal population in The Netherlands. International Journal of Aging and Human Development, 45(3), 207-221.

Prudic, J., Peyser, S., \& Sackeim, H. A. (2000). Subjective memory complaints: a review of patient self-assessment of memory after electroconvulsive therapy. The Journal of ECT, 16(2), 121-132.

Reid, L. M. \& Maclullich, A. M. (2006). Subjective memory complaints and cognitive impairment in older people. Dementia and Geriatric Cognitive Disorders, 22(5-6),471-85.

Ribeiro, F., de Mendonca, A., \& Guerreiro, M. (2006). Mild cognitive impairment: deficits in cognitive domains other than memory. Dementia and Geriatric Cognitive Disorders, 21(56), 284-290.

Robertson, I. H. L., B. (2001). Goal Management Training. Dublin.

Satz, P., Morgenstern, H., Miller, E. N., Selnes, O. A., McArthur, J. C., Cohen, B. A., et al. (1993). Low education as a possible risk factor for cognitive abnormalities in HIV-1: findings from the multicenter AIDS Cohort Study (MACS). Journal of Acquired Immune Deficiency Syndrome, 6(5), 503-511.

Smith, A. (1968). The Symbol Digit Modalities Test: a neuropsychological test for economic screening of learning and other cerebral disorders. Learning Disorders, 36, 83-91.

Smith, G. E., Petersen, R. C., Ivnik, R. J., Malec, J. F., \& Tangalos, E. G. (1996). Subjective memory complaints, psychological distress, and longitudinal change in objective memory performance. Psychology and Aging, 11(2), 272-279.

Stroop, J. R. (1935). Studies of interference in serial verbal reactions. Journal of Experimental Psychology, 18, 643-662.

Timiras, P. S. (1995). Education, homeostasis, and longevity. Experimental Gerontology, 30(3-4), 189-198.

van Boxtel, M. P., Buntinx, F., Houx, P. J., Metsemakers, J. F., Knottnerus, A., \& Jolles, J. (1998). The relation between morbidity and cognitive performance in a normal aging population. Journal of Gerontology: Biological Sciences and Medical Sciences, 53(2), M147154.

Van der Elst, W., Van Boxtel, M. P., Van Breukelen, G. J., \& Jolles, J. (2006a). Normative data for the Animal, Profession and Letter M Naming verbal fluency tests for Dutch speaking participants and the effects of age, education, and sex. Journal of International Neuropsychological Society, 12(1), 80-89.

Van der Elst, W., Van Boxtel, M. P., Van Breukelen, G. J., \& Jolles, J. (2006b). The Stroop 
color-word test: influence of age, sex, and education; and normative data for a large sample across the adult age range. Assessment, 13(1), 62-79.

Van der Elst, W., van Boxtel, M. P. J., van Breukelen, G. J. P., \& Jolles, J. (2006). The Letter Digit Substitution Test: Normative data for 1,858 healthy participants aged 24-81 from the Maastricht Aging Study (MAAS): influence of Age, Education, and Sex. Journal of Clinical and Experimental Neuropsychology, 28, 998-1009.

Van der Elst, W., van Boxtel, M. P. J., van Breukelen, G. J. P., \& Jolles, J. (2007). The Concept Shifting Test: Adult normative data. Psychological Assesment.

van Hooren, S. A., Valentijn, S. A., Bosma, H., Ponds, R. W., van Boxtel, M. P., Levine, B., et al. (2007). Effect of a structured course involving goal management training in older adults: A randomised controlled trial. Patient Education and Counseling, 65(2), 205-213.

Vink, M., \& Jolles, J. (1985). A new version of the Trail-Making Test as an information processing task. Journal of Clinical Neuropsychology, 7, 162.

Ware, J. E., Jr., \& Sherbourne, C. D. (1992). The MOS 36-item short-form health survey (SF36). I. Conceptual framework and item selection. Medical Care, 30(6), 473-483.

WHO. (2001). International Classification of Functioning, Disability and Health. Geneva: WHO. Zee, K. I., v.d., Xanderman, R., \& Heyink, J. (1993). Psychometrische kwaliteiten van de MOS 36-item Short Form Health Survey (SF-36) in een Nederlandse populatie. Tijdschrift voor Sociale Gezondheidszorg, 71, 183-191. 


\section{APPENDIX 1}

\section{Maastricht Attention and memory Checklist (MAC)}

1. Generally speaking, are you able to put in firm mental effort (e.g. are you able to work, read, talk, concentrate for a longer period of time)? Yes/No

2. I have no problems keeping up my appointments.
a. Totally disagree
b. Disagree
c. Do not agree/disagree
d. Agree
e. Totally agree

3. I have no trouble remembering where I laid my things.
a. Totally disagree
b. Disagree
c. Do not agree/disagree
d. Agree
e. Totally agree

4. To what degree were you, in the past week (including today) troubled by: restlessness, in the sense that you could not sit still.
a. Not at all
b. A little bit
c. Somewhat
d. Rather
e. A lot

5. In comparison with other people of my age, I am able to concentrate ... on things I hear, see or read.
a. Much easier
b. Somewhat easier
c. The same
d. More difficult
e. Much more difficult

6. In comparison with other people of my age, I can focus my attention ... on one task for a longer time.
a. Much easier
b. Somewhat easier
c. The same 

d. More difficult
e. Much more difficult

7. In comparison with other people of my age, I have ... problems concentrating on more than one task (e.g. driving a car and having a conversation; prepare a meal and listen to the radio).
a. Far less
b. Less
c. The same
d. More
e. Much more

8. In comparison with other people of my age, I am easily distracted from what I am doing.
a. Much less
b. Less
c. Just as
d. More
e. Much more

9 a. Are you forgetful?

b. If the answer is "Yes"; what are the most important causes? Give an account by filling in the number of importance, for instance most important cause is "1"; the next is " 2 ", etc. More answers are possible.

$\square$ Age

$\square$ Stress and emotional problems

$\square$ Sickness/trauma

$\square$ Concentration problems

$\square$ Interest

$\square$ Cognitive decline

$\square$ Little mental exercise

$\square$ Medication

$\square$ Surgical procedure under general anaesthesia

$\square$ Other, namely

10 a. I have trouble concentrating (sustaining attention)

Yes/No

b. If the answer is "Yes"; to what degree?

口 Sometimes

$\square$ Often

$\square$ Always 
Attention dysfunction and ADHD in adults: determinants and interventions 



\section{Characteristics of Attention-Deficit/Hyperactivity Disorder (ADHD) in healthy adults are related to depression, anxiety and reduced Quality of Life: results in 912 subjects from the Maastricht Aging Study (MAAS)}

Dymphie Scholtissen-In de Braek, Petra Hurks, Martin van Boxtel, Jeanette Dijkstra \& Jelle Jolles

\section{Abstract}

Objective: To investigate characteristics and consequences of Attention-Deficit/ Hyperactivity Disorder (ADHD) in healthy subjects from the general adult and elderly population.

Methods: Investigation of cognitive complaints with the Maastricht Cognitive Questionnaire (MCQ), Quality of Life (QoL) and complaints of depression and anxiety as measured by standard questionnaires in a cross-sectional sample drawn from a large-scale longitudinal study ( 912 healthy subjects aged 33 to 89 years).

Results: Two out of five factors of the MCQ reflected characteristics of ADHD. Complaints of inattention in combination with impulsivity/hyperactivity were related to a higher level of complaints of depression and anxiety. In addition, there was diminished satisfaction with life in these subjects. Inattention in childhood was not related to adult depression or anxiety.

Conclusions: Characteristics of ADHD in healthy subjects are related to diminished QoL and to problems of depression and anxiety as seen in clinical samples, although to a lesser extent. In this study, we found that subjective complaints of inattention, hyperactivity, and impulsivity in a healthy population were related to a higher levels of depressed mood, more anxiety, and less satisfaction with 
life. Likewise, we found inattention, hyperactivity, and impulsivity to be related to a higher degree of role limitations due to emotional problems. Healthy adults with complaints of attention in combination with impulsivity/hyperactivity have a higher risk for the development of affective disorders.

\section{Introduction}

Until now, most research on cognitive complaints in the healthy adult and elderly population has focused on memory complaints and forgetfulness (Commissaris, 1998; McDougall, Becker, \& Arheart, 2006; Mol, van Boxtel, Willems, \& Jolles, 2006; Ponds, Commissaris, \& Jolles, 1997). Although healthy persons often report complaints of attention, planning and organization of behaviour, little research has paid attention to these aspects of cognition. Research on the topic of attention and executive complaints has focused primarily on clinical studies in the field of Attention-Deficit/Hyperactivity Disorder (ADHD). ADHD is a highly prevalent neurodevelopmental disorder which is characterized by inattention, hyperactivity and impulsive symptoms (APA, 2000). Cognitive complaints in the domain of attention and executive functioning are the core problems of ADHD. ADHD is not merely a child psychiatric disorder that persists into young adulthood, but an important and unique manifestation of psychopathology across the lifespan (Kessler et al., 2005; Kooij et al., 2005). Few prevalence studies have addressed symptoms of ADHD in the general population (Kessler et al., 2006; Kooij et al., 2005). To the best of our knowledge, little research has investigated characteristics of ADHD, in the general population. The aim of this study was to gain insight into the frequency of ADHD characteristics in the general population and to investigate the relationship between these characteristics, depression, anxiety and Quality of Life (QoL). It is of high importance to investigate ADHD characteristics in the general population, since these can cause a lot of problems in several domains, including mental health, social and occupational functioning. In addition, these problems could be a risk factor for development of psychopathology, such as depression and anxiety. In this study, we focused on the prevalence of ADHD-characteristics in the healthy population. In order to do this, we used selfreports on a dedicated questionnaire on the domain of attention and executive dysfunction.

Given the objectives of this study, the first aim of the study was to investigate whether, in the general population, an association between characteristics of ADHD and QoL, or the degree of well-being (physically and mentally) experienced by an individual or group of people, exists. Based on the knowledge 
derived from previously mentioned clinical studies and the high level of comorbidity in persons with ADHD (Spencer, Biederman, \& Mick, 2007), we expected an association between the two (Alptekin et al., 2005; Leavitt \& Katz, 2006; Ribeiro, de Mendonca, \& Guerreiro, 2006).

The second aim of the study was to determine if certain clusters of symptoms of ADHD such as attention, impulse- and activation-regulation were associated with depression, anxiety and QoL. This is of scientific and clinical interest because clinical samples of patients with Attention-Deficit (Hyperactivity) Disor$\operatorname{der}(A D(H) D)$ appears to be characterized by distinct subtypes, each with their own pattern of cognitive and behavioural profile and each with different underlying mechanisms (Diamond, 2005; Nolan, Gadow, \& Sprafkin, 2001). Because few studies have focused on the different profiles of cognitive complaints and because we believe that the identification of different profiles may lead to better management of complaints, we chose to investigate the relationship between certain clusters of symptoms of ADHD, depression, anxiety and QoL.

\section{Methods}

\section{Participants}

The present study was based on cross-sectional data derived from a longitudinal study of the determinants of cognitive aging called the Maastricht Aging Study (MAAS) (Jolles, Verhey, Riedel, \& Houx, 1995; van Boxtel et al., 1998). In MAAS, a broad range of experimental and standardised instruments of health and psychological functioning were used to collect data at baseline and at three, six and nine years follow up. More details about the enrolment procedure and in- and exclusion criteria can be found elsewhere (Jolles, Verhey, Riedel, \& Houx, 1995). All participants provided informed consent. The sample was stratified at baseline according to sex, and level of education (eight point scale ranging from primary to university education) (De Bie, 1987). For this study, age (at the time of neuropsychological testing) was considered as a continuous variable. In the present study, participants who completed the Maastricht Cognitive Questionnaire (MCQ), at third follow up (nine years) were selected for participation. This resulted in a total study population of 912 participants. Due to the longitudinal design of the study, outcome measures were retrospectively investigated at six years of follow up. The mean age of participants was 58.7 (range: 33-89; $S D=15.1$ ) and the mean level of education was $3.6(\mathrm{SD}=1.6)$. In this study, $51 \%$ of the participants were male while $49 \%$ were female. 


\section{Tests}

\section{Maastricht Cognitive Questionnaire (MCQ) for Adults}

The MCQ measures attention and executive complaints in adulthood and childhood. It comprises 50 items that investigate ADHD symptoms in childhood and adolescence, (early) cognitive and motor development, and recent neurovegetative symptoms. It consists of 20 items covering childhood functioning and 30 items covering current functioning. Examples of cognitive items are: "I can concentrate well on the things I see, read, or hear"; "as a child, I did things before thinking". An example of an item questioning motor development was: "I was an early crawler, walker, etc." Neurovegetative symptoms were also questioned, for instance with an item like "I often have problems falling asleep". Items are scored on a three-point scale ranging from "I totally agree" to "I totally disagree", with a higher score on the MCQ indicating more complaints.

To gain insight regarding possible correlations and the cohesion of the 50 MCQ items, a principal component analysis was performed using an orthogonal rotational procedure (Varimax). The criteria used to determine the most appropriate number of factors to retain were a maximum of five factors, a minimum factor loading of 0.30 , and a meaningful interpretation of the factors. The results of the factor analyses indicated that the most comprehensive model meeting the criteria was a five factor solution with the factors inattention, hyperactivity, impulsivity (factor 1), vitality (factor 2), learning and creativity (factor 3), inattention (factor 4), and motor functioning (factor 5). Together, these five factors explained $35.5 \%$ of the variance. Factor 1 reflects attention complaints, hyperactivity and executive problems (e.g. problems with planning and impulsivity) in childhood and adulthood. Factor 4 includes only symptoms of inattention in childhood.

\section{Outcome measures}

The Satisfaction With Life Scale (SWLS) was used to measure the cognitive component of subjective well-being. This five item self-reported scale assesses the individual's satisfaction with life on a seven-point Likert scale. The internal consistency and temporal stability of this scale is satisfactory (Pavot, Diener, Colvin, \& Sandvik, 1991). Cronbach's alpha in the current study was 0.88 . The range of the scale is 5 to 35 , with a higher score indicating greater satisfaction with life.

The RAND-36, or SF-36 (Short Form) (Dutch version) is a validated, self-administered questionnaire that was used in this study to measure health status on several dimensions, namely physical functioning (score range 10-30), social functioning (score range 2-10), role limitations due to physical problems (score range 4-8) 
and emotional problems (score range 5-25), pain (score range 11-60), mental health (score range 5-30), vitality (score range 4-24), and general health perception (score range 5-25) (Aaronson et al., 1998; Ware \& Sherbourne, 1992; Zee, 1993). In this study, the dimensional scores were treated as dependent variables. On every dimension, a higher score is considered to indicate better health.

To gain further insight regarding recent subjective complaints, we measured feelings of depression, anxiety, and sleep, as dependent variables, using three scales of the Symptom Check List (SCL-90). The SCL-90 is a multidimensional, selfreported inventory of psychopathology (Derogatis, Rickels, \& Rock, 1976). The scores for the anxiety, depression and sleep subscales ranged from 0-50, 0-80 and $0-15$, respectively. For all three scales, a higher score is considered indicative of more symptoms.

\section{Statistical analyses}

The 12th version of the Statistical Package for the Social Sciences (SPSS) for Windows was used for the statistical analyses (SPSS inc., USA). Linear regression analyses were used to investigate the nature of the specific relationships between the five factors of the MCQ for adults (independent variables) and the earlier mentioned variables of QoL and cognition (dependent variables). Age, education, and sex were also included in the regression analyses because these factors are known to affect cognitive functioning (Van der Elst, Van Boxtel, Van Breukelen, \& Jolles, 2006a, 2006b; Van der Elst, van Boxtel, van Breukelen \& Jolles, 2006). Level of education was measured on an eight point scale that ranged from primary to university education (De Bie, 1987).

\section{Results}

A significant relationship was found between factor 1, namely inattention, hyperactivity, and impulsivity, and the SWLS total score. A higher score on factor 1 indicated less satisfaction with life. A higher score on factor 1 was also related to more emotional problems (as measured by the SF-36), a higher level of anxiety (as measured by the SCL-90).

Higher scores on factor 2, vitality, were found to be related to: (1) the SWLS total score; (2) all subscales of the SF-36; and (3) anxiety, depression, and sleep problems (as measured by the SCL-90). Problems with vitality were also related to more psychiatric symptoms and diminished health and well-being.

Factor 3, namely learning and creativity, was found to be related to the higher SWLS total score, diminished social and physical functioning, emotional prob- 
TABLE 1 Regression coefficients, $R$ and $R$ square of the linear regression analyses of the five factor model of the MCQ for Adult, along with age, sex, education and the outcome measure, QoL

\begin{tabular}{|r|l|l|l|l|l|l|}
\hline & Factor 1 & Factor 2 & Factor 3 & Factor 4 & Factor 5 & $\begin{array}{c}\text { R square / } \\
\text { adjusted R2 }\end{array}$ \\
\cline { 2 - 7 } & $\beta$ & $\beta$ & $\beta$ & $\beta$ & $\beta$ & \\
\hline SWLS tot & $-0.13^{* * *}$ & $-0.35^{* * *}$ & $-0.19^{* * *}$ & -0.06 & $-0.07^{*}$ & $0.17 / 0.16$ \\
\hline PHF & -0.02 & $-0.26 * * *$ & -0.03 & 0.04 & -0.05 & $0.36 / 0.35$ \\
\hline SOCF & -0.02 & $-0.45^{* * *}$ & $-0.07^{*}$ & -0.00 & $-0.07^{*}$ & $0.25 / 0.24$ \\
\hline RLPH & -0.05 & $-0.39^{* * *}$ & $-0.07^{*}$ & 0.04 & $-0.09^{* *}$ & $0.21 / 0.20$ \\
\hline RLEM & $-0.91^{* *}$ & $-0.38^{* * *}$ & $-0.07^{*}$ & -0.04 & $-0.07^{*}$ & $0.18 / 0.18$ \\
\hline PAIN & -0.01 & $-0.35^{* * *}$ & -0.21 & 0.31 & $-0.78^{*}$ & $0.20 / 0.19$ \\
\hline MH & 0.03 & $-0.23^{* * *}$ & -0.63 & 0.00 & -0.05 & $0.07 / 0.06$ \\
\hline VIT & -0.06 & $-0.54^{* * *}$ & $-0.20^{* * *}$ & -0.01 & $-0.13^{* * *}$ & $0.36 / 0.35$ \\
\hline GHP & -0.06 & $-0.43^{* * *}$ & $-1.16^{* * *}$ & -0.00 & $-0.12^{* * *}$ & $0.33 / 0.32$ \\
\hline SCLANG & $0.16^{* * *}$ & $0.50^{* * *}$ & $0.11^{* * *}$ & 0.03 & $0.13^{* * *}$ & $0.31 / 0.30$ \\
\hline SCLDEP & $0.16^{* * *}$ & $0.57^{* * *}$ & $0.18^{* * *}$ & 0.03 & $0.16 * * *$ & $0.40 / 0.40$ \\
\hline SCLSLA & 0.01 & $0.69 * * *$ & 0.04 & $-0.59^{*}$ & 0.33 & $0.46 / 0.45$ \\
\hline ALCAGE & $-1 *$ & -0.12 & 0.18 & -0.00 & 0.00 & $0.27 / 0.26$ \\
\hline
\end{tabular}

SWLS tot $=$ SWLS total score, PHF = Physical Functioning (SF-36), SOCF = Social Functioning (SF-36), RLPH = role limitations due to physical problem (SF-36), RLEM = role limitations due to emotional problem (SF-36), PAIN (SF-36), MH = Mental Health (SF-36), VIT = Vitality (SF36), GHP = General Health Perception (SF-36), SCLANG = Anxiety (SCL-90), SCLDEP = Depression (SCL-90), SCLSLA = Sleep (SCL-90), ALCAGE = frequent alcohol use on young age ${ }^{*} p<0.05,{ }^{* *} p<0.01, * * * p<0.001$

lems, vitality, general health perception (as measured by the SF-36), and depression and anxiety (as measured by the SCL-90).

Factor 4, inattention, was found to be associated with fewer sleeping problems (as measured by the SCL-90). This factor was not found to be related to QoL.

Finally, factor 5, motor functioning, was found to be related to social functioning, physical problems, emotional/vitality problems, pain, overall health, and a change in health (as measured by the SF-36). It was also found to be related to anxiety and depression symptoms (as measured by the SCL-90). See Table 1 for further information regarding the linear regression analyses on QoL.

As said earlier, age, sex and education were included in the regression analyses. Age was found to be significantly related to the SWLS total score, physical 
functioning, social functioning, role limitations due to physical problems, pain, general health perception, depression and sleep. These results indicate that with increasing age, more subjective complaints arose. Education was found to be significantly related to physical functioning, pain and general health perception. Education was thus not related to cognitive and/or psychological complaints. Finally, sex was found to be significantly related to the SWLS total score and general health perception.

\section{Discussion}

The aim of the present study was to investigate the relationship between ADHD characteristics with depression, anxiety and QoL in the general adult and elderly population. Based on evidence from previous clinical studies (Chan 2001; Alptekin, et al. 2005; Leavitt and Katz 2006; Ribeiro, et al. 2006), we hypothesised that particular cognitive complaints in the domain of attention and executive functioning would be related to depression, anxiety and QoL.

As an independent outcome measure the Maastricht Cognitive Questionnaire (MCQ) for Adults was used. The factor analyses on the MCQ for Adults revealed five factors: (1) inattention, hyperactivity, and impulsivity; (2) vitality; (3) learning and creativity; (4) inattention; and (5) motor functioning. Factor analyses revealed that, in the general population, different profiles of subjective cognitive complaints can be discerned.

In this study, we found that subjective complaints of inattention, hyperactivity, and impulsivity in a healthy population were related to a higher levels of depressed mood, more anxiety, and less satisfaction with life. Likewise, we found inattention, hyperactivity, and impulsivity to be related to a higher degree of role limitations due to emotional problems. Subjective complaints of attention alone (factor 4) were not found to be related to any of the QoL measures. This last finding is not strange, since factor 4 only represents cognitive complaints of inattention in childhood. Inattention was found to be related to sleep problems. This is in line with clinical research findings, suggesting an association between inattention, a greater need for sleep and greater difference between sleep need and self-estimated nocturnal sleep duration (Gau et al., 2007). Clinical research also showed that the inattentive subtype of ADHD is the subtype with the least complex co-occurring symptoms (Sprafkin, Gadow, Weiss, Schneider, \& Nolan, 2007).

Evidently, the major difference between factor 1 (inattention, hyperactivity, and impulsivity) and factor 4 (inattention) is that factor 1 includes hyperactive and impulsive behaviour. The differences in the findings for these two factors 
are in accordance with the DSM-IV-TR, in which three distinct subtypes of ADHD are mentioned, namely the combined type, the predominantly inattentive type, and the predominantly hyperactive/impulsive subtype (APA, 2000). Several theories hypothesise that the combined subtype is marked by a higher level of problem behaviour due to problems with response inhibition. These theories also contend that problems with response inhibition can lead to several secondary executive functioning problems (APA, 2000; Barkley, 1997). With this in mind, we contend that problems with response inhibition and impulsivity are responsible for higher rates of psychiatric comorbidity. This also corresponds with the clinical literature on the various subtypes of ADHD (with and without hyperactivity/ impulsivity). All in all, this study suggests that it is very relevant to look at specific cognitive complaints and our findings are in line with clinical research suggesting that subtypes can be regarded as different disorders with different phenomenology and different underlying mechanisms (Diamond, 2005). The literature also indicates that, in a clinical population, certain comorbid disorders such as depression and personality problems are more common in the combined subtype of ADHD when compared to the predominantly inattentive subtype (Murphy, Barkley, \& Bush, 2002). Our findings are also in accordance with the literature on impulse control disorders and anger, whereby impulse control problems and anger have been found to be related to more psychological and emotional problems (Lara \& Akiskal, 2006).

Clearly, the present study is the first which has provided support for the contention that a continuum of attention, hyperactivity, and impulsivity complaints exists in the general adult and elderly population. Furthermore, our study supports the idea that the phenomenology of inattention complaints alone appears to be different from that of inattention in combination with hyperactivity and impulsivity complaints. However, one has to notice that factor 1 and 4 are different in the sense that factor 4 only involves childhood inattention, whereas factor 1 includes complaints of attention, hyperactivity and impulsivity in adulthood and childhood. Nonetheless, it is important to look at the differences between the two factors, since problems of inattention (which are included in both factors) are most often recognised in children and seem to decline as the individual grows up (Barkley, Fischer, Smallish, \& Fletcher, 2002; Biederman, 1998). Still, in clinical studies $60-80 \%$ of symptoms of inattention, hyperactivity and impulsivity persist into adulthood (Barkley, Fischer, Smallish, \& Fletcher, 2002; Biederman, 1998).

In this study, no association was found between subjective cognitive complaints of inattention alone and QoL. One possible explanation is that, in comparison to externalising behaviour such as hyperactive/impulsive behaviour, 
internalising behaviour such as distractibility leads to less negative feedback and problems with, for example, relationships and work. Hyperactive and impulsive behaviour is likely to be disruptive for the person and his or her environment, which, in turn, may be reflected in QoL measures. It has previously been shown that executive functioning weaknesses are associated with specific symptoms of inattention and disorganisation, but not with hyperactivity/impulsivity (Nigg et al., 2005). As stated previously, different profiles of subjective cognitive complaints can be discriminated in the general population. These different profiles may reflect a different underlying cognitive mechanism.

Furthermore, in this study, subjective complaints of vitality were, as one would expect (Shibata, Oka, Nakamura, \& Muraoka, 2007), related to all variables of QoL. This could be explained by the fact that the vitality items included in the MCQ for Adults also relate to current neurovegetative symptoms. Learning and creativity and motor functioning were also found to be related to several QoL measures. This suggests that learning difficulties, problems with creativity, and difficulties with motor functioning are, even at a young age, associated with a lower QoL later in life. It is obvious that e.g. learning disabilities can have serious consequences for academic and occupational outcome. However little research has concentrated on this topic and more research in this field is wanted.

Obviously, because the present study used cross sectional data, we were unable to prospectively predict changes in functioning. Due to the design of the study, retrospective data were used. In this study there was a three-year separation between assessment of outcome measures and assessment of the MCQ. In three years a lot can happen and obtained correlations might be lower because of this separation. However, a Finn study has shown that for instance life satisfaction was moderately stable during 15 years (Koivumaa-Honkanen, Kaprio, Honkanen, Viinamaki, \& Koskenvuo, 2005). Another limitation of this study was that we did not include mediating factors, like personality or insight, although research has indicated that subjective feelings of cognitive impairment are closely associated with personality traits and drive subjective complaints (Hanninen et al., 1994). Nonetheless, the main purpose of this article was to see whether -despite the three-year separation- there was an association between characteristics of ADHD, depression, anxiety and QoL. Finally, we did not use statistical corrections for multiple comparisons. Post-hoc Bonferroni analyses for multiple testing indicated that the effects on the subjective measures we used would, in general, remain the same.

In summary, using a large sample of healthy adult and elderly individuals, evidence was found that supports the existence of a continuum of characteristics 
of ADHD. Furthermore, special attention should be paid to specific, attention and executive complaints in the general population as they appear to be related to a higher level of depression, anxiety and diminished QoL. The study shows that the MCQ can have an important contribution in the recognition of specific cognitive complaints in the healthy population and it indicates that attention and executive complaints are a risk factor for psychopathology, including depression and anxiety. Evidently, in order to adequately manage cognitive complaints, early recognition is imperative. 


\section{References}

Aaronson, N. K., Muller, M., Cohen, P. D., Essink-Bot, M. L., Fekkes, M., Sanderman, R., et al. (1998). Translation, validation, and norming of the Dutch language version of the SF-36 Health Survey in community and chronic disease populations. Journal of Clinical and Experimental Neuropsychology, 51(11), 1055-1068.

Alptekin, K., Akvardar, Y., Kivircik Akdede, B. B., Dumlu, K., Isik, D., Pirincci, F., et al. (2005). Is quality of life associated with cognitive impairment in schizophrenia? Progress in Neuropsychopharmacology and Biological Psychiatry, 29(2), 239-244.

APA. (2000). Diagnostic and Statistical Manual of Mental Disorders (4th Edition-Text Revision). Washington D.C.: American Psychiatric Association.

Barkley, R. A. (1997). Behavioral inhibition, sustained attention, and executive functions: constructing a unifying theory of ADHD. Psychological Bulletin, 121(1), 65-94.

Barkley, R. A., Fischer, M., Smallish, L., \& Fletcher, K. (2002). The persistence of attentiondeficit/hyperactivity disorder into young adulthood as a function of reporting source and definition of disorder. Journal of Abnormal Psychology, 111(2), 279-289.

Biederman, J. (1998). Attention-deficit/hyperactivity disorder: a life-span perspective. Journal of Clinical Psychiatry, 59 Suppl 7, 4-16.

Commissaris, C. J. A. M., Ponds, R.W.H.M. \& Jolles, J. (1998). Subjective forgetfulness in a normal dutch population: Possibilities for health education and other interventions. . Patient Education and Counseling, 34, 25-32.

De Bie, S. E. (1987). Standaardvragen 1987: Voorstellen voor uniformering van vraagstellingen naar achtergrondkenmerken en interviews [Standard questions 1987: Proposal for uniformisation of questions regarding background variables]. (2nd ed. ed.). Leiden, The Netherlands: Leiden University Press.

Derogatis, L. R., Rickels, K., \& Rock, A. F. (1976). The SCL-90 and the MMPI: a step in the validation of a new self-report scale. British Journal of Psychiatry, 128, 280-289.

Diamond, A. (2005). Attention-deficit disorder (attention-deficit/ hyperactivity disorder without hyperactivity): a neurobiologically and behaviorally distinct disorder from attention-deficit/hyperactivity disorder (with hyperactivity). Developmental Psychopathology, 17(3), 807-825.

Gau, S. S., Kessler, R. C., Tseng, W. L., Wu, Y. Y., Chiu, Y. N., Yeh, C. B., et al. (2007). Association between sleep problems and symptoms of attention-deficit/hyperactivity disorder in young adults. Sleep, 30(2), 195-201.

Hanninen, T., Reinikainen, K. J., Helkala, E. L., Koivisto, K., Mykkanen, L., Laakso, M., et al. (1994). Subjective memory complaints and personality traits in normal elderly subjects. Journal of American Geriatric Society, 42(1), 1-4.

Jolles, J., Verhey, F. R., Riedel, W. J., \& Houx, P. J. (1995). Cognitive impairment in elderly people. Predisposing factors and implications for experimental drug studies. Drugs \& Aging, 7(6), 459-479.

Kessler, R. C., Adler, L., Barkley, R., Biederman, J., Conners, C. K., Demler, O., et al. (2006). The prevalence and correlates of adult ADHD in the United States: results from the National Comorbidity Survey Replication. 163(4), 716-723. 
Kessler, R. C., Adler, L. A., Barkley, R., Biederman, J., Conners, C. K., Faraone, S. V., et al. (2005). Patterns and predictors of attention-deficit/hyperactivity disorder persistence into adulthood: results from the national comorbidity survey replication. American Journal of Psychiatry, 57(11), 1442-1451.

Koivumaa-Honkanen, H., Kaprio, J., Honkanen, R. J., Viinamaki, H., \& Koskenvuo, M. (2005). The stability of life satisfaction in a 15-year follow-up of adult Finns healthy at baseline. BMC Psychiatry, 5(4).

Kooij, J. J., Buitelaar, J. K., van den Oord, E. J., Furer, J. W., Rijnders, C. A., \& Hodiamont, P. P. (2005). Internal and external validity of attention-deficit hyperactivity disorder in a population-based sample of adults. Psychological Medicine, 35(6), 817-827.

Lara, D. R., \& Akiskal, H. S. (2006). Toward an integrative model of the spectrum of mood, behavioral and personality disorders based on fear and anger traits: II. Implications for neurobiology, genetics and psychopharmacological treatment. Journal of Affective Disorders.

Leavitt, F., \& Katz, R. S. (2006). Distraction as a key determinant of impaired memory in patients with fibromyalgia. Journal of Rheumatology, 33(1), 127-132.

McDougall, G. J. Jr., Becker, H., \& Arheart, K. L. (2006). Older Adults in the SeniorWISE Study At Risk for Mild Cognitive Impairment. Archives of Psychiatric Nursing, 20(3), 126-134.

Mol, M. E., van Boxtel, M. P., Willems, D., \& Jolles, J. (2006). Do subjective memory complaints predict cognitive dysfunction over time? A six-year follow-up of the Maastricht Aging Study. International Journal of Geriatric Psychiatry, 21(5), 432-441.

Murphy, K. R., Barkley, R. A., \& Bush, T. (2002). Young adults with attention deficit hyperactivity disorder: subtype differences in comorbidity, educational, and clinical history. Journal of Nervous Mental Disorders, 190(3), 147-157.

Nigg, J. T., Stavro, G., Ettenhofer, M., Hambrick, D. Z., Miller, T., \& Henderson, J. M. (2005). Executive functions and ADHD in adults: evidence for selective effects on ADHD symptom domains. Journal of Abnormal Psychology, 114(4), 706-717.

Nolan, E. E., Gadow, K. D., \& Sprafkin, J. (2001). Teacher reports of DSM-IV ADHD, ODD, and CD symptoms in schoolchildren. Journal of the American Child and Adolescent Psychiatry, 40(2), 241-249.

Pavot, W., Diener, E., Colvin, C. R., \& Sandvik, E. (1991). Further validation of the Satisfaction with Life Scale: evidence for the cross-method convergence of well-being measures. Journal of Personality Assessment, 57(1), 149-161.

Ponds, R. W., Commissaris, K. J., \& Jolles, J. (1997). Prevalence and covariates of subjective forgetfulness in a normal population in The Netherlands. International Journal of Aging and Human Development, 45(3), 207-221.

Ribeiro, F., de Mendonca, A., \& Guerreiro, M. (2006). Mild cognitive impairment: deficits in cognitive domains other than memory. Dementia and Geriatric Cognitive Disorders, 21(56), 284-290.

Shibata, A., Oka, K., Nakamura, Y., \& Muraoka, I. (2007). Recommended level of physical activity and health-related quality of life among Japanese adults. Health and Quality of Life Outcomes, 28(5(1)), 64. 
Spencer, T. J., Biederman, J., \& Mick, E. (2007). Attention-deficit/hyperactivity disorder: diagnosis, lifespan, comorbidities, and neurobiology. Journal of Paediatric Psychology, 32(6), 631-642.

Sprafkin, J., Gadow, K. D., Weiss, M. D., Schneider, J., \& Nolan, E. E. (2007). Psychiatric comorbidity in ADHD symptom subtypes in clinic and community adults. Journal of Attention Disorders, 11(2), 114-124.

van Boxtel, M. P., Buntinx, F., Houx, P. J., Metsemakers, J. F., Knottnerus, A., \& Jolles, J. (1998). The relation between morbidity and cognitive performance in a normal aging population. Journal of Gerontology: Biological Sciences and Medical Sciences, 53(2), M147154.

Van der Elst, W., Van Boxtel, M. P., Van Breukelen, G. J., \& Jolles, J. (2006a). Normative data for the Animal, Profession and Letter M Naming verbal fluency tests for Dutch speaking participants and the effects of age, education, and sex. Journal of International Neuropsychological Society, 12(1), 80-89.

Van der Elst, W., Van Boxtel, M. P., Van Breukelen, G. J., \& Jolles, J. (2006b). The Stroop color-word test: influence of age, sex, and education; and normative data for a large sample across the adult age range. Assessment, 13(1), 62-79.

Van der Elst, W., van Boxtel, M. P. J., van Breukelen, G. J. P., \& Jolles, J. (2006). The Letter Digit Substitution Test: Normative data for 1,858 healthy participants aged 24-81 from the Maastricht Aging Study (MAAS): influence of Age, Education, and Sex. Journal of Clinical and Experimental Neuropsychology, 28, 998-1009.

Ware, J. E., Jr., \& Sherbourne, C. D. (1992). The MOS 36-item short-form health survey (SF36). I. Conceptual framework and item selection. Medical Care, 30(6), 473-483.

Zee, K. I., v.d., Xanderman, R., \& Heyink, J. (1993). Psychometrische kwaliteiten van de MOS 36-item Short Form Health Survey (SF-36) in een Nederlandse populatie. Tijdschrift voor Sociale Gezondheidszorg, 71, 183-191. 
Attention dysfunction and ADHD in adults: determinants and interventions 



\title{
The role of the clinical neuropsychologist in Attention-Deficit/Hyperactivity Disorder (ADHD) in adults: an overview
}

Dymphie Scholtissen-In de Braek, Natalie Marchetta, Petra Hurks, Jeanette Dijkstra \& Jelle Jolles

\begin{abstract}
Attention-Deficit/Hyperactivity Disorder (ADHD) is a complex, multi-determined neurodevelopmental disorder that has to be diagnosed within the context of biological, psychological and social factors. Symptoms like inattentiveness, restlessness and impulsivity often persist into adulthood. Neuropsychological studies in adults with ADHD have shown subtle impairments on tests of verbal memory and executive functioning. Various models have been proposed to explain the multidimensional picture. Apart from executive dysfunction, also delay aversion, cognitive-energetic problems or working memory have been proposed as an endophenotype in ADHD. The present paper reviews neuropsychological findings and (neuro)cognitive models of ADHD (primarily in adults) and tries to bridge the gap between theory and clinical practice.
\end{abstract}




\section{Introduction}

Attention-Deficit/Hyperactivity Disorder (ADHD) refers to a complex, neurodevelopmental disorder that is prevalent in $4-12 \%$ of all school-age children (APA, 2000). Symptoms of ADHD, such as inattentiveness, restlessness, and impulsivity, often persist into adolescence and adulthood (Barkley, Fischer, Smallish, \& Fletcher, 2002). The estimated prevalence of ADHD in adults is $1-4.7 \%$ (Faraone \& Biederman, 2005; Kooij et al., 2005). In 60-80\% of adults with ADHD, comorbid disorders such as depression, anxiety, substance abuse, and personality problems also occur (Biederman, 2005). Furthermore, ADHD has serious consequences for social, occupational, and academic outcome (Barkley, 2002; Biederman et al., 1993). ADHD is a developmental disorder, suggesting an early expression of ADHD symptomatology that influences the development of the majority of persons affected into adulthood.

The relatively high prevalence of adult ADHD could be of major interest to clinical neuropsychologists. Yet, relatively little is known about the neuropsychological phenomenology of adult ADHD. Moreover, few studies published to date have approached the matter from a multidimensional point of view, which is essential to grasp the essence of the condition. The problem starts with the diagnosis of ADHD in adulthood. From a pragmatic point of view, the DSM-IVTR (2000) is the most frequently used diagnostic classification system used to describe mental disorders (APA, 2000). The diagnostic investigation into ADHD is always multidisciplinary, including a clinical interview to gather information about functioning in adulthood and childhood, and a thorough psychiatric investigation. Yet, the question is whether the DSM-IV-TR classification method adequately detects all of the problems that adults encounter in the domain of neuropsychological skills, neurocognitive and behavioural complaints, and dysfunction. In this article, we argue that clinical neuropsychology can make an important contribution to the process leading to the diagnosis and treatment of adult ADHD. Clinical neuropsychologists are seeing more and more adults with attention disorders. Because of the high level of (psychiatric) comorbidity, ADHD can be very challenging for clinical neuropsychologists and health care psychologists who work in the domain of mental health. Research into cognitive processes in children with ADHD has shown that several cognitive problems start early in the development. Notable in this respect are dysfunctions in processing speed, speed variability, visuomotor preparation, and executive functioning in children (Hurks et al., 2005; Kalff et al., 2003; Kalff, Sonneville, de, Hurks, Hendriksen, Kroes, Feron, Steyaert, Zeben, van, Vles, and Jolles, 2005). Yet, there is still little knowledge of the neuropsychological underpinnings of ADHD, especially in 
adults (Seidman et al., 2004). Moreover, although the term "ADHD" refers to problems with attention, an objective dysfunction in this domain is not always confirmed by traditional neuropsychological tests of attention (Tannock, 1998). Of profound clinical relevance is the overwhelming evidence that adult ADHD, in particular, is multidimensional and involves major comorbidity, and also that part of the clinical picture may consist of inadequate coping behaviour. Neuropsychologists are better educated than psychiatrists when it comes to evaluating the contribution of neurocognitive skills (primary) versus coping styles (secondary). The present paper argues that ADHD in adults is primarily a neuropsychological condition and that the clinical neuropsychologist should have an important role in the diagnostic investigation and treatment of ADHD.

Several theoretical models have been developed to gain insight into ADHD and to explain the symptoms from a neuropsychological or neurocognitive perspective. These models are based primarily on observations and research findings in children and adults. A question arises regarding the implications of these models for clinical practice. This article gives an overview of neuropsychological findings, and models of ADHD (primarily in adults) and provides some indications of the contribution of neuropsychological assessment to ADHD. It is written for clinical neuropsychologists who are confronted with symptoms of both mild attentional deficits in adults and severe forms of ADHD, as well as for others who want to gain more insight into the clinical picture, neuropsychology, and recent theoretical models of ADHD.

\section{Background}

ADHD is a complex, heterogeneous, neurodevelopmental condition. It is predominantly known as a child psychiatric disorder. According to the Diagnostic and Statistical Manual of Mental Disorders-IV-TR (DSM-IV-TR), the main symptoms are inattention, hyperactivity, and impulsivity (APA, 2000). Some of these symptoms must appear before the age of 7 and lead to impairment in at least two areas, for example, both in school and at home. There are, however, inconsistencies in the literature regarding how many, or more specifically which, criteria are necessary or sufficient for the diagnosis of ADHD. These criteria are dependent on the age group. Some authors have suggested adopting modified thresholds (four or five out of nine criteria for adults). This is based on the idea that the cut-off point used for children may be too stringent for adults with ADHD (e.g., Barkley, 1998; Kooij et al., 2005). In addition, the symptoms must lead to significant social, cognitive, or school dysfunction (APA, 2000). Also, three different subtypes can be 
distinguished, namely, the combined subtype (with symptoms of inattention and hyperactivity/impulsivity), the predominantly inattentive subtype (with primarily symptoms of inattention), and the predominantly hyperactive/impulsive subtype (with primarily hyperactive/impulsive symptoms). However, these criteria and threshold levels are based on children. Unfortunately, little is known about the exact nature, expression, and progress of the condition in adults. Longitudinal studies show that, in at least $60 \%$ of all children with ADHD, symptoms (with fluctuations in severity) persist into adulthood (Barkley, Fischer, Smallish, \& Fletcher, 2002; Biederman, 1998; Faraone et al., 2000; Mannuzza, Klein, Bessler, Malloy, \& LaPadula, 1998). These symptoms can have serious consequences for school, occupational outcome, and relationships (Barkley, 2002). Furthermore, the risk of developing anxiety and mood disorders, personality problems, and substance abuse is significantly elevated (Biederman, 2005; Biederman et al., 1993). This high level of comorbidity is a complicating factor in the diagnostic process of ADHD. In fact, comorbidity is a distinct clinical feature of ADHD (Spencer, Biederman, \& Mick, 2007). An important difference between ADHD and most comorbid disorders is that ADHD is an early-onset, chronic condition. Adults must have childhood onset and persistent and current symptoms of ADHD to be diagnosed with the disorder. The diagnosis of ADHD is made retrospectively by careful clinical history-taking. Yet, many adults have trouble remembering their childhood. For this reason, it is important to consult several sources of information, e.g., parents and teachers and other 'significant others', such as brothers and sisters (Roy-Byrne et al., 1997).

\section{Biological, psychological, and social factors in ADHD}

Although it is not the main focus of this article, this next section will provide some background information that is needed in order to be able to evaluate factors that contribute to ADHD.

First of all, several biological factors contribute to the development of ADHD and can thus be considered as 'risk factors'. The evidence for the relevant biological and biopsychological factors comes from genetic research, brain imaging studies, and behavioural observations. In 1902, Still first described impulsive, aggressive, oppositional behaviour in children (Still, 1902). In 1920, the same symptoms were described in young children suffering from encephalopathy (Barkley, 1998). During the same period of time, researchers found evidence of hyperactive behaviour in monkeys with frontal lobe damage (Levin, 1938). Based on this, it was hypothesized that the behaviour observed was the result of a neurobehavioural disorder. Later, the terms "minimal brain damage" (MBD) 
and/or "minimal brain dysfunction" came into use. However, these terms could not fully explain the symptoms of ADHD, and in 1979 some doubts were raised concerning the neurological basis of ADHD. With the term "ADHD", the focus shifted more towards behavioural symptoms, like inattention, hyperactivity, and impulsivity, and away from aetiology. Nevertheless, the idea that ADHD has an underlying biological cause continues to be postulated.

Brain imaging studies show that there are differences in brain structures and function in ADHD patients compared to healthy controls, and there are differences in neurochemical balance in ADHD patients compared to subjects without the diagnosis (Faraone et al., 2000; Swanson et al., 1998; Tannock, 1998). Primarily, evidence exists that there are anatomical differences and an underlying dysfunction of cerebellar-striatal-prefrontal circuits, in both children and adults (Castellanos, 2001). Seidman et al. (2005) found structural brain differences in other areas, including the cerebellum and other cortical areas (Seidman, Valera, \& Makris, 2005). Recent findings suggest a delay in cortical maturation, most prominently in prefrontal regions, which is important for control of cognitive processes (Shaw et al., 2007). These areas are involved in executive functioning and regulation of attention. However, the exact nature of the dysfunction is unknown. Both hypofunction and hyperfunction in these areas have been reported (Rubia et al., 1999; Vaidya et al., 1998). Electrophysiological studies show, for example, hypofunction of catecholaminergic circuits (dopaminergic and noradrenergic), especially those circuits with projections to prefrontal areas (Tannock, 2003).

With respect to the genetic basis of the condition, evidence exists that a number of different genes most likely play a role in the genetic vulnerability of ADHD (Faraone, 2004; Madras, Miller, \& Fischman, 2002). Genes related to dopamine and noradrenalin metabolism, in particular, are said to be involved in the development of the condition. Furthermore, the risk of developing ADHD is $20-40 \%$ higher in gene carriers. Research in this area is, however, still inconclusive and not specific for ADHD (Tannock, 2003).

Apart from genetics and neurology, other biological factors have been proposed as contributors to ADHD. These include pre-, peri-, and early postnatal problems like maternal smoking and alcohol use during pregnancy, low birth weight, and hypoxia (Biederman, 2005). There is no evidence that diets or food additives cause ADHD (Banerjee, Middleton, \& Faraone, 2007), which is relevant as such claims have been made in earlier years. However, research in this area is not conclusive; more research is warranted.

There is proof that the brains of children and adults with ADHD are different, or mature differently, from those of controls in various respects. Apart from 
biological factors, environmental factors play an important role in adults with ADHD. Several risk factors, including low social class, maternal psychopathology, and family conflict, are associated with a greater risk for ADHD (Biederman, Faraone, \& Monuteaux, 2002). Family and socio-environmental factors must also be considered in the diagnostic process of ADHD because of the genetic predisposition, misunderstandings about the symptoms among family and friends, and problems in social communication in patients with ADHD (Stefanatos \& Baron, 2007). Also, a chaotic household organization and a lack of structure contribute to the development of ADHD (Biederman et al., 1995). One theory explains ADHD from a dynamic, developmental perspective (Sagvolden, Johansen, Aase, \& Russell, 2005). It suggests that behaviour and symptoms in ADHD result from the interplay between individual predispositions and the environment (e.g., medication, parental style, societal style). In this model, dopamine hypofunctioning represents the main individual predisposition. The symptoms of ADHD at a given time vary and are influenced by several factors (Sagvolden, Johansen, Aase, \& Russell, 2005). The abovementioned findings suggest that ADHD is the result of a combination of genetic, biological, social, and psychological factors.

\section{Neuropsychological findings}

Because most neuropsychological and neurocognitive models of ADHD are based upon neuropsychological findings in ADHD (in children and adults), in the following section an evaluation is given of neuropsychological studies and the current position of neuropsychological assessment in the diagnostic process of ADHD. It is important to bear in mind that the cognitive profile of adult ADHD remains understudied, possibly because of difficulty in its diagnosis (Schweiger, Abramovitch, Doniger, \& Simon, 2007). Also, no neuropsychological test battery has been shown to be valid in adult ADHD. On the other hand, it has been suggested that adults with ADHD have a particular profile of neuropsychological functioning (Gallagher \& Blader, 2001), and the use of neuropsychological assessment in adult ADHD is supported by various authors, including Woods, Lovejoy, and Ball (2002) and Kaplan and Stevens (Kaplan \& Stevens, 2002; Woods, Lovejoy, \& Ball, 2002). Here, we will point out some important findings per cognitive domain.

Intelligence: Because adults with ADHD often report that they are not able to finish their education and obtain a diploma or degree, and because certain aspects of intelligence tests rely upon attention and executive functioning (e.g., fluency or digit span), it has been assumed that individuals with ADHD will perform poorly on general tests of intelligence. However, general measures of intelligence do not discriminate between adults with ADHD, adults without ADHD, 
and clinical controls (Seidman, Biederman, Weber, Hatch, \& Faraone, 1998). There are studies, however, that show the expected significant differences between adults with ADHD and controls on some subtests that rely upon attention and executive functions, like the Digit Span (Walker, Shores, Trollor, Lee, \& Sachdev, 2000).

Speed of information processing, attention, and inhibition: Performance on simple motor reaction time tasks are mostly unimpaired in ADHD (Tannock, 2003). On more complex standard attention, and speed of information processing tasks (like the Stroop Colour Word Test), inconsistent patterns have been found. However, a recent study showed that interference control is consistently compromised in individuals with ADHD (Lansbergen \& Kenemans, 2008). In the meta-analytic study of Hervey, Epstein, and Curry (2004), measures of attention discriminated between adults with ADHD and controls (Hervey, Epstein, \& Curry, 2004). Problems with inhibitory control have been demonstrated on the Stop Signal Task (Wodushek \& Neumann, 2003). Adults with ADHD needed more time to stop an activity or a planned course of action than those without ADHD. This problem with inhibitory control explained a greater part of the variance of ADHD symptomatology than other cognitive variables (attention or executive functions). On other non-inhibition-related executive measures, like verbal fluency, differences have been shown between ADHD subjects and controls (Marchetta, Hurks, Krabbendam, \& Jolles, 2008). Strikingly, adults with ADHD did not differ from controls on the Wisconsin Card Sorting Test, a measure of set-shifting (Hervey, Epstein, \& Curry, 2004). Furthermore, studies in the field of executive functioning in adult ADHD are, unfortunately, still inconsistent (Barkley, 1997; Johnson et al., 2001; Kalff et al., 2003; Murphy, Barkley, \& Bush, 2002; Pennington \& Ozonoff, 1996; Rapport, Van Voorhis, Tzelepis, \& Friedman, 2001; Seidman, Biederman, Faraone, Weber, \& Ouellette, 1997; Sergeant, Geurts, \& Oosterlaan, 2002; Tannock, 1998). Also, in a meta-analytic review, it was shown that neuropsychological problems in ADHD are not limited to executive problems (Boonstra, Oosterlaan, Sergeant, \& Buitelaar, 2005).

Memory: Impairments on memory tests were also found in adults with ADHD. However, results vary according to the tests used. Working memory performance is important to maintain adequate functioning in cognitive, academic, and social activities. Research suggests that there are prevalent working memory deficits in adults with ADHD (Hervey, Epstein, \& Curry, 2004; Schoechlin \& Engel, 2005). On the Verbal Learning Test (VLT), impairments are found in encoding, retrieval, and recognition and organization of words by means of semantic clustering (Hervey, Epstein, \& Curry, 2004; Marchetta et al., Submitted). 
The review of Woods, Lovejoy, and Ball (2002) indicates that there are subtle impairments on attention and executive measures, VLT (auditive form), and speed of complex information processing in adults with ADHD compared to healthy controls (Woods, Lovejoy, \& Ball, 2002). Schoechlin and Engel (2005) confirmed these findings when they found significantly compromised performance on eight out of ten neuropsychological tests in adults with ADHD compared with controls. Small effects were found for visual information processing and, remarkably, executive functioning. Large effects were found for verbal memory, selective and sustained attention, and verbal abstract reasoning (including working memory) (Schoechlin \& Engel, 2005). Wilcutt et al. (2005) concluded that difficulties with executive dysfunction are one important component of the complex neuropsychology of ADHD (Willcutt, Doyle, Nigg, Faraone, \& Pennington, 2005).

Neuropsychological findings in adult ADHD are somewhat inconsistent but, in general, there is evidence of executive problems in ADHD (especially inhibition). Moreover, neuropsychological problems are not limited to executive problems. Verbal memory deficits are also found in adult ADHD (Marchetta et al., submitted).

The studies in this area have several limitations. They are not always easy to compare as exclusion criteria, for example, are sometimes dissimilar. Furthermore, in individual studies, the diagnosis of ADHD is made on the basis of different sources (e.g., using rating scales or in a multidisciplinary team), and often no difference is made between the ADHD subtypes (Schweitzer, Hanford, \& Medoff, 2006). The subtypes (combined, predominantly inattentive, and predominantly hyperactive-impulsive, respectively) may constitute a different type of attention disorder (Schweitzer, Hanford, \& Medoff, 2006). Until now, few studies have investigated neuropsychological performance across ADHD subtypes. Moreover, comorbidity is not always considered. Recently, it was suggested that having ADHD and at least one other comorbid disorder might be synergistic (i.e., greater than the sum of impairments of the disorders alone) (Marchetta, Hurks, De Sonneville, Krabbendam, \& Jolles, Submitted). In these studies too, different cognitive variables and control groups (healthy versus clinical) were used.

To summarize, in traditional neuropsychological studies of adults with ADHD, subtle impairments are found on tests of verbal memory and executive functioning. Castellanos' model (2005) suggests the possibility of different neuropsychological subtypes of ADHD (Castellanos et al., 2005). On the basis of neuropsychological assessment alone, the diagnosis of ADHD cannot be made. It can, however, reveal certain strengths and weaknesses, which gives us a better understanding of the cognitive functioning of the individual and a new starting point and guidelines for treatment. 


\section{Neuropsychological and cognitive models}

Based on the notion that ADHD has a biological core, and in an attempt to gain more insight into ADHD, several neuropsychological and cognitive models have been developed and used in the past decade. Despite the fact that the term "ADHD" suggests that it is primarily an attention problem, inconsistent performance on widely used neuropsychological tests has been observed, as mentioned earlier. The question then arises whether ADHD is a neuropsychological problem. Interestingly, a number of theoretical models have been proposed to explain the condition. Some of the successive models may be able to contribute to a better understanding of ADHD and are presented here.

\section{Attentional network model}

According to Swanson (1998), ADHD is a problem in attention functioning (Swanson et al., 1998). His model is based on findings of Posner and Peterson (1990). These authors differentiate three distinct neural network systems that are related to different attention functions and that are thought to be defective in ADHD. The three attention processes they distinguish are "alerting", "orienting", and "executive control". Alerting is assumed to involve the suppression of background information in order to sustain attention ("sustained attention"). Orienting is related to selective inhibition, like set shifting, and executive control is related to divided attention (Posner \& Petersen, 1990). An advantage of this model is that it tries to link certain clusters of symptoms to specific areas of the brain. Problems sustaining attention and problems finishing or avoiding certain tasks are associated with alerting and are related to right frontal lobe functioning. Being distracted easily and absentmindedness are associated with orienting and are thought to be related to posterior parietal functioning. Hyperactivity and impulsivity are associated with executive control, which is related to the anterior cingulate cortex. A person with ADHD can have problems in one, two, or all three domains. This could explain the heterogeneity of the presentation of ADHD in adults and the inconsistent findings on neuropsychological tasks (Tannock, 2003).

\section{Inhibition model}

There are several models that consider ADHD to be a primary deficit in inhibitory control, which is an aspect of executive dysfunction. This deficit is thought to be independent of age. Quay (1997) used Gray's (1982) model on the neuropsychology of fear and discerned three brain systems: a reward system (behavioural activation system, BAS), a punishment system (behavioural inhibition system, BIS), and a "fight or flight" system. The BAS is activated by conditioned stimuli that 
lead to a reward (e.g., the smell of apple pie) and, consequently, to approach of the object in question. The BIS is activated when punishment is expected or when reward is delayed (e.g., the teacher who gives a warning). When the BIS is activated, behaviour is inhibited. As a result, avoidance behaviour develops. The $\mathrm{BIS}$ and the BAS are thought to be mediated by dopaminergic and noradrenergic systems. These are the systems involved in ADHD (Tannock, 2003). According to Quay (1997), impulsivity in ADHD arises as a consequence of underactivation of the BIS. This means that it is difficult for a person with ADHD to inhibit his/her behaviour after receiving a warning signal but that it is also difficult for a person to extinguish certain behaviours following a reward (Gray, 1982). This has been confirmed by studies in children (laboni, Douglas, \& Ditto, 1997).

Barkley (1997) agrees that ADHD is primarily a deficit in inhibitory control. He relates this inhibitory deficit to prefrontal lobe functioning or to a delay in brain development, as suggested by other authors (Shaw et al., 2007). According to him, inhibition is a multidimensional construct that consists of several components. Barkley distinguishes three related cognitive processes, namely: (1) inhibition of a "prepotent" response (a response that was rewarded earlier); (2) inhibition of an ongoing response; and (3) interference control, or the possibility to suppress irrelevant information.

ADHD is characterized by problems in all three processes. The primary deficit in inhibition can secondarily lead to executive problems, such as non-verbal working memory, verbal working memory (e.g., keeping goals in mind), self-regulation of affect-motivation and arousal (e.g., overreacting or not reacting objectively) and, finally, the possibility to reconstitute information ('reconstitution'), which is involved in problem-solving (Barkley, 1997; Barkley, Edwards, Laneri, Fletcher, \& Metevia, 2001). Therefore, the deficit in inhibition would be responsible for problems in goal-directed behaviour and self-monitoring/self-regulation. In clinical practice, this means that a person with ADHD is not able to inhibit his/ her behaviour, to keep information in working memory, to think of the consequences of his/her behaviour, or to set achievable goals or adjust these goals in light of new information ('monitoring'). Thus, problems inhibiting behaviour can have serious consequences for daily life functioning. This model is only applicable to the combined subtype of ADHD (i.e., that with inattention and hyperactivity-impulsivity), but not to the inattentive subtype. The latter is assumed to reflect a problem in the speed of information processing (Barkley, 1997).

\section{Cognitive-energetic model}

Sanders (1983) distinguished three levels of information processing. Sergeant, 
Oosterlaan, and van der Meere (1999) elaborated on this model and came up with a cognitive-energetic model of ADHD that states that the efficiency of information processing is determined by cognitive processes (e.g., encoding of stimuli and searching through memory), energetic processes, and executive functioning (Sergeant, Oosterlaan, \& van der Meere, 1999).

On the first level one has cognitive processes that are involved in the process of stimulus recognition and stimulus response. At the second level, energetic processes are defined, namely, "effort", "arousal", and "activation". Executive functions are situated on the third level. "Effort" depends on the difficulty of the task and is associated with the hippocampus, which regulates the balance between the "arousal" and "activating" systems. Noradrenalin and serotonin are the main neurotransmitters of the arousal system; dopamine and acetylcholine are involved in the activation-system (Tucker \& Williamson, 1984). Arousal is defined as a phasic reaction that is concerned with sensory activity. It is timelimited and related to the processing of certain stimuli. Arousal is associated with noradrenergic neural network systems. By activation, activation of the dopaminergic system is meant. This system is especially involved in premotor response or the preparation of a response.

The cognitive-energetic model of Sergeant, Oosterlaan, and van der Meere explains the symptoms of ADHD, particularly in terms of energetic problems (Sergeant, Oosterlaan, \& van der Meere, 1999). Disinhibition is a secondary problem that is also caused by inadequate activation of the inhibitory system (Sergeant, 2000). Both top-down and bottom-up processes are possible in this model. The model assumes that, in ADHD, disturbances in all three processes are present.

Evidence for this model comes from research in children with ADHD, who show increased motor activity, also during their sleep (Konofal, Lecendreux, Bouvard, \& Mouren-Simeoni, 2001). Borger and van der Meere (Borger \& van der Meere, 2000) showed that children with ADHD are slower in their reactions to "Go" signals than controls. This suggests less motor activation (Sergeant, 2005).

\section{Delay-aversion model}

The delay-aversion model considers the idea of a motivational problem instead of a cognitive problem in ADHD (Sonuga-Barke, Taylor, Sembi, \& Smith, 1992). Yet, motivational aspects can have a significant effect on cognition. According to the delay-aversion model, individuals with ADHD have trouble waiting and, therefore, are not able to stop their reaction. The difference with earlier mentioned models is that the delay-aversion model is based on observations of situations in which the symptoms of ADHD are demonstrated sooner (Sonuga-Barke, Taylor, 
\& Heptinstall, 1992). In some situations, children are able to wait, even when inhibition of a response is required. In other situations, ADHD children cannot wait and choose the quicker, but smaller, reward. They choose to reduce the waiting (delay) instead of increasing the reward (Sonuga-Barke, Taylor, Sembi, \& Smith, 1992). This model explains some symptoms of the clinical picture of ADHD (e.g., having difficulty waiting one's turn or interrupting others during conversation). In particular, it explains the impulsive symptoms seen in ADHD, especially in the hyperactive-impulsive subtype. However, it cannot account for all of the symptoms of ADHD, and little research on delay-aversion has focused on adults with ADHD.

There is much data to support the abovementioned cognitive models of ADHD (Barkley, 1997; Quay, 1997; Sergeant, Geurts, Huijbregts, Scheres \& Oosterlaan, 2003). Each of these models has increased our understanding of ADHD and encouraged new research. These models are based mostly on research findings in children with ADHD. The question that arises is whether these models can be generalized to adults with ADHD. Also, the models mentioned emphasize only one single cause. The group of adults with ADHD is very heterogeneous; it is unlikely that a single cause can explain ADHD to its full extent. A number of multidimensional models are, therefore, proposed.

\section{Multidimensional models of ADHD}

Sonuga-Barke (2005) and Castellanos et al. (2006) proposed a dual pathway hypothesis of the psychopathophysiology of ADHD. They suggest that both the executive ('cognitive') circuit (modulated by cortical dopamine) and the reward ('motivational') circuit (modulated by mesolimbic dopamine) contribute to the expression of ADHD, leading to executive deficits and delay-aversion. This means that both executive dysfunction/inhibitory deficits and delay-aversion can account for symptoms of ADHD. However, in this model, executive dysfunction, for example, is neither a necessary, nor a sufficient condition for the expression of the disorder (Castellanos, Sonuga-Barke, Milham \& Tannock, 2006; SonugaBarke, 2005). This is important for the clinician and for the researcher since this model could explain the neuropsychological heterogeneity and the possibility of different neuropsychological subtypes of ADHD (Castellanos et al., 2005). In addition, recent findings support the notion that executive deficits and delay-aversion are two possible pathways to ADHD (Thorell, 2007).

Nigg (2005) proposed a different multiple pathway model, in which operations of both frontostriatal and frontocerebellar neural networks are empha- 
sized in detecting and predicting "what" and "when" events in the environment. These can both be compromised in ADHD. Furthermore, the model emphasizes the interaction with fronto-amygdala networks, which assign emotional meaning to events. Problems in the three abovementioned networks could lead to less cognitive and affective control which, in turn, could lead to the cognitive problems, behavioural problems (such as impulsive behaviour), and comorbid problems (e.g., antisocial behaviour) observed in ADHD (Nigg \& Casey, 2005). In sum, they state that prefrontal projections are a critical aspect of the basic elements of cognitive and affective control that are involved in ADHD (Nigg \& Casey, 2005).

Another multicausal developmental model was proposed by Castellanos and Tannock (2002). In this model, candidate endophenotypes for ADHD are deficits in reward-related circuitry (shortened delay gradient), temporal processing, and working memory. These endophenotypes are based on neuroscience (Castellanos \& Tannock, 2002; Tannock, 2003).

For clinical neuropsychology, it is important to use the theoretical knowledge mentioned above in describing different aspects/subtypes of ADHD. The neuropsychologist can use multi-causal models to describe or explain the clinical picture or behaviour of a person with ADHD. It is necessary to know how this theoretical knowledge about ADHD can be used in clinical practice. In the next section, two case descriptions are presented as illustrations of the contribution that can be made by the clinical neuropsychologist.

\section{Case descriptions}

Case 1. Based on the 'Cognitive-energetic model' (Sergeant, Oosterlaan \& van der Meere, 1999)':

A 32-year-old single woman is sent to the Memory Clinic of the University Hospital Maastricht complaining of memory problems and burnout. Further investigation reveals that the woman often 'dreams' during meetings. She has trouble reading and mentions having to read one and the same page over and over. This leads to problems with time management in her work as an ICT employee. A clear deadline has to be set for her to finish certain tasks since she has problems focusing on a certain goal. Dual tasking, e.g., cooking and talking, is very stressful. She needs more time than others to complete tasks and is easily fatigued. She also has a low level of self-esteem because she has not been able to keep a job or maintain a relationship. She remembers having the same cognitive problems in her childhood. 
The woman's psychiatric history reports mood swings and burnout. Neuropsychological examination reveals speed variability and variability in reaction time on a sustained attention task. Her intelligence level is within the normal range. Other cognitive functions (e.g., memory and executive functions) seem intact. One observes that she is easily distracted (seems 'absent') and has trouble focusing. A semi-structured interview and specific questionnaires in the areas of inattention, hyperactivity, and impulsivity reveal a pattern of chronic cognitive complaints that is also mentioned by parents.

In this case, after careful investigation, the diagnosis of ADHD, predominantly inattentive subtype, is given. In the clinic, this is often were the diagnostic assessment stops and for instance pharmacological treatment is advised. In addition, however, from the cognitive-energetic point of view, many of the woman's symptoms can be explained. Not only cognitive factors, but also motivational factors seem to play an important role. At times, she is able to put concentrated mental effort into her actions while at other times she is unable to do so. Under high levels of stress (e.g., when a deadline approaches), she is able to perform well while in other situations she is not. This inconsistent performance and variability is also found on neuropsychological examination. Using the cognitive-energetic model, one might argue that the woman has energetic problems (arousal, activation, and effort) that secondarily lead to cognitive problems (sustaining attention or interference control). A lack of effort plays an important role in the complaints since she is able to finish her work under high levels of stress. As we have seen before, effort is strongly related to task difficulty.

On the basis of the neuropsychological examination, psycho-education was indicated in this patient's case. It was very helpful in explaining to the woman the inconsistent pattern of symptoms in her daily life functioning. It also helped her to define more efficient coping styles and strategies. An explanation of the underlying mechanism also appeared to be of value as it counteracted the low self-esteem and the negative schemas that she had (e.g., "I am lazy", "This is how I am, it is my character"). Psycho-education was also indicated for the woman's family and friends since the inconsistencies in her symptoms appeared to be difficult for them to understand and led to problems in her/their social relationships.

Case 2. Based on the 'Multiple pathway model (Nigg \& Casey, 2005)':

A 21-year-old man is sent to the ADHD outpatient clinic because of aggressiveness, impulsivity, and cognitive complaints. During the first two visits, he admits that he has had a drinking problem for the last two years and that he has a prob- 
lem stopping himself once he starts drinking ('I have no brake'). Moreover, he and his girlfriend broke up two months ago because of aggressive behaviour on his part. The man has been working as a painter for four years. Before, he worked at a car factory and as a car mechanic (without a license). He never finished high school. Because of fights with teachers, he left school early. When he was 18-19 years old, the man was involved in criminal activities, including burglary. Because of this, he spent six months in jail. He does not show any remorse for his actions. He is also known to the court authorities for reckless driving and driving under influence. His history includes experiments with several kinds of drugs, including XTC and cocaine. His major problems are impulsivity, aggressiveness, and restlessness. A thorough examination reveals that the man's disruptive behaviour was already present in his early childhood (when he was 5 years old). His older sister recalls that, as a child, he was always playing outside, looking for trouble and being involved in risky business. He always got himself into trouble and he did not listen to his parents (who became divorced when he was 7 years old). At school, he was always playing and displayed intense motor activity. He could not concentrate and had trouble reading and paying attention to his teacher. He was the "clown of the class" and always tried to keep the other children from doing their work.

Neuropsychological examination revealed primarily executive problems (problems with set shifting, heightened distractibility, a high number of errors on a sustained attention task, and a high number of errors on the stop signal task). The multiple pathway model of Nigg and Casey (2005) points to the man's impulsive and dysregulated behaviour as being the possible result of an impairment in prefrontal functioning. His aggressiveness (which is likely the result of an under-reactive amygdala-frontal circuit) leads to poor socialization of empathy and social rules and this, in turn, leads to antisocial behaviour. The antisocial behaviour is primary but, in this case, ADHD can be expected to be an underlying cause. ADHD is also a known risk factor in the development of substance abuse disorder (Wilens \& Biederman, 2006). The impulsive and dysregulated behaviour is probably responsible for this. Given what we know about the role of the prefrontal cortex (i.e., that a maturational lag in prefrontal areas underlies behavioural problems), this notion is consistent with the idea that drug use in adults with ADHD can be seen as a form of self-medication. In this case, our patient might have used drugs in order to help control his own impulses (Wilens, 2004).

In conclusion, in case 1 neuropsychological testing showed speed variability and variability in reaction time, which corresponded with the variable pattern of complaints and daily functioning. This information, together with the theoretical 
information from the cognitive-energetic model, can be used as a starting point for treatment (psycho-education and cognitive therapy). Until now, this information is often not considered at the start of a treatment program. In case 2, neuropsychological outcome (executive dysfunction), together with information from the multiple pathway model can give an explanation for the impulsive and aggressive behaviour observed. In this case, the diagnosis antisocial personality is correct, but insufficient to fully understand the clinical picture. Neuropsychological insights are essential in understanding the complete clinical picture.

\section{Discussion}

ADHD is a complex, multi-determined, neurodevelopmental disorder that can affect an individual from childhood into adulthood. ADHD has to be diagnosed within the context of biological, psychological, and social factors, all of which contribute to the symptoms of the disorder. In most common neuropsychological studies in adults with ADHD, subtle impairments are found on tests of verbal memory and executive functioning. There is neuropsychological heterogeneity among individuals with ADHD, and this heterogeneity can be explained by multi-causal models of ADHD. These models take into account biological, cognitive, and motivational factors as contributors to the symptoms of ADHD. Knowledge about neurobiological and neuropsychological factors and models is clearly important in understanding the clinical picture of ADHD, and this suggests a significant role for the clinical neuropsychologist. For example, because cognitive and energetic mechanisms appear to be involved within the heterogenic group of ADHD, certain subtypes can be distinguished. This knowledge is important for the clinical neuropsychologist since energetic problems can influence cognitive performance. The neuropsychologist has to take this into consideration during the neuropsychological examination (e.g., by dividing test sessions).

In addition, neuropsychological investigation is useful because it provides information about the cognitive and behavioural strengths and weaknesses of individuals. In this respect, it is essential for neuropsychologists to use theoretical knowledge to describe different aspects/subtypes of ADHD. The neuropsychologist can use multi-causal models to describe or explain the clinical picture or behaviour of a person with ADHD, this in addition to the traditional "psychiatric" point of view. An important aspect of the neuropsychological examination in ADHD is observing the patient. The clinical neuropsychologist is able to describe behaviour based upon biological and theoretical models. He/she is often the only professional who sees the person 'at work', when he is cog- 
nitively challenged. This yields a great deal of extra information, much more than (hetero)anamnestic information alone. With the abovementioned models in mind, the clinical neuropsychologist is able to explain clinical symptoms of ADHD and the heterogeneity among patients (e.g., the influence of energetic factors on cognitive test performance). Not only are neuropsychological test results important, but insight into cognitive processes (e.g., how to solve problems) is also very informative. Moreover, it is important to determine the cognitive capacities, or intelligence level, of the patient. Neuropsychological testing is also valuable in predicting cognitive problems in daily life and factors that influence cognitive problems, like mood and energetic problems, as well as in giving advice on how to deal with these problems adequately. Additionally, neuropsychological investigation creates a new starting point for treatment and evaluation. It is valuable to use neuropsychological tools to evaluate treatment. Furthermore, if more insight were to be gained into the neuropsychological evaluation of interventions, it might be possible in the future to predict which treatment is the best option for a given patient, taking his/her neuropsychological profile into account. Psycho-education and strategy training seem to be important aspects in the treatment of ADHD, although more research on cognitive interventions (in different subgroups) is needed. Finally, because of the complexity (heterogeneity, comorbidity, and multi-causality) of ADHD, the clinician has to focus more on individual differences and or severity of symptoms. In the DSM-IV-TR (2000), individual differences and variability across age groups in ADHD are not incorporated (APA, 2000). Furthermore, the DSM-IV-TR does not sufficiently address the multi-causality seen in ADHD. The specificity of certain symptoms per age group and the detection of a so-called "symptom threshold level" for adults with ADHD is essential. A thorough, multidimensional examination, including cognitive and behavioural functioning in adulthood and childhood, is essential in describing specific phenotypes of ADHD. In this paper, we suggest an important role for the clinical neuropsychologist in the diagnosis and treatment of ADHD in adults. 


\section{References}

APA. (2000). Diagnostic and Statistical Manual of Mental Disorders (4th Edition-Text Revision). Washington D.C.: American Psychiatric Association.

Banerjee, T. D., Middleton, F., \& Faraone, S. V. (2007). Environmental risk factors for attention-deficit hyperactivity disorder. Acta Paediatrica, 96(9), 1269-1274.

Barkley, R. A. (1997). Behavioral inhibition, sustained attention, and executive functions: constructing a unifying theory of ADHD. Psychological Bulletin, 121(1), 65-94.

Barkley, R. A. (1998). Attention Deficit Hyperactivity Disorder- A handbook for Diagnosis and Treatment. New York: The Guilford Press.

Barkley, R. A. (2002). Major life activity and health outcomes associated with attentiondeficit/hyperactivity disorder. Journal of Clinical Psychiatry, 63 Suppl 12, 10-15.

Barkley, R. A., Edwards, G., Laneri, M., Fletcher, K., \& Metevia, L. (2001). Executive functioning, temporal discounting, and sense of time in adolescents with attention deficit hyperactivity disorder (ADHD) and oppositional defiant disorder (ODD). Journal of Abnormal Child Psychology, 29(6), 541-556.

Barkley, R. A., Fischer, M., Smallish, L., \& Fletcher, K. (2002). The persistence of attentiondeficit/hyperactivity disorder into young adulthood as a function of reporting source and definition of disorder. Journal of Abnormal Psychology, 111(2), 279-289.

Biederman, J. (1998). Attention-deficit/hyperactivity disorder: a life-span perspective. Journal of Clinical Psychiatry, 59 Suppl 7, 4-16.

Biederman, J. (2005). Attention-deficit/hyperactivity disorder: a selective overview. Biological Psychiatry, 57(11), 1215-1220.

Biederman, J., Faraone, S. V., \& Monuteaux, M. C. (2002). Differential effect of environmental adversity by gender: Rutter's index of adversity in a group of boys and girls with and without ADHD. American Journal of Psychiatry, 159(9), 1556-1562.

Biederman, J., Faraone, S. V., Spencer, T., Wilens, T., Norman, D., Lapey, K. A., et al. (1993). Patterns of psychiatric comorbidity, cognition, and psychosocial functioning in adults with attention deficit hyperactivity disorder. American Journal of Psychiatry, 150(12), 1792-1798.

Biederman, J., Milberger, S., Faraone, S. V., Kiely, K., Guite, J., Mick, E., et al. (1995). Familyenvironment risk factors for attention-deficit hyperactivity disorder. A test of Rutter's indicators of adversity. Archives of General Psychiatry, 52(6), 464-470.

Boonstra, A. M., Oosterlaan, J., Sergeant, J. A., \& Buitelaar, J. K. (2005). Executive functioning in adult ADHD: a meta-analytic review. Psychological Medicine, 35(8), 1097-1108.

Borger, N., \& van der Meere, J. (2000). Motor control and state regulation in children with ADHD: a cardiac response study. Biological Psychology, 51(2-3), 247-267.

Castellanos, F. X. (2001). Neural substrates of attention-deficit hyperactivity disorder. Advances in Neurology, 85, 197-206.

Castellanos, F. X., Sonuga-Barke, E. J., Milham, M. P., \& Tannock, R. (2006). Characterizing cognition in ADHD: beyond executive dysfunction. Trends in Cognitive Sciences, 10(3), $117-123$.

Castellanos, F. X., Sonuga-Barke, E. J., Scheres, A., Di Martino, A., Hyde, C., \& Walters, J. R. 
(2005). Varieties of attention-deficit/hyperactivity disorder-related intra-individual variability. Biological Psychiatry, 57(11), 1416-1423.

Castellanos, F. X., \& Tannock, R. (2002). Neuroscience of attention-deficit/hyperactivity disorder: the search for endophenotypes. Nature Reviews Neuroscience, 3(8), 617-628.

Faraone, S. V. (2004). Genetics of adult attention-deficit/hyperactivity disorder. Psychiatric Clincis of North America, 27(2), 303-321.

Faraone, S. V., \& Biederman, J. (2005). What is the prevalence of adult ADHD? Results of a population screen of 966 adults. Journal of Attention Disorders, 9(2), 384-391.

Faraone, S. V., Biederman, J., Spencer, T., Wilens, T., Seidman, L. J., Mick, E., et al. (2000). Attention-deficit/hyperactivity disorder in adults: an overview. Biological Psychiatry, 48(1), 9-20.

Gallagher, R., \& Blader, J. (2001). The diagnosis and neuropsychological assessment of adult attention deficit/hyperactivity disorder. Scientific study and practical guidelines. Annals of the New York Academy of Sciences, 931, 148-171.

Gray, J. A. (1982). Precis of the neuropsychology of anxiety: an inquiry into the functions of the septo-hippocampal system. Behavioural Brain Research, 5, 469-534.

Hervey, A. S., Epstein, J. N., \& Curry, J. F. (2004). Neuropsychology of adults with attentiondeficit/hyperactivity disorder: a meta-analytic review. Neuropsychology, 18(3), 485-503.

Hurks, P. P., Adam, J. J., Hendriksen, J. G., Vles, J. S., Feron, F. J., Kalff, A. C., et al. (2005). Controlled visuomotor preparation deficits in attention-deficit/hyperactivity disorder. Neuropsychology, 19(1), 66-76.

Iaboni, F., Douglas, V. I., \& Ditto, B. (1997). Psychophysiological response of ADHD children to reward and extinction. Psychophysiology, 34(1), 116-123.

Johnson, D. E., Epstein, J. N., Waid, L. R., Latham, P. K., Voronin, K. E., \& Anton, R. F. (2001). Neuropsychological performance deficits in adults with attention deficit/hyperactivity disorder. Archives of Clinical Neuropsychology, 16(6), 587-604.

Kalff, A. C., de Sonneville, L. M., Hurks, P. P., Hendriksen, J. G., Kroes, M., Feron, F. J., et al. (2003). Low- and high-level controlled processing in executive motor control tasks in 5-6-year-old children at risk of ADHD. Journal of Child Psychology and Psychiatry, 44(7), 1049-1057.

Kalff, A. C., Sonneville, L.M.J. de, Hurks, P.P.M., Hendriksen, J.G.M., Kroes, M., Feron, F.J.M., Steyaert, J., Zeben, T.M.C.B. van, Vles, J.S.H., and Jolles, J. (2005). Speed, speed variability, and accuracy of information processing in 5/6-year-old children at risk of ADHD. Journal of International Neuropsychological Society, 11, 173-183.

Kaplan, R. F., \& Stevens, M. (2002). A review of adult ADHD: a neuropsychological and neuroimaging perspective. CNS Spectrums, $7(5), 355-362$.

Konofal, E., Lecendreux, M., Bouvard, M. P., \& Mouren-Simeoni, M. C. (2001). High levels of nocturnal activity in children with attention-deficit hyperactivity disorder: a video analysis. Psychatry and Clinical Neuroscience, 55(2), 97-103.

Kooij, J. J., Buitelaar, J. K., van den Oord, E. J., Furer, J. W., Rijnders, C. A., \& Hodiamont, P. P. (2005). Internal and external validity of attention-deficit hyperactivity disorder in a population-based sample of adults. Psychological Medicine, 35(6), 817-827.

Lansbergen, M. M., \& Kenemans, J. L. (2008). Stroop interference and the timing of selec- 
tive response activation. Clinical Neurophysiology 119(10), 2247-2254.

Levin, P. M. (1938). Restlessness in children. Archives of Neurology and Psychiatry, 39, 764770.

Madras, B. K., Miller, G. M., \& Fischman, A. J. (2002). The dopamine transporter: relevance to attention deficit hyperactivity disorder (ADHD). Behavioural Brain Research, 130(1-2), 57-63.

Mannuzza, S., Klein, R. G., Bessler, A., Malloy, P., \& LaPadula, M. (1998). Adult psychiatric status of hyperactive boys grown up. American Journal of Psychiatry, 155(4), 493-498.

Marchetta, N. D., Hurks, P. M., Meijs, C. J. C., Scholtissen-In de Braek, D. M. J. M., Rozendaal, N., \& Jolles, J. Submitted. Verbal learning and organisational strategies in adults with ADHD: ADHD subtypes and the impact of comorbidity.

Marchetta, N. D., Hurks, P. P., De Sonneville, L. M., Krabbendam, L., \& Jolles, J. Submitted. Sustained and Focused Attention Deficits in Adult ADHD.

Marchetta, N. D., Hurks, P. P., Krabbendam, L., \& Jolles, J. (2008). Interference control, working memory, concept shifting, and verbal fluency in adults with attention-deficit/ hyperactivity disorder (ADHD). Neuropsychology, 22(1), 74-84.

Murphy, K. R., Barkley, R. A., \& Bush, T. (2002). Young adults with attention deficit hyperactivity disorder: subtype differences in comorbidity, educational, and clinical history. Journal of Nervous Mental Disorders, 190(3), 147-157.

Nigg, J. T., \& Casey, B. J. (2005). An integrative theory of attention-deficit/ hyperactivity disorder based on the cognitive and affective neurosciences. Development and Psychopathology, 17(3), 785-806.

Pennington, B. F., \& Ozonoff, S. (1996). Executive functions and developmental psychopathology. Journal of Child Psychology and Psychiatry, 37(1), 51-87.

Posner, M. I., \& Petersen, S. E. (1990). The attention system of the human brain. Annual Reviews of Neuroscience, 13, 25-42.

Quay, H. C. (1997). Inhibition and attention deficit hyperactivity disorder. Child Psychology, 25(1), 7-13.

Rapport, L. J., Van Voorhis, A., Tzelepis, A., \& Friedman, S. R. (2001). Executive functioning in adult attention-deficit hyperactivity disorder. Clinical Neuropsychology, 15(4), 479-491.

Roy-Byrne, P., Scheele, L., Brinkley, J., Ward, N., Wiatrak, C., Russo, J., et al. (1997). Adult attention-deficit hyperactivity disorder: assessment guidelines based on clinical presentation to a specialty clinic. Comprehensive Psychiatry, 38(3), 133-140.

Rubia, K., Overmeyer, S., Taylor, E., Brammer, M., Williams, S. C., Simmons, A., et al. (1999). Hypofrontality in attention deficit hyperactivity disorder during higher-order motor control: a study with functional MRI. American Journal of Psychiatry, 156(6), 891-896.

Sagvolden, T., Johansen, E. B., Aase, H., \& Russell, V. A. (2005). A dynamic developmental theory of attention-deficit/hyperactivity disorder (ADHD) predominantly hyperactive/ impulsive and combined subtypes. Behavioural and Brain Sciences, 28(3), 397-419; discussion 419-368.

Schoechlin, C., \& Engel, R. R. (2005). Neuropsychological performance in adult attentiondeficit hyperactivity disorder: meta-analysis of empirical data. Archives of Clinical Neuropsychology, 20(6), 727-744. 
Schweiger, A., Abramovitch, A., Doniger, G. M., \& Simon, E. S. (2007). A clinical construct validity study of a novel computerized battery for the diagnosis of ADHD in young adults. Journal of Clinical and Experimental Neuropsychology, 29(1), 100-111.

Schweitzer, J. B., Hanford, R. B., \& Medoff, D. R. (2006). Working memory deficits in adults with ADHD: is there evidence for subtype differences? Behavioural and Brain Functions, $2,43$.

Seidman, L. J., Biederman, J., Faraone, S. V., Weber, W., \& Ouellette, C. (1997). Toward defining a neuropsychology of attention deficit-hyperactivity disorder: performance of children and adolescents from a large clinically referred sample. Journal of Consulting and Clinical Psychology, 65(1), 150-160.

Seidman, L. J., Biederman, J., Weber, W., Hatch, M., \& Faraone, S. V. (1998). Neuropsychological function in adults with attention-deficit hyperactivity disorder. Biological Psychiatry, 44(4), 260-268.

Seidman, L. J., Doyle, A., Fried, R., Valera, E., Crum, K., \& Matthews, L. (2004). Neuropsychological function in adults with attention-deficit/hyperactivity disorder. Psychiatric Clinics of North America, 27(2), 261-282.

Seidman, L. J., Valera, E. M., \& Makris, N. (2005). Structural brain imaging of attention-deficit/hyperactivity disorder. Biological Psychiatry, 57(11), 1263-1272.

Sergeant, J. (2000). The cognitive-energetic model: an empirical approach to attentiondeficit hyperactivity disorder. Neuroscience and Biobehavioral Reviews, 24(1), 7-12.

Sergeant, J. A. (2005). Modeling attention-deficit/hyperactivity disorder: a critical appraisal of the cognitive-energetic model. Biological Psychiatry, 57(11), 1248-1255.

Sergeant, J. A., Geurts, H., Huijbregts, S., Scheres, A., \& Oosterlaan, J. (2003). The top and the bottom of ADHD: a neuropsychological perspective. Neuroscience and Biobehavioral Reviews, 27(7), 583-592.

Sergeant, J. A., Geurts, H., \& Oosterlaan, J. (2002). How specific is a deficit of executive functioning for attention-deficit/hyperactivity disorder? Behavioural Brain Research, 130(1-2), 3-28.

Sergeant, J. J., Oosterlaan, J. \& van der Meere, J.J. (1999). Handbook of disruptive behaviour. New York: Cambridge University Press.

Shaw, P., Eckstrand, K., Sharp, W., Blumenthal, J., Lerch, J. P., Greenstein, D., et al. (2007). Attention-deficit/hyperactivity disorder is characterized by a delay in cortical maturation. The Proceedings of the National Academy of Sciences USA, 104(49), 19649-19654.

Sonuga-Barke, E. J. (2005). Causal models of attention-deficit/hyperactivity disorder: from common simple deficits to multiple developmental pathways. Biological Psychiatry, 57(11), 1231-1238.

Sonuga-Barke, E. J., Taylor, E., \& Heptinstall, E. (1992). Hyperactivity and delay aversion--II. The effect of self versus externally imposed stimulus presentation periods on memory. Journal of Child Psychology and Psychiatry, 33(2), 399-409.

Sonuga-Barke, E. J., Taylor, E., Sembi, S., \& Smith, J. (1992). Hyperactivity and delay aversion--I. The effect of delay on choice. Journal of Child Psychology and Psychiatry, 33(2), 387-398.

Spencer, T. J., Biederman, J., \& Mick, E. (2007). Attention-deficit/hyperactivity disorder: 
diagnosis, lifespan, comorbidities, and neurobiology. Journal of Paediatric Psychology, 32(6), 631-642.

Stefanatos, G. A., \& Baron, I. S. (2007). Attention-Deficit/Hyperactivity Disorder: A Neuropsychological Perspective Towards DSM-V. Neuropsychology Review, 17(1), 5-38.

Still, G. F. (1902). Some abnormal psychical conditions in children. The Lancet, 1, 1008-1012, 1077-1082, 1163-1168.

Swanson, J. M., Sergeant, J. A., Taylor, E., Sonuga-Barke, E. J., Jensen, P. S., \& Cantwell, D. P. (1998). Attention-deficit hyperactivity disorder and hyperkinetic disorder. The Lancet, 351(9100), 429-433.

Tannock, R. (1998). Attention deficit hyperactivity disorder: advances in cognitive, neurobiological, and genetic research. Journal of Child Psychology and Psychiatry, 39(1), 65-99.

Tannock, R. (2003). Neuropsychology of attention disorders. In S. Rapin (Ed.), Handbook of Neuropsychology (2nd ed., Vol. 8 Part II, pp. 753-783). Amsterdam, the Netherlands: Elsevier Science B.V.

Thorell, L. B. (2007). Do delay aversion and executive function deficits make distinct contributions to the functional impact of ADHD symptoms? A study of early academic skill deficits. Journal of Child Psychology and Psychiatry, 48(11), 1061-1070.

Tucker, D. M., \& Williamson, P. A. (1984). Asymmetric neural control systems in human selfregulation. Psychological Review, 91(2), 185-215.

Vaidya, C. J., Austin, G., Kirkorian, G., Ridlehuber, H. W., Desmond, J. E., Glover, G. H., et al. (1998). Selective effects of methylphenidate in attention deficit hyperactivity disorder: a functional magnetic resonance study. The Proceedings of the National Academy of Sciences USA, 95(24), 14494-14499.

Walker, A. J., Shores, E. A., Trollor, J. N., Lee, T., \& Sachdev, P. S. (2000). Neuropsychological functioning of adults with attention deficit hyperactivity disorder. Journal of Clinical and Experimental Neuropsychology, 22(1), 115-124.

Wilens, T. E. (2004). Attention-deficit/hyperactivity disorder and the substance use disorders: the nature of the relationship, subtypes at risk, and treatment issues. Psychiatric Clinics of North America, 27(2), 283-301.

Wilens, T. E., \& Biederman, J. (2006). Alcohol, drugs, and attention-deficit/ hyperactivity disorder: a model for the study of addictions in youth. Journal of Psychopharmacology, 20(4), 580-588.

Willcutt, E. G., Doyle, A. E., Nigg, J. T., Faraone, S. V., \& Pennington, B. F. (2005). Validity of the executive function theory of attention-deficit/hyperactivity disorder: a meta-analytic review. Biological Psychiatry, 57(11), 1336-1346.

Wodushek, T. R., \& Neumann, C. S. (2003). Inhibitory capacity in adults with symptoms of Attention Deficit/Hyperactivity Disorder (ADHD). Archives of Clinical Neuropsychology, 18(3), 317-330.

Woods, S. P., Lovejoy, D. W., \& Ball, J. D. (2002). Neuropsychological characteristics of adults with ADHD: a comprehensive review of initial studies. Clinical Neuropsychology, 16(1), 12-34. 



\section{Cognitive complaints and neuropsychological functioning in adults with and without Attention-Deficit/Hyperactivity Disorder (ADHD) referred for multidisciplinary assessment}

Dymphie Scholtissen-In de Braek, Jeanette Dijkstra \& Jelle Jolles

\section{Abstract}

Objective: The present study aims to gain insight into the clinical presentation (viz. self-reported complaints and neuropsychological functioning) of adults referred for ADHD diagnosis.

Methods: The investigation of group differences between an ADHD and a nonADHD sample ( $n=30$ and $n=42$, respectively), all of which had been clinically referred for multidisciplinary assessment of ADHD.

Results: $42 \%$ of all referred patients were diagnosed with adult ADHD. Adults with ADHD made significantly more errors on a verbal learning task than the nonADHD control group, which indicates an impairment of the self-monitoring function in adult ADHD. The ADHD group reported more problems than the control group in the domains of executive functioning, but not in the domains of attention and hyperactivity.

Conclusion: More attention should be paid to executive complaints and functioning (present and past) when referring adults suspected of ADHD for multidisciplinary assessment. Also, characteristics that are thought to be striking symptoms of adult ADHD, such as problems with concentration and hyperactive behaviour, are in fact not distinctive symptoms of ADHD at all. 


\section{Introduction}

As the recognition of adult Attention-Deficit/Hyperactivity Disorder (ADHD) has increased, ADHD has sometimes been regarded as a disease symptomatic of the age of technological development and of changes in society (e.g. more working mothers, less discipline) (Nieweg, 2006). However, there are more and more signs that ADHD is a serious developmental disorder to which biological, psychological and social factors contribute (Barkley, Fischer, Smallish, \& Fletcher, 2006; Biederman, 1998; Mannuzza, Klein, Bessler, Malloy, \& LaPadula, 1998). Until now, research has rarely focused on the differences between adults with and without ADHD. The present study is therefore unique in its aim to identify a new benchmark for referral by medical specialists and other clinicians who encounter adults with complaints in the domain of attention, hyperactivity and impulsivity.

This study reports on adults who were referred for multidisciplinary assessment of ADHD. The general goal was to gain insight into the clinical presentation (viz. self-reported complaints and neuropsychological functioning) of adults who were referred for ADHD diagnosis. In order to do this, differences between an ADHD and a non-ADHD sample (which were both comprised of adults clinically referred for diagnostic research into ADHD) were investigated, since this might lead to the identification of tools for referral that will help medical specialists and other clinicians identify cases of ADHD correctly. This is important, because early recognition of adult ADHD is a necessary step towards adequate prevention programs and effective treatment programs.

The percentage of adults diagnosed with adult ADHD in a university outpatient clinic in the Netherlands is about 69\% (Vegt, Tulen, van Tuijl, Twigt, \& Hengeveld, 2007). However, as clinicians' awareness of adult ADHD increases, patients might be more easily suspected of suffering from adult ADHD. In addition, the diagnostic process of adult ADHD is very complex. First of all, the diagnostic process of adult ADHD depends for an important part on the recollection of childhood events. Secondly, a high level of comorbidity is found in (adult) ADHD. The risk of developing anxiety and mood disorders, of personality problems and of substance abuse is significantly elevated in ADHD; while certain other problems, like impulsive behaviour and aggressiveness, are also present in other disorders such as personality disorders and substance abuse (Biederman, 2005; Biederman et al., 1993). It is reasonable to assume that medical specialists (who refer adults for multidisciplinary assessment) lack the tools or knowledge to differentiate ADHD from other psychiatric disorders because of the complexity of the clinical picture of adult ADHD. 
Our first question was whether neuropsychological test measures in the domain of executive functioning and inhibition would discriminate adults with ADHD from a referred clinical control group. Numerous studies have investigated neuropsychological functioning in childhood and adult ADHD (Hervey, Epstein, \& Curry, 2004; Murphy, Barkley, \& Bush, 2001; Schweiger, Abramovitch, Doniger, \& Simon, 2007; Seidman et al., 2004; Woods, Lovejoy, \& Ball, 2002). However, inconsistencies in neuropsychological findings exist, although most researchers pinpoint executive deficits to be the main defect in adult ADHD (Barkley, 1997; Lovejoy et al., 1999; Marchetta, Hurks, Krabbendam, \& Jolles, 2008; Rapport, Van Voorhis, Tzelepis, \& Friedman, 2001; Walker, Shores, Trollor, Lee, \& Sachdev, 2000). Based on the literature about neuropsychological findings and ADHD, our first hypothesis was that executive measures of response inhibition and executive measures of verbal learning would be the primary means of discriminating the ADHD group from the non-ADHD group.

Our second hypothesis was that specific cognitive complaints (self-report) in the domain of executive functioning would be more evident in adult ADHD compared to the adult non-ADHD sample. Persons with ADHD often report problems with the planning and organization of their behaviour, for instance with regard to housekeeping or organizing their finances. Some authors suggest that impulsivity persists in adults with ADHD and might be at the basis of much of the impairment observed in the daily lives of such individuals (Barkley, 1997; MalloyDiniz, Fuentes, Leite, Correa, \& Bechara, 2007). Therefore, it was expected that cognitive complaints (self-report) with respect to impulsivity and planning would differentiate adults with ADHD from adults without ADHD (who were referred for multidisciplinary assessment). On the other hand, we hypothesized that complaints of hyperactivity would not differentiate adults with ADHD from the non-ADHD group, because it is known that hyperactivity diminishes in adulthood (Biederman, Mick, \& Faraone, 2000). As attention and concentration complaints are reported in various clinical samples, like Parkinson's Disease (PD), Fibromyalgia, Mild Cognitive Impairment (MCl), and Chronic Fatigue (CF) (Bronnick et al., 2006; Leavitt \& Katz, 2006; Ribeiro, de Mendonca, \& Guerreiro, 2006), we also hypothesized that complaints of inattention would not discriminate adults with ADHD from a non-ADHD sample.

A third and final issue that is considered in this study is the previously mentioned high level of comorbidity in ADHD. ADHD in adults often co-occurs with other psychiatric conditions including mood disorders, personality disorders, substance abuse and learning disabilities (Biederman et al., 1993; Murphy, Barkley, \& Bush, 2002; Sobanski et al., 2007). It is known that comorbid disorders 
are associated with ADHD and affect the cognitive abilities of the individual (Seidman, Biederman, Faraone, Weber, \& Ouellette, 1997). Therefore, it is difficult to determine whether measured cognitive impairments are due to the presence of comorbid disorders or to ADHD itself. We expected to find that in a group of referred participants both the ADHD and the non-ADHD group would display complaints of depression, anxiety and cognitive complaints to an equal degree, since they had all sought the help of a medical specialist.

\section{Methods}

\section{Participants}

The members of both the ADHD group and the non-ADHD group had been referred by a medical specialist to the outpatient facility for adults with ADHD at Mondriaan Zorg Groep, location Vijverdal in Maastricht, the Netherlands. At the time of referral, all of the participants exhibited one or more symptoms of ADHD and had sought the help of a medical specialist who then referred them to the abovementioned specialized outpatient clinic.

Participant characteristics are presented in Table 1a. Education was measured on a three-point level (low, medium and high) and age was included as a continuous variable. The estimated IQ was measured by three subtasks (Doing sums, Mental Rotation \& Analogies) that are a part of the Groningen Intelligence Test, which is a frequently used Dutch intelligence test (Luteijn, 1983). The combination of these subtasks is a good approximation of a full-scale IQ (Luteijn, 1983).

A multidisciplinary diagnostic assessment included a standardized psychiatric and (neuro)psychological diagnostic and research protocol, which corresponds with procedures used in previous studies (Barkley, Murphy, Dupaul, \& Bush, 2002; Walker, Shores, Trollor, Lee, \& Sachdev, 2000). This procedure also included a semi-structured interview with both the patient and informant (usually parent), which were conducted by experienced health care psychologists. The boundaries for childhood age were set between 0-12 years old, as is done in other specialized clinics (Kooij et al., 2005). A self-report rating scale and parent rating scale were given to the patient and informant and completed at home (Barkley, 1998).

Finally, a full neuropsychological examination, including generally used tests of intelligence, speed of information processing, attention, memory and executive functioning was conducted. A multidisciplinary team of board certificated psychiatrists and licensed health care psychologists determined the diagnosis of ADHD. The diagnosis was determined by clinical consensus ratings of all the 
available data, except for certain questionnaires that were included for research goals only. All individuals received a diagnosis based on the DSM-IV-TR diagnostic criteria of ADHD (APA, 2000) in childhood and adulthood.

In this study, and based on the literature (Kooij et al., 2005), modified thresholds for adult criteria (five out of nine criteria, instead of six out of nine criteria) were used. In Table 1a. the mean number of criteria of attention-deficit and hyperactivity/impulsivity in adulthood and childhood from the semi-structured interview are presented. Significant differences between the ADHD and nonADHD group were found for the number of ADHD criteria in childhood and number of attention-deficit criteria in adulthood (but not with regard to hyperactivity/impulsivity), which was expected. In addition, a flow chart based on the DSM-IV-TR was used to monitor the diagnostic process (APA, 2000; Kooij, 2004).

The non-ADHD group was comprised of individuals who, although having been referred for assessment because of certain ADHD symptoms, did not meet the diagnostic criteria for the disorder. See Table $1 \mathrm{~b}$. for the relevant DSM-IV-TR Axis-1 diagnosis. Also, subtypes were described according to the DSM-IV-TR (APA, 2000). In this sample only four persons were identified as ADHD-IA, or inattentive subtype. The other participants belonged to the ADHD-C, or combined subtype. To test our hypotheses we dichotomized the population into an ADHD and a non-ADHD group. There were no significant differences between the ADHD and the non-ADHD group with respect to current medication use (present or not

Table 1a. Participant characteristics: means and significance levels of student-t test and chi-square test for the ADHD ( $n=30)$ and non-ADHD-group ( $n=42)$

\begin{tabular}{|c|c|c|c|}
\hline & $\begin{array}{l}\text { ADHD } \\
(n=30)\end{array}$ & $\begin{array}{c}\text { Non-ADHD } \\
(n=42)\end{array}$ & Sign. \\
\hline Age & 31.6 & 35.9 & 0.09 \\
\hline $\operatorname{Sex}(m / f)$ & $23 / 7$ & $30 / 12$ & 0.74 \\
\hline Estimated IQ & 94.0 & 94.2 & 0.97 \\
\hline Education (1-3) & 1.65 & 1.95 & 0.05 \\
\hline Adult Attention Deficit & 6.3 & 5.3 & 0.07 \\
\hline Child Attention Deficit & 6.1 & 4.5 & $0.01 *$ \\
\hline Adult Hyperactivity/Imp & 5.2 & 4.5 & 0.31 \\
\hline Child Hyperactivity/Imp & 5.9 & 4.2 & $0.03^{*}$ \\
\hline
\end{tabular}

Adult and Child Attention Deficit = number of criteria of attention-deficit (maximum 9) on the semi-structured interview in adulthood and childhood; Adult and Child Hyperactivity/Imp = number of criteria of attention-deficit (maximum is 9) on the semi-structured interview in adulthood and childhood. Sign. = ANOVA, * $=p<0.05$ 
Table 1b. Relevant number of DSM-IV-TR Axis-I Diagnosis

\begin{tabular}{|c|c|c|}
\hline & ADHD & Non-ADHD \\
\hline Mood Disorder & 4 & 13 \\
\hline Dysthymic Disorder & 0 & 2 \\
\hline Anxiety Disorder & 0 & 4 \\
\hline Panic Disorder & 1 & 3 \\
\hline Adjustment Disorders & 3 & 2 \\
\hline Eating Disorder & 1 & 1 \\
\hline IES & 1 & 1 \\
\hline Cannabis Abuse & 3 & 5 \\
\hline Alcohol Abuse & 2 & 1 \\
\hline Substance Dependence & 2 & 1 \\
\hline Developmental Disorder & 1 & 1 \\
\hline Factitious Disorder NOS & 1 & 0 \\
\hline Dyslexia & 1 & 0 \\
\hline GAD & 1 & 1 \\
\hline PTSD & 1 & 2 \\
\hline Social Phobia & 1 & 0 \\
\hline Specific Phobia & 0 & 1 \\
\hline Psychotic Disorder NOS & 0 & 1 \\
\hline OCD & 0 & 2 \\
\hline Cognitive Disorder NOS & 0 & 1 \\
\hline Tourette's Disorder & 0 & 1 \\
\hline No diagnosis & 0 & 11 \\
\hline
\end{tabular}

$\mathrm{IES}=$ Intermittent Explosive Disorder; NOS = not otherwise specified; GAD = Generalized Anxiety Disorder; PTSD = Post Traumatic Stress Disorder; $O C D=$ Obsessive Compulsive Disorder

present). Only one participant (from the ADHD group) had used psychostimulants (methylphenidate) previously (three years ago; not at the moment of referral).

\section{Tests}

\section{Questionnaires}

The Wender Utah Rating Scale (WURS) is a reliable 60-item self-report measure for the retrospective diagnosis of childhood ADHD (Retz-Junginger et al., 2002). Because we hypothesized that of the three main symptoms of ADHD it was most likely that executive complaints, such as problems with inhibition and planning would discriminate adults with ADHD from non-ADHD adults, we selected two 
specific items namely "loss of control" (WURS27) and "doing without thinking/ impulsivity" (WURS24) as independent measures. Items were scored on a 4-point scale of inconvenience ( $0=$ not at all; $1=$ little bit; $2=$ moderate; $3=$ =quite a lot; $4=v e r y$ much).

The Maastricht Cognitive Questionnaire (MCQ) measures higher order cognitive functioning in adulthood and childhood. It comprises 50 items that investigate higher order cognitive complaints in childhood and adolescence, (early) cognitive and motor development, and recent neurovegetative symptoms. Items included as independent measures were items that reflect the three core symptoms of ADHD, namely attention, hyperactivity and executive functioning. The selected items were "I am able to concentrate on one activity for a long period of time" (MCQ3); "As a child my thinking was very chaotic" (MCQ17), and "I find it difficult to sit quiet for a long period of time" (MCQ20). Items were scored on a threepoint scale ranging from "I totally agree" to "I totally disagree".

The Symptom Check List (SCL-90) was used to gain insight into recent subjective complaints. The SCL-9o is a multidimensional self-reported inventory of psychopathology (Derogatis, Rickels, \& Rock, 1976). The subscales for depression and insufficiency were used as independent outcome measures with a higher score indicating more symptoms in these domains.

\section{Neuropsychological test measures}

The Stroop Colour Word Test was used to assess information processing speed, attention, and inhibition (Stroop, 1935; Van der Elst, Van Boxtel, Van Breukelen, \& Jolles, 2006). The test involves three cards with 100 stimuli each. The first card displays colour names printed in black, which have to be read aloud as quickly and as accurately as possible. The second card then displays coloured patches, which have to be named as quickly and as accurately as possible. The last card displays colour names printed in incongruously coloured ink. At this time, participants are asked to name the colour of the ink in which the words are printed, also as quickly and as accurately as possible. The extra time needed to suppress salient but irrelevant information (reading) in favour of less salient information (colour naming) is then recorded by subtracting the average time needed to complete the first two subtasks from the time needed to complete the third subtask. This is termed interference (interference $=$ Stroop III - [(Stroop I + Stroop II)/2]. The variables of interest for this study were the interference score and number of mistakes on card three. 
The Verbal Learning Test (VLT) was used to evaluate learning capacity and retrieval from memory (Brand \& Jolles, 1985). In this test, 15 words are presented in a fixed order on a computer screen, one after another. Participants are asked to recall as many words in any order. This procedure is repeated five times. After 20 minutes, delayed recall was tested.

Because it was suggested that deficient inhibition plays an important role in memory impairments in ADHD (Marchetta et al., Submitted), the dependent variable chosen was the total number of correct words and errors over the total of five trials. The total number of words learned over five trials is used as a measure of learning capacity. The total number of errors was regarded as measure of self-monitoring of memory.

\section{Statistical Analyses}

First of all, differences in demographic variables (e.g. age and education level) between groups were compared using Student $t$-tests. A chi-square test was used to analyse group differences with respect to sex (see Table 1. Participant characteristics). A comparison of the number of comorbid Axis-1 DSM-IV-TR diagnosis (except for ADHD) between the ADHD and non-ADHD group was done. Groups did not differ regarding the number of Axis-1 comorbid disorders $(p=0.64)$. The mean average number of comorbid disorders (Axis-1) was 1.05 in the non-ADHD group, and 0.94 in the ADHD group. In the ADHD group, in $61.3 \%$ of patients a comorbid disorder was diagnosed: 11 patients received one other Axis-1 Diagnosis, six patients received two other Axis-1 Diagnosis and three patients received two other Axis-1 Diagnosis.

The scores of the MCQ items did not meet the assumptions for General Linear Model (GLM), since these consisted of three answer categories. These variables were analysed using nonparametric Mann-Whitney U-tests. Analysis of Variance (ANOVA) was used to compare complaints and cognitive performance in the ADHD and non-ADHD group for the other variables. For the cognitive variables outliers were analysed and one patient (ADHD group) was excluded because of an extreme high number of errors (namely 23) on the verbal learning task. Analyses were performed with group (ADHD or non-ADHD group) as between-subject factor.

The $15^{\text {th }}$ version of the Statistical Package for the Social Sciences (SPSS) for Windows was used for the statistical analyses (SPSS inc., USA), with $p=0.05$ as significance level. 
Table 2. Mean (M), Mean Rank (MR), standard deviation (SD) and results of tests for group differences of subjective test measures.

\begin{tabular}{|r|c|c|c|}
\hline & ADHD & Non-ADHD & p-value \\
\hline MCQ & MR & MR & \\
\hline Item 3 & 30.14 & 28.11 & 0.604 \\
\hline Item 17 & 23.36 & 32.65 & 0.018 \\
\hline Item 20 & 25.88 & 31.44 & 0.134 \\
\hline \multicolumn{5}{|l}{} \\
\hline WURS & M(SD) & M(SD) & \\
\hline Item 24 & $3.5(0.75)$ & $2.9(1.2)$ & 0.039 \\
\hline Item 27 & $2.6(1.2)$ & $1.8(1.3)$ & 0.019 \\
\hline SCL-90 & \multicolumn{3}{|l}{} \\
\hline Dep & $30.2(10.3)$ & $36.4(13.5)$ & 0.047 \\
\hline Ins & $22.5(6.7)$ & $23.7(8.01)$ & 0.525 \\
\hline
\end{tabular}

$M C Q=$ Maastricht Cognitive Questionnaire; $M C Q 3=$ "I am able to concentrate on one activity for a long period of time"; MCQ17 = "As a child my thinking was very chaotic" and MCQ20 = "I find it difficult to sit quiet for a long period of time". WURS= Wender Utah Rating Scale; WURS24 = "doing without thinking/"impulsivity"; WURS27 = "loss of control". SCL-90 Dep= Depression subscore; SCL-9o Ins= Insufficiency score.

Note: Mann-Whitney U-tests were used for MCQ-items. WURS was analysed using ANOVA

Table 3. Mean (M), standard deviation (SD) and results of tests for group differences of the objective test measures (ANOVA-analyses).

\begin{tabular}{|r|c|c|c|}
\hline & ADHD & Non-ADHD & p-value \\
\hline & M (SD) & M (SD) & \\
\hline STR3error & $0.8(1.8)$ & $0.6(1.2)$ & 0.50 \\
\hline STRINT & $49.0(21.4)$ & $49.4(21.0)$ & 0.94 \\
\hline VLT & $39.3(8.8)$ & $43.5(10.0)$ & 0.09 \\
\hline VLT error & $2.16(3.8)$ & $0.67(1.1)$ & 0.03 \\
\hline
\end{tabular}

STRzerror= Number of errors on Stroop card three; STRINT= Stroop interference score; VLT= Verbal Learning Test total number of words over five trials; VLT error= Verbal Learning Test total number of errors over five trials 


\section{Results}

Missing values on the MCQ and WURS were found in 14 cases. In 10 instances, this was due to the new introduction of the research protocol (questionnaires were not given to the patients). In the other instances (4), the reason for the missing values was unknown. In these cases, patients were excluded from further analysis (but were included in demographic analysis, since the same diagnostic process was followed).

ANOVA on the four cognitive measures revealed significant differences between the two groups with respect to the number of errors on the verbal learning task $(p=0.031)$. See Table 2 and Table 3 . The ADHD group made more errors compared to the non-ADHD group. No differences were found between the two groups with respect to verbal learning capacity $(p=0.089)$. Also, no differences were found with respect to the number of errors on Stroop card three $(p=0.498)$ and Stroop interference score $(p=0.939)$.

The Mann-Whitney U-test was performed for the three MCQ items (selfreport of complaints). The score on item 17 of the MCQ, which relates to chaotic thinking in childhood, was significantly different between the two groups $(p=0.018)$. The ADHD group had the tendency to agree more with this statement than the non-ADHD group. The two other items (items 3 and 20) that relate to attention and hyperactivity did not significantly differ between the two groups ( $p=0.604$ and $p=0.134$, respectively). Furthermore, ANOVA showed that both item 24 and item 27 of the WURS did significantly differ between the two groups (respectively $p=0.039$ and $p=0.019$ ), indicating more complaints in the domain of impulsivity and loss of control in the ADHD group. ANOVA further revealed statistically significant differences between the ADHD and non-ADHD group with respect to subscores on depression ( $p=0.047)$, but not insufficiency $(p=0.525)$.

\section{Discussion}

The aim of this study was to gain insight into group differences between a group of adults with ADHD and a non-ADHD group (with attention complaints, hyperactivity and impulsivity); the members of both groups had been referred for multidisciplinary assessment.

This insight is important because referring medical specialists who lack the tools for a proper diagnosis might more easily suspect a patient of ADHD. Multidisciplinary assessment in adult ADHD is important because of a number of difficulties in diagnosing ADHD in adulthood. Some ADHD criteria are not specific for ADHD, for instance "impulsivity" is also a characteristic of a number of other 
personality disorders, and attention complaints are also present in the case of e.g. mood disorders (APA, 2000).

Another problem in the current process of diagnosing ADHD is the fact that the diagnosis is based on the DSM-IV or DSM-IV-TR manual (APA, 2000). Unfortunately, this manual does not provide a separate definition of ADHD in adults. This means that the diagnosis of ADHD is made retrospectively and based on criteria for childhood ADHD. However, adults with ADHD appear to be the best informants of their symptoms (Kooij et al., 2008). The current study was specifically focused on investigating differences in a patient population referred for multidisciplinary assessment in order to provide medical specialists with more accurate tools for referral. This is of the highest importance, given that ADHD must be taken as a serious disorder.

The present study found that $42 \%$ of all referred patients were diagnosed with adult ADHD. This is a lower percentage than in other reported studies (Biederman et al., 1993; Kooij, Aeckerlin, \& Buitelaar, 2001; Murphy \& Barkley, 1996; Vegt, Tulen, van Tuijl, Twigt, \& Hengeveld, 2007). This finding is especially interesting because the present study used modified thresholds (five criteria in adulthood instead of six) as was suggested by several authors (Barkley, 1998; Kooij et al., 2004). A possible explanation is that in certain specialized outpatient clinics even less stringent thresholds are used (four criteria in adulthood instead of six) (Kooij et al., 2005).

Another possible explanation is that in this study, except for modified thresholds and less strict boundaries with respect to age (between 0-12 years old instead of before the age of seven), other DSM-IV criteria were used very strictly. For example, ADHD was not diagnosed if the symptoms could be accounted for by another disorder (criteria E, (APA, 2000)). It is not quite clear how this was done in other specialized outpatient clinics. Also, in some outpatient facilities there is often a telephone screening prior to face-to-face assessment which might influence the selection process and account for differences in the percentages that were found.

Yet another feasible explanation for the low percentage of adults diagnosed with ADHD upon referral is that referring medical specialists lack sufficient knowledge about adult ADHD and this might lead to wrong referrals. The current findings suggest that medical specialists do indeed refer patients with symptoms of ADHD even though these patients, for example, hardly exhibited any ADHD symptoms in childhood.

The ADHD and non-ADHD group in this study did not differ with regard to age, education level, sex, estimated IQ and number of Axis-I Diagnosis (APA, 2000). As expected, the mean number of childhood ADHD criteria between the 
two groups did differ. The non-ADHD group reported less symptoms of childhood ADHD in the semi-structured interview compared to the ADHD group. Even though the boundaries with respect to age were less strictly used, a great number of adults diagnosed with ADHD had exhibited symptoms in childhood, as expected. Hence, it is important that referring medical specialists gain some insight into childhood symptoms (between the age of $0-12$ ). Also, in this study we found that mood disorders were the most prominent Axis-I diagnosis in the non-ADHD group, suggesting it is useful to gather information on current mood, by using rating scales or clinical interviews.

With respect to neuropsychological functioning this study found that the number of errors on the verbal learning task discriminated adults with ADHD from adults without ADHD. Adults with ADHD made significantly more errors than the non-ADHD control group. This suggests that the self-monitoring function of learning in adult ADHD is impaired, which is in line with, for instance, the theory of Barkley (Barkley, 1997). Barkley states that a primary deficit in inhibition can secondarily lead to executive problems, like nonverbal or verbal working memory, self-regulation of affect-motivation-arousal, and finally the ability to reconstitute information, which is involved in problem solving (Barkley, 1997; Barkley, Edwards, Laneri, Fletcher, \& Metevia, 2001). Furthermore, the present study suggests that specific neuropsychological measures can provide additional cues in the differential diagnosis of adult ADHD. Because of the complexity of the diagnostic process in adult ADHD, neuropsychological evaluation can make an important contribution to the understanding of the adult ADHD picture.

With respect to cognitive complaints, the current study showed that complaints in the domain of executive functioning, for example chaotic thinking in childhood, impulsivity and loss of control significantly differed between the ADHD and non-ADHD group, with the ADHD group reporting more problems in these domains. Furthermore, there were no between-group differences with regard to attention complaints and complaints of hyperactivity. This suggests that characteristics, which are often thought to be striking symptoms of adult ADHD, are in fact not distinctive symptoms of ADHD at all. Overt hyperactivity ("problems with sitting still") is not a distinct clinical feature of adult ADHD. It is important that referring medical specialists are aware of these findings, since this might lead to more correct referrals.

On the basis of these findings, we recommend that the semi-structured interview for adult ADHD should pay more attention to executive complaints, also in childhood. The current study also suggests the importance of distinct adult criteria of ADHD. 
Even though this study used a relative small sample, its strength lies in the fact that every participant was extensively and multidisciplinary examined and that a structured diagnostic research protocol was followed.

In sum, group differences were clearly found between the adult ADHD and the non-ADHD group examined in this study, both of which were comprised of adults who had been referred for multidisciplinary assessment. The current study showed that the ADHD group reported more problems in the domain of executive functioning. Furthermore, there were no between-group differences with regard to attention complaints and complaints of hyperactivity. This suggests that characteristics that are often thought to be striking symptoms of adult ADHD, are in fact not distinctive symptoms of ADHD at all. Also, neuropsychological data showed that the self-monitoring function of verbal learning in adult ADHD is impaired. These findings indicate that more attention should be paid to executive complaints and functioning (present and past) when referring adults suspected of ADHD for multidisciplinary assessment. 


\section{References}

APA. (2000). Diagnostic and Statistical Manual of Mental Disorders (4th Edition-Text Revision). Washington D.C.: American Psychiatric Association.

Barkley, R. A. (1997). Behavioral inhibition, sustained attention, and executive functions: constructing a unifying theory of ADHD. Psychological Bulletin, 121(1), 65-94.

Barkley, R. A. (1998). Attention Deficit Hyperactivity Disorder- A handbook for Diagnosis and Treatment. New York: The Guilford Press.

Barkley, R. A., Edwards, G., Laneri, M., Fletcher, K., \& Metevia, L. (2001). Executive functioning, temporal discounting, and sense of time in adolescents with attention deficit hyperactivity disorder (ADHD) and oppositional defiant disorder (ODD). Journal of Abnormal Child Psychology, 29(6), 541-556.

Barkley, R. A., Fischer, M., Smallish, L., \& Fletcher, K. (2006). Young adult outcome of hyperactive children: adaptive functioning in major life activities. Journal of American and Academic Child and Adolescent Psychiatry, 45(2), 192-202.

Barkley, R. A., Murphy, K. R., Dupaul, G. I., \& Bush, T. (2002). Driving in young adults with attention deficit hyperactivity disorder: knowledge, performance, adverse outcomes, and the role of executive functioning. Journal of International Neuropsychological Society, 8(5), 655-672.

Biederman, J. (1998). Attention-deficit/hyperactivity disorder: a life-span perspective. Journal of Clinical Psychiatry, 59 Suppl 7, 4-16.

Biederman, J. (2005). Attention-deficit/hyperactivity disorder: a selective overview. Biological Psychiatry, 57(11), 1215-1220.

Biederman, J., Faraone, S. V., Spencer, T., Wilens, T., Norman, D., Lapey, K. A., et al. (1993). Patterns of psychiatric comorbidity, cognition, and psychosocial functioning in adults with attention deficit hyperactivity disorder. American Journal of Psychiatry, 150(12), $1792-1798$.

Biederman, J., Mick, E., \& Faraone, S. V. (2000). Age-dependent decline of symptoms of attention deficit hyperactivity disorder: impact of remission definition and symptom type. American Journal of Psychiatry, 157(5), 816-818.

Brand, N., \& Jolles, J. (1985). Learning and retrieval rate of words presented auditorily and visually. Journal of General Psychology, 112(2), 201-210.

Bronnick, K., Ehrt, U., Emre, M., De Deyn, P. P., Wesnes, K., Tekin, S., et al. (2006). Attentional deficits affect activities of daily living in dementia associated with PD. Journal of Neurology, Neurosurgery and Psychiatry.

Derogatis, L. R., Rickels, K., \& Rock, A. F. (1976). The SCL-90 and the MMPI: a step in the validation of a new self-report scale. British Journal of Psychiatry, 128, 280-289.

Hervey, A. S., Epstein, J. N., \& Curry, J. F. (2004). Neuropsychology of adults with attentiondeficit/hyperactivity disorder: a meta-analytic review. Neuropsychology, 18(3), 485-503.

Kooij, J. J., Aeckerlin, L. P., \& Buitelaar, J. K. (2001). [Functioning, comorbidity and treatment of 141 adults with attention deficit hyperactivity disorder (ADHD) at a psychiatric outpatient department]. Nederlands Tijdschrift voor Geneeskunde, 145(31), 1498-1501.

Kooij, J. J., Buitelaar, J. K., van den Oord, E. J., Furer, J. W., Rijnders, C. A., \& Hodiamont, 
P. P. (2005). Internal and external validity of attention-deficit hyperactivity disorder in a population-based sample of adults. Psychological Medicine, 35(6), 817-827.

Kooij, J. J., Burger, H., Boonstra, A. M., Van der Linden, P. D., Kalma, L. E., \& Buitelaar, J. K. (2004). Efficacy and safety of methylphenidate in 45 adults with attention-deficit/ hyperactivity disorder. A randomized placebo-controlled double-blind cross-over trial. Psychological Medicine, 34(6), 973-982.

Kooij, J. J. S. (2004). De waarschijnlijkheid van de diagnose ADHD op volwassen leeftijd. ADHD actueel, 4.

Kooij, S. J. J., Boonstra, M. A., Swinkels, S. H., Bekker, E. M., de Noord, I., \& Buitelaar, J. K. (2008). Reliability, validity, and utility of instruments for self-report and informant report concerning symptoms of ADHD in adult patients. Journal of Attention Disorders, 11(4), 445-458.

Leavitt, F., \& Katz, R. S. (2006). Distraction as a key determinant of impaired memory in patients with fibromyalgia. Journal of Rheumatology, 33(1), 127-132.

Lovejoy, D. W., Ball, J. D., Keats, M., Stutts, M. L., Spain, E. H., Janda, L., et al. (1999). Neuropsychological performance of adults with attention deficit hyperactivity disor$\operatorname{der}(A D H D)$ : diagnostic classification estimates for measures of frontal lobe/executive functioning. Journal of International Neuropsychological Society, 5(3), 222-233.

Luteijn, F., Ploeg, F. A. E. van der. (1983). Manual Groningen Intelligence Test. Lisse, the Netherlands: Swets \& Zeitlinger.

Malloy-Diniz, L., Fuentes, D., Leite, W. B., Correa, H., \& Bechara, A. (2007). Impulsive behavior in adults with attention deficit/ hyperactivity disorder: characterization of attentional, motor and cognitive impulsiveness. Journal of International Neuropsychological Society, 13(4), 693-698.

Mannuzza, S., Klein, R. G., Bessler, A., Malloy, P., \& LaPadula, M. (1998). Adult psychiatric status of hyperactive boys grown up. American Journal of Psychiatry, 155(4), 493-498.

Marchetta, N. D., Hurks, P. M., Meijs, C. J. C., Scholtissen-In de Braek, D. M. J. M., Rozendaal, N., \& Jolles, J. Verbal learning and organisational strategies in adults with ADHD: ADHD subtypes and the impact of comorbidity. Submitted

Marchetta, N. D., Hurks, P. P., Krabbendam, L., \& Jolles, J. (2008). Interference control, working memory, concept shifting, and verbal fluency in adults with attention-deficit/ hyperactivity disorder (ADHD). Neurospsychology, 22(1), 74-84.

Murphy, K., \& Barkley, R. A. (1996). Attention deficit hyperactivity disorder adults: comorbidities and adaptive impairments. Comprehensive Psychiatry 37(6), 393-401.

Murphy, K. R., Barkley, R. A., \& Bush, T. (2001). Executive functioning and olfactory identification in young adults with attention deficit-hyperactivity disorder. Neuropsychology, 15(2), 211-220.

Murphy, K. R., Barkley, R. A., \& Bush, T. (2002). Young adults with attention deficit hyperactivity disorder: subtype differences in comorbidity, educational, and clinical history. Journal of Nervous Mental Disorders, 190(3), 147-157.

Nieweg, E. H. (2006). [ADHD, a 'fashion' that won't go out of fashion. An illustration of the many-sidedness of earlier psychiatry]. Tijdschrift voor Psychiatrie, 48(4), 303-312. 
Rapport, L. J., Van Voorhis, A., Tzelepis, A., \& Friedman, S. R. (2001). Executive functioning in adult attention-deficit hyperactivity disorder. Clinical Neuropsychology, 15(4), 479491.

Retz-Junginger, P., Retz, W., Blocher, D., Weijers, H. G., Trott, G. E., Wender, P. H., et al. (2002). [Wender Utah rating scale. The short-version for the assessment of the attention-deficit hyperactivity disorder in adults]. Nervenarzt, 73(9), 830-838.

Ribeiro, F., de Mendonca, A., \& Guerreiro, M. (2006). Mild cognitive impairment: deficits in cognitive domains other than memory. Dementia and Geriatric Cognitive Disorders, 21(5-6), 284-290.

Schweiger, A., Abramovitch, A., Doniger, G. M., \& Simon, E. S. (2007). A clinical construct validity study of a novel computerized battery for the diagnosis of ADHD in young adults. Journal of Clinical and Experimental Neuropsychology, 29(1), 100-111.

Seidman, L. J., Biederman, J., Faraone, S. V., Weber, W., \& Ouellette, C. (1997). Toward defining a neuropsychology of attention deficit-hyperactivity disorder: performance of children and adolescents from a large clinically referred sample. Journal of Consulting and Clinical Psychology, 65(1), 150-160.

Seidman, L. J., Doyle, A., Fried, R., Valera, E., Crum, K., \& Matthews, L. (2004). Neuropsychological function in adults with attention-deficit/hyperactivity disorder. Psychiatric Clinics of North America, 27(2), 261-282.

Sobanski, E., Bruggemann, D., Alm, B., Kern, S., Deschner, M., Schubert, T., et al. (2007). Psychiatric comorbidity and functional impairment in a clinically referred sample of adults with attention-deficit/hyperactivity disorder (ADHD). European Archives of Psychiatry and Clinical Neuroscience, 257(7), 371-7.

Stroop, J. R. (1935). Studies of interference in serial verbal reactions. Journal of Experimental Psychology, 18, 643-662.

Van der Elst, W., Van Boxtel, M. P., Van Breukelen, G. J., \& Jolles, J. (2006). The Stroop color-word test: influence of age, sex, and education; and normative data for a large sample across the adult age range. Assessment, 13(1), 62-79.

Vegt, M., Tulen, J. H., van Tuijl, H. R., Twigt, C. W., \& Hengeveld, M. W. (2007). [Psychiatric and neuropsychological characterization of a group of adults referred to a university outpatient clinic for ADHD]. Tijdschrift voor Psychiatrie, 49(5), 289-299.

Walker, A. J., Shores, E. A., Trollor, J. N., Lee, T., \& Sachdev, P. S. (2000). Neuropsychological functioning of adults with attention deficit hyperactivity disorder. Journal of Clinical and Experimental Neuropsychology, 22(1), 115-124.

Woods, S. P., Lovejoy, D. W., \& Ball, J. D. (2002). Neuropsychological characteristics of adults with ADHD: a comprehensive review of initial studies. Clinical Neuropsychology, 16(1), 12-34. 



\section{Diagnostic assessment of adults with Attention-Deficit/Hyperactivity Disorder (ADHD): the role of childhood factors}

Dymphie Scholtissen-In de Braek, Jeanette Dijkstra \& Jelle Jolles

\section{Abstract}

Objective: Until now, it is unknown whether specific characteristics in childhood predict adult Attention-Deficit/Hyperactivity Disorder (ADHD). The present paper aims at evaluating whether childhood functioning and symptoms of ADHD in childhood, as assessed retrospectively by a parent rating scale, can aid in the diagnosis of adult ADHD.

Methods: The authors investigated group differences between an ADHD and nonADHD group of adults on the Wender's ten-item Parent Rating Scale (WPRS).

Results: GLM analyses revealed significant differences between the ADHD and non-ADHD group for eight (out of ten) items of the WPRS. These included childhood symptoms of "restlessness, impulsivity, disturbing others, not able to finish tasks, agitation, easily frustrated, rapid mood swings and rage outbursts". Scores on these items were higher in the ADHD group. Notably, the two groups did not differ with respect to complaints of distractibility in childhood, even though this is considered to be a core symptom of ADHD. Also, the sensitivity and specificity of the WPRS were determined. Finally, this study showed only moderate positive correlations on some of the similar WPRS and Wender Utah Rating Scale (WURS) items

Conclusion: this study suggests that specific additional information about childhood functioning from parents is important in the diagnosis of adult ADHD. 


\section{Introduction}

The estimated prevalence of Attention-Deficit/Hyperactivity Disorder (ADHD) in adults is $1-4.7 \%$ (Faraone \& Biederman, 2005; Kooij et al., 2005). Prevalence figures in children indicate that an even higher number, viz. 10\%, of all school-age children have ADHD, even though symptoms of ADHD often persist into adulthood (Barkley, 1998; Biederman, 2005; Kroes et al., 2001).

Until now, it has not been known whether specific characteristics in childhood predict adult ADHD. The present paper investigates this question by taking a checklist which is frequently employed to determine whether children have ADHD and using it to assess ADHD in the case of adults. The aim is thus to evaluate whether childhood functioning and symptoms of ADHD in childhood can aid in the diagnosis of adults with ADHD. We therefore compared adults with ADHD to adults without ADHD by using a dedicated parent rating scale which retrospectively assesses childhood functioning, including childhood characteristics that go beyond meeting the DSM-IV-TR criteria, (Wender, Wolf, \& Wasserstein, 2001). The rationale is as follows: if there are differences in childhood functioning, this information is valuable when it comes to understanding the concept of $\mathrm{ADHD}$ and it could make a potential contribution to the diagnostic process in the case of adults.

With respect to the question whether specific characteristics in childhood are predictive of adult ADHD, there are some considerations which have to be addressed. First of all, there are no adult-specific diagnostic criteria for Attention-Deficit/Hyperactivity Disorder (ADHD) in the DSM-IV-TR (APA, 2000; Wilens et al., 2002). The diagnosis of ADHD in adults is based on detailed history taking and uses DSM-IV standards by retroactively looking for ADHD symptoms in childhood and adulthood. ADHD is a life-long condition, which suggests that the manifestation of symptoms must have been present in childhood. For a diagnosis of adult ADHD the persistence of symptoms into adulthood is required. Therefore, information about childhood is essential in the diagnostic process of ADHD (RoyByrne et al., 1997).

Secondly, the diagnosis of adult ADHD is made retrospectively by careful clinical history taking. Many adults have trouble remembering their childhood. For this reason parents and other informants are often consulted. It is imperative to consult several sources of information such as parents and teachers and other 'significant others' such as brothers/sisters in the diagnostic assessment of adult ADHD (Roy-Byrne et al., 1997). However, it is not exactly clear what the use of informant scales contributes to the diagnostic process of adult ADHD. The diagnostic process of adult ADHD is very time-consuming and the clinician is in need 
of easy-to-use and sensitive instruments. In general, patients and partners both underreport symptoms and there is a low level of agreement between patients and informants (Kooij et al., 2008; Young \& Gudjonsson, 2005). However, both self-report scales and informant scales have been shown to confirm interviewbased diagnoses in children and adults (Magnusson et al., 2006). Moreover, there is another important problem with relying only on self-rating scales as patients might suffer from 'recall bias' (Mannuzza, Klein, Klein, Bessler, \& Shrout, 2002).

This study investigated group differences between an ADHD and non-ADHD group of adults on the Wender's ten-item Parent Rating Scale (WPRS). The WPRS is based on the Wender Utah Rating Scale (WURS) criteria which include symptoms of impulsivity, affective lability, over-reactivity, and hot temper, that go beyond meeting the DSM-IV-TR criteria (Wender, Wolf, \& Wasserstein, 2001). Also, correlations between the WPRS en WURS were investigated.

In sum, the primary goal of the present study was to investigate group differences in childhood functioning (as rated by parents), by retrospectively examining childhood functioning in two groups of adults, viz. one with and one without ADHD. In order to do this, a short parent rating scale was used and examined. The secondary goal of the study was to investigate the specificity and sensitivity of this parent rating scale in the diagnostic process of adult ADHD.

\section{Methods}

\section{Participants}

Participants were clinically referred by a medical specialist to the outpatient facility for adults with ADHD at the Mondriaan Zorg Groep, location Vijverdal in Maastricht, the Netherlands. At the time of referral, all of the participants exhibited one or more symptoms of ADHD and had sought the help of a medical specialist who then referred them to the abovementioned specialized outpatient clinic.

On the basis of the diagnostic outcome (the diagnostic process is described below), patients were appointed to the ADHD or non-ADHD group and matched with regard to age (plus or minus 5 years). Participant characteristics are presented in Table 1. Education was measured on a 3-point level (low, medium and high); age was measured as a continuous variable. The mean age was 30.2 in the ADHD group and 31.1 in the non-ADHD group. The mean level of education was 1.71 in the ADHD group and 2.2 in the non-ADHD group. The estimated IQ was measured by three subtasks (Doing sums, Mental Rotation \& Analogies) that are a part of the Groningen Intelligence Test, which is a frequently used Dutch intel- 
ligence test (Luteijn, 1983). The mean estimated IQ was 90.9 in the ADHD-group and 97.5 in the non-ADHD group.

\section{Diagnostic Procedure}

A multidisciplinary diagnostic assessment included a standardized psychiatric and (neuro)psychological diagnostic and research protocol, which corresponds with procedures used in previous studies (Barkley, Murphy, Dupaul, \& Bush, 2002; Walker, Shores, Trollor, Lee, \& Sachdev, 2000). This procedure also included a semi-structured interview with both the patient and informant (usually a parent), which were conducted by experienced health care psychologists (APA, 2000; Epstein \& Kollins, 2006; Kooij, Aeckerlin, \& Buitelaar, 2001). A self-report rating scale and parent rating scale were given to the patient and informant and completed at home (Barkley, 1998).

Finally, a full neuropsychological examination, including generally used tests of intelligence, speed of information processing, attention, memory and executive functioning was conducted. The diagnosis of ADHD was determined by a multidisciplinary team of board certificated psychiatrists and licensed health care psychologists/clinical neuropsychologists. The diagnosis was determined by clinical consensus ratings of all the available data, except for the questionnaires that were included for research goals only. All individuals received a diagnosis based on the DSM-IV-TR diagnostic criteria of ADHD in childhood and adulthood (APA, 2000). A flow chart based on the DSM-IV-TR was used to monitor the diagnostic process (APA, 2000; Kooij, 2004).

In this study, and based on the literature (Kooij et al., 2005), modified thresholds for adult criteria (five out of nine criteria, instead of six out of nine criteria) were used. None of the participants were using psychostimulants at the time of testing.

\section{$A D H D$ versus non-ADHD group}

The non-ADHD group was comprised of individuals who, although having been referred for assessment because of certain ADHD symptoms, did not meet the diagnostic criteria for the disorder. The ADHD group ( $n=21)$ and non-ADHD $(n=21)$ group were matched with regard to age.

\section{Instruments}

\section{Wender's ten-item Parental Rating Scale (WPRS)}

The WPRS is based on the Connors Rating Scale and consists of 10 items which the parent uses to rate the patient as a child between the age of six and ten 
Table 1. Participant characteristics: means and significance levels of ANOVA and chi-square test for the ADHD ( $n=21)$ and non-ADHD-group ( $n=21)$

\begin{tabular}{|r|c|c|c|} 
& ADHD & Non-ADHD & Sign. \\
\hline Age & 30.2 & 31.1 & 0.75 \\
\hline Sex (m/f) & $16 / 5$ & $15 / 6$ & 0.73 \\
\hline Estimated IQ & 90.9 & 97.5 & 0.23 \\
\hline Education (1-3) & 1.71 & 2.2 & $0.02^{*}$ \\
\hline Adult Attention Deficit & 6.4 & 5.5 & 0.21 \\
\hline Child Attention Deficit & 6.3 & 4.7 & $0.03^{*}$ \\
\hline Adult Hyperactivity/Imp & 5.7 & 4.8 & 0.35 \\
\hline Child Hyperactivity/Imp & 6.0 & 4.5 & 0.11 \\
\hline
\end{tabular}

Adult and Child Attention Deficit = number of criteria of attention-deficit (maximum 9) on the semi-structured interview in adulthood and childhood; Adult and Child Hyperactivity/Imp = number of criteria of attention-deficit (maximum is 9) on the semi-structured interview in adulthood and childhood. Sign. $=$ ANOVA, ${ }^{*}=p<0.05$

on a 4-point scale (Goyette, Conners, \& Ulrich, 1978). The WPRS is based on the Wender Utah Rating Scale criteria which covers seven psychopathological domains: inattention, hyperactivity, disorganisation, impulsivity, affective lability, over-reactivity, and hot temper. The WPRS measures observations of motor overt activity, distractibility and impulsivity. As mentioned earlier, the items on this scale are based on childhood characteristics (between the age of 6 and 10 years old).

\section{Wender Utah Rating Scale (WURS)}

The WURS is one of the most widely investigated and used self-rating scales for ADHD. It consists of 61 items and includes childhood characteristics that go beyond minimally meeting the DSM-IV-TR criteria, plus specific adult characteristics (Wender, Wolf, \& Wasserstein, 2001). For the purpose of this paper we investigated the self-scores of the items that are also included in the WPRS. In this case, we examined single items, more specifically the items 1, 5, 6, 7, 9, 10, 20, 24 and 36 , which correspond with nine of the ten items on the WPRS.

\section{Statistical analyses}

First of all, differences in demographic variables (e.g. age, education level and estimated IQ) between groups were compared using ANOVA. A chi-square test was used to analyse group differences with respect to sex (see Table 1. Partici- 
pant characteristics). A comparison of the number of comorbid Axis-1 DSM-IV-TR diagnosis (except for ADHD) between the ADHD and non-ADHD group was made. The WPRS total score was computed. Cronbach's alpha for the WPRS items in this study was 0.827 . Pearson correlations between the items on the WPRS and WURS were examined.

General Linear Model (GLM) was used to examine the differences between the ADHD and non-ADHD group (respectively $n=21, n=19$ ). For two participants there was one missing item on the WPRS (reason unknown). These were not included in further analyses. The independent variables in this study were the separate scores on the ten items of the WPRS. Group differences with respect to the WPRS total score were calculated by using ANOVA. Bonferroni analyses were used to correct for multiple testing.

The WPRS sensitivity (i.e. number of ADHD patients correctly identified) and WPRS specificity (i.e. number of non-ADHD patients that were identified as 'nonADHD') were examined with the aid of varying cut-off scores (between 16 en 19).

The $15^{\text {th }}$ version of the Statistical Package for the Social Sciences (SPSS) for Windows was used for the statistical analyses (SPSS inc., USA). $p<0.05$ was considered statistically significant.

\section{Results}

The ADHD and non-ADHD group did not differ regarding the number of Axis-1 comorbid disorders $(p=1.00)$. The mean average number of comorbid disorders (Axis-1) was 0.95 in both groups. The two groups did not differ regarding estimated IQ $(p=0.23)$. Education level was significantly different between the two groups $(p=0.018)$. The ADHD group had a lower level of education.

In Table 1 the mean number of ADHD criteria in adulthood and childhood from the semi-structured interview are presented. Significant differences between the ADHD and non-ADHD group were found for a number of criteria indicating attention deficiency in childhood. ANOVA revealed significant group differences in the WPRS total score. The mean score for the ADHD group on the WPRS was 21.4; the mean score for the non-ADHD group was $14.3(p=0.00)$. Only some moderate positive correlations were found between the WPRS items and the WURS items. One single WURS item (item 24; 'act without thinking/impulsivity') was positively correlated with a number of WPRS items, including items 1, 2, $3,4,5,7,10$.

GLM analyses revealed significant differences between the ADHD and nonADHD group for eight (out of ten) items of the WPRS. These included childhood 
Table 2. General Linear Model for the ten WPRS items (ADHD: $n=21$; non-ADHD: $n=19$ ).

\begin{tabular}{|r|c|c|c|}
\hline & ADHD & non-ADHD & Sign. \\
\hline Item 1: restlessness & 2.48 & 1.74 & $0.011^{*}$ \\
\hline Item 2: impulsivity & 2.62 & 1.68 & $0.001^{* *}$ \\
\hline Item 3: disturbing others & 2.24 & 1.42 & $0.005^{* *}$ \\
\hline Item 4: not able to finish tasks & 2.52 & 1.79 & $0.004^{* *}$ \\
\hline Item 5: agitation & 2.14 & 1.16 & $0.002^{* *}$ \\
\hline Item 6: distractibility & 2.57 & 2.21 & 0.109 \\
\hline Item 7: easily frustrated & 2.43 & 1.21 & $0.000^{* *}$ \\
\hline Item 8: crying & 0.91 & 1.16 & 0.343 \\
\hline Item 9: rapid mood swings & 1.81 & 1.16 & $0.017^{*}$ \\
\hline Item 10: rage outbursts & 1.71 & 0.79 & $0.004^{* *}$ \\
\hline
\end{tabular}

$* p<0.05$

** $p<0.01$

symptoms as reported by parents with respect to restlessness, impulsivity, disturbing others, not able to finish tasks, agitation, easily frustrated, rapid mood swings and rage outbursts. Scores on these items were higher in the ADHD group (see Table 2). Interestingly, no differences were found for childhood symptoms of distractibility. Post-hoc analyses showed that if we included 'Education' as a covariate in the GLM, significant effects were found for six items, including restlessness, impulsivity, not able to finish tasks, agitation, easily frustrated and rage outbursts.

With regard to the second aim of this paper, viz. the investigation of the sensitivity and specificity of the WPRS in the diagnosis of adult ADHD, the following results were obtained: at a cut-off score of 16 on the WPRS, the sensitivity was 0.86 and the specificity 0.56 ; at a cut-off score of 17 the sensitivity was 0.76 and the specificity was 0.63 ; at a cut-off score of 18 the sensitivity was 0.67 and the specificity was 0.74 ; and finally, at a cut-off score of 19 the sensitivity was 0.67 and the specificity was 0.84 .

\section{Discussion}

The diagnostic process of adult ADHD is complicated by a number of factors, which include a high level of comorbidity in childhood, adolescence and adulthood and the use of retrospective information in the diagnostic process. Often, the diagnosis of ADHD is based on the DSM-IV-TR criteria, but unfortunately 
there are no adult-specific diagnostic criteria for Attention-Deficit/Hyperactivity Disorder (ADHD) that take childhood symptoms into account (APA, 2000; Wilens et al., 2002).

The current study investigated group differences in childhood functioning (as rated by parents), by retrospectively examining childhood functioning in two groups of adults, viz. one with and one without ADHD. In order to do this, a short parent rating scale (WPRS) was used and examined. Significant differences between the ADHD and non-ADHD group with respect to childhood functioning were found on eight of the ten items of the WPRS.

In this analyses, education was not treated as a covariate because a lower level of education was expected in ADHD patients and this can be seen as an inherent characteristic of ADHD (Biederman et al., 1993). However, analyses showed that when 'education' was treated as a covariate, significant differences for six items remained.

These results indicate that, in retrospect, parents scored children who received an ADHD diagnosis in adulthood significantly higher on certain behavioural aspects, such as low frustration tolerance, rapid mood swings, agitation, temper tantrums and impulsivity. In childhood these complaints seem to be an important part of the clinical picture of ADHD and they are reported retrospectively by parents. In adulthood, the semi-structured interview on childhood characteristics should take these aspects into account in the diagnostic process of adult ADHD.

Notably, the two groups did not differ with respect to complaints of distractibility in childhood, even though this is considered to be a core symptom of ADHD. Complaints of impulsivity and restlessness, which are part of the childhood criteria of ADHD, did differ between the two groups in childhood. These findings are in line with the idea that ADHD is primarily an executive problem (Barkley, 1997). ADHD seems to be a lifelong condition with a varying clinical picture. In adulthood, overt motor activity and hyperactivity declines, whereas attention complaints persist in the majority of ADHD cases. Also, this study showed only moderate positive correlations on some of the similar WPRS and WURS items, suggesting that additional information about childhood from parents is important in the diagnosis of adult ADHD.

The second aim of this study was to examine the sensitivity and specificity of the WPRS for the diagnostic process of adult ADHD. Depending on the diagnostic question different cut-off scores can be used. At a cut-off score of 16 the sensitivity of the WPRS is high (0.86), suggesting that the WPRS can correctly identify $86 \%$ of all ADHD cases. At a cut-off score of 19 the specificity of the WPRS is 
reasonably high (0.84), suggesting that the WPRS can correctly identify $84 \%$ of non-ADHD cases.

This study shows that the inclusion of a short parent rating scale measuring symptoms that go beyond the DSM-IV criteria can be useful in the diagnosis of adult ADHD. Childhood characteristics like low frustration tolerance, rapid mood swings, agitation, temper tantrums and impulsivity do seem to predict adult ADHD. Informants possess valuable information about childhood functioning, which helps the diagnostic process in adult ADHD. 


\section{References}

APA. (2000). Diagnostic and Statistical Manual of Mental Disorders (4th Edition-Text Revision). Washington D.C.: American Psychiatric Association.

Barkley, R. A. (1997). Behavioral inhibition, sustained attention, and executive functions: constructing a unifying theory of ADHD. Psychological Bulletin, 121(1), 65-94.

Barkley, R. A. (1998). Attention Deficit Hyperactivity Disorder- A handbook for Diagnosis and Treatment. New York: The Guilford Press.

Barkley, R. A., Murphy, K. R., Dupaul, G. I., \& Bush, T. (2002). Driving in young adults with attention deficit hyperactivity disorder: knowledge, performance, adverse outcomes, and the role of executive functioning. Journal of International Neuropsychological Society, 8(5), 655-672.

Biederman, J. (2005). Attention-deficit/hyperactivity disorder: a selective overview. Biological Psychiatry, 57(11), 1215-1220.

Biederman, J., Faraone, S. V., Spencer, T., Wilens, T., Norman, D., Lapey, K. A., et al. (1993). Patterns of psychiatric comorbidity, cognition, and psychosocial functioning in adults with attention deficit hyperactivity disorder. American Journal of Psychiatry, 150(12), $1792-1798$.

Epstein, J. N., \& Kollins, S. H. (2006). Psychometric properties of an adult ADHD diagnostic interview. Journal of Attention Disorders, 9(3), 504-514.

Faraone, S. V., \& Biederman, J. (2005). What is the prevalence of adult ADHD? Results of a population screen of 966 adults. Journal of Attention Disorders, 9(2), 384-391.

Goyette, C. H., Conners, C. K., \& Ulrich, R. F. (1978). Normative data on revised Conners Parent and Teacher Rating Scales. Journal of Abnormal Child Psychology 6(2), 221-236.

Kooij, J. J., Aeckerlin, L. P., \& Buitelaar, J. K. (2001). [Functioning, comorbidity and treatment of 141 adults with attention deficit hyperactivity disorder (ADHD) at a psychiatric outpatient department]. Nederlands Tijdschrift voor Geneeskunde, 145(31), 1498-1501.

Kooij, J. J., Buitelaar, J. K., van den Oord, E. J., Furer, J. W., Rijnders, C. A., \& Hodiamont, P. P. (2005). Internal and external validity of attention-deficit hyperactivity disorder in a population-based sample of adults. Psychological Medicine, 35(6), 817-827.

Kooij, J. J. S. (2004). De waarschijnlijkheid van de diagnose ADHD op volwassen leeftijd. ADHD actueel(4).

Kooij, S. J. J., Boonstra, M. A., Swinkels, S. H., Bekker, E. M., de Noord, I., \& Buitelaar, J. K. (2008). Reliability, validity, and utility of instruments for self-report and informant report concerning symptoms of ADHD in adult patients. Journal of Attention Disorders, 11(4), 445-458.

Kroes, M., Kalff, A. C., Kessels, A. G., Steyaert, J., Feron, F. J., van Someren, A. J., et al. (2001). Child psychiatric diagnoses in a population of Dutch schoolchildren aged 6 to 8 years. Journal of the American Academy of Child and Adolescent Psychiatry, 40(12), 1401-1409.

Luteijn, F., Ploeg, F. A. E. van der. (1983). Manual Groningen Intelligence Test. Lisse, the Netherlands: Swets \& Zeitlinger.

Magnusson, P., Smari, J., Sigurdardottir, D., Baldursson, G., Sigmundsson, J., Kristjans- 
son, K., et al. (2006). Validity of self-report and informant rating scales of adult ADHD symptoms in comparison with a semistructured diagnostic interview. Journal of Attention Disorders, 9(3), 494-503.

Mannuzza, S., Klein, R. G., Klein, D. F., Bessler, A., \& Shrout, P. (2002). Accuracy of adult recall of childhood attention deficit hyperactivity disorder. American Journal of Psychiatry, 159(11), 1882-1888.

Roy-Byrne, P., Scheele, L., Brinkley, J., Ward, N., Wiatrak, C., Russo, J., et al. (1997). Adult attention-deficit hyperactivity disorder: assessment guidelines based on clinical presentation to a specialty clinic. Comprehensive Psychiatry, 38(3), 133-140.

Walker, A. J., Shores, E. A., Trollor, J. N., Lee, T., \& Sachdev, P. S. (2000). Neuropsychological functioning of adults with attention deficit hyperactivity disorder. Journal of Clinical and Experimental Neuropsychology, 22(1), 115-124.

Wender, P. H., Wolf, L. E., \& Wasserstein, J. (2001). Adults with ADHD. An overview. Annals of the New York Academy of Sciences, 931, 1-16.

Wilens, T. E., Biederman, J., Brown, S., Tanguay, S., Monuteaux, M. C., Blake, C., et al. (2002). Psychiatric comorbidity and functioning in clinically referred preschool children and school-age youths with ADHD. Journal of the American Academy of Child and Adolescent Psychiatry, 41(3), 262-268.

Young, S., \& Gudjonsson, G. H. (2005). Neuropsychological correlates of the YAQ-S and YAQ-I self- and informant-reported ADHD symptomatology, emotional and social problems and delinquent behaviour. British Journal of Clinical Psychology, 44(Pt 1), 47-57. 
Attention dysfunction and ADHD in adults: determinants and interventions 


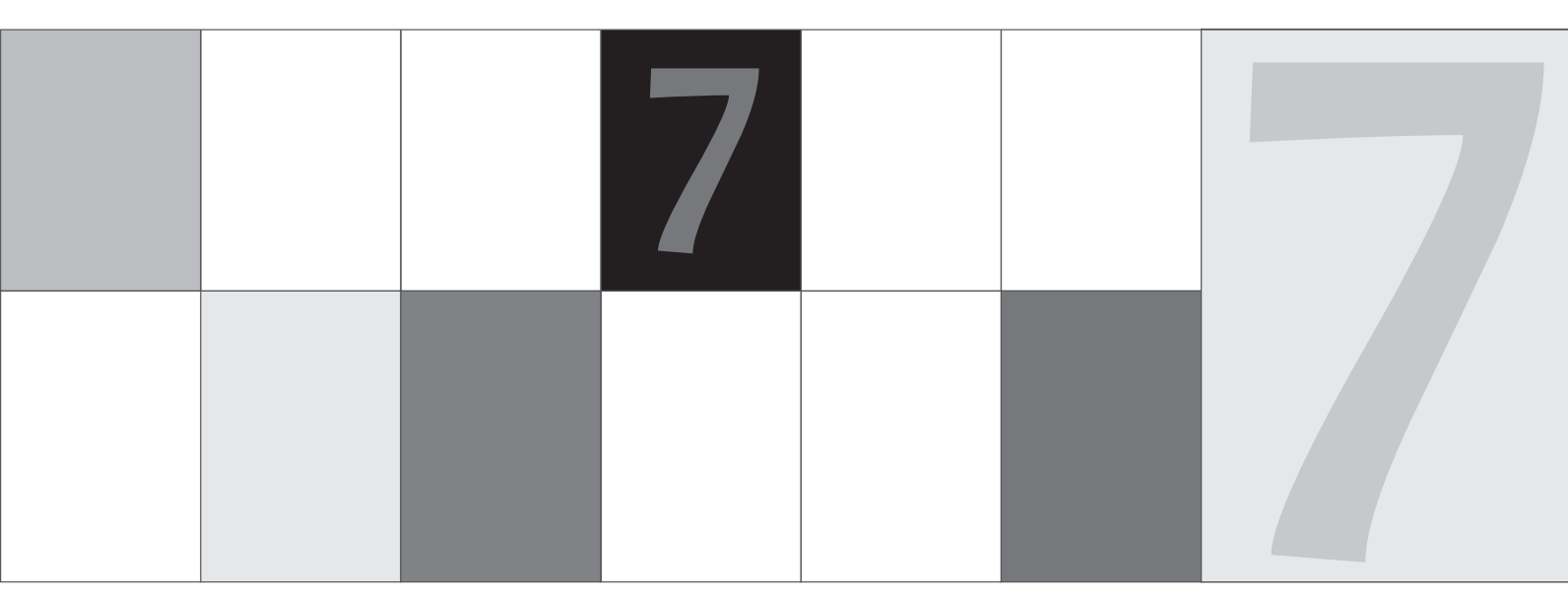





\section{Goal Management Training in adults with Attention-Deficit/Hyperactivity Disorder (ADHD): an intervention study}

Dymphie Scholtissen-In de Braek, Jeanette Dijkstra, Rudolf Ponds \& Jelle Jolles

\section{Abstract}

Objective: This paper describes a controlled, neuropsychological intervention study in adult Attention-Deficit/Hyperactivity Disorder (ADHD). We examined whether adults with ADHD would benefit from a structured course based on Goal Management Training (GMT). The comprehensive course also included psycho-education on the important aspects of executive functioning as well as counselling with respect to coping behaviours.

Methods: The intervention group was compared to a control group of patients who received psycho-education only ( $n=12$ and $n=15$, respectively). The effects of the intervention were evaluated using subjective and objective test measures. In addition, a structured pre-assessment, an evaluation and a group comparison were carried out by an experienced clinician, who was blinded to the intervention itself.

Results: The results of the structured clinical interview obtained in the active intervention group were significantly better in the intervention group than those of the control group.

Conclusion: The findings suggest that the combination of GMT with psycho-education and counselling may have validity for adults with ADHD. 


\section{Introduction}

In treatment studies in adult Attention-Deficit/Hyperactivity Disorder (ADHD), a major focus has been pharmacological interventions (Adler, 2008; Kooij et al., 2004; Lerner \& Wigal, 2008; Stein, 2008). Unfortunately, research of psychological treatments is virtually absent. There is only some preliminary evidence supporting the combination of cognitive behavioural therapy and medication (Davidson, 2008; Virta et al., 2008). In addition, not all patients respond to pharmacotherapy and they often ask for counselling or additional training. In clinical settings, interventions regarding planning and organisation, or coaching are often requested. Although there is abundant neuropsychological knowledge of ADHD, this is not used on a regular basis in current treatment programmes. There are several neuropsychological models that consider ADHD as a primary deficit in inhibitory control, which is an aspect of executive dysfunction. Barkley (1997) also suggests that ADHD is primarily a deficit in inhibitory processes involving executive function (Barkley, 1997). He relates this inhibitory deficit to prefrontal lobe functioning, possibly related to a delay in brain development as other authors also suggest (Shaw et al., 2007). It is a challenging opportunity to examine whether adults with ADHD benefit from an intervention directed at executive functions, notably the organization and planning of activities in daily life.

Our enquiry was whether patients with ADHD would benefit from a structured course involving several aspects of executive functioning including psycho-education. Our hypothesis was that patients who were taught an executive strategy would be able to cope better with cognitive failures and would display fewer cognitive complaints compared to a control group of patients who received psycho-education only. Van Hooren et al. (2007) investigated the effect of a 6-week structured course on the executive functioning of older adults in a controlled study (van Hooren et al., 2007). Their findings indicated that a combination of psycho-education and training had the potential to change the attitude of patients towards their functioning.

The aim of the current study was to investigate the efficacy of cognitive strategy training in adults with ADHD. Because executive functioning skills are often compromised in adults with ADHD (Barkley, Edwards, Laneri, Fletcher, \& Metevia, 2001; Boonstra, Oosterlaan, Sergeant, \& Buitelaar, 2005; Marchetta, Hurks, Krabbendam, \& Jolles, 2008), we developed an intervention based on the Goal Management Training (GMT) for use in adults with ADHD (Robertson, 2001). GMT involves different aspects of goal management, which include defining problems, encoding, retrieval strategies and self-monitoring (Robertson, 2001). Since adults with ADHD often suffer from mood swings and low self-esteem, we added psy- 
cho-education to GMT to provide the patient with more insight into their condition. The aim of psycho-education was to give the patient an additional tool to control their behaviour and enable the selection of the most efficient coping strategy. The psycho-education was concerned with various aspects of ADHD and various neurocognitive functions, like attention, memory, planning, distraction and coping strategies, in particular. These issues were presented in a fixed order in every session. The intervention evaluated in the present paper consisted of eleven group sessions (one session per week) and one individual session per participant.

The intervention was performed in an evidence-based fashion. A randomized waiting list control group design was used and we examined whether this intervention was effective in reducing complaints and in improving cognitive functioning. During the course the emphasis was on complaints experienced by the participants. We therefore expected that this new neuropsychological treatment programme would have an effect on general functioning and on cognitive complaints in particular rather than on actual cognitive performance. The study was carried out in a controlled manner using two active interventions. There were two complementary methods used to assess the effects of the intervention studied. First, a neuropsychological test battery as well as questionnaires were used, which are known for their sensitivity in this type of intervention study (Valentijn et al., 2005; van Hooren et al., 2007). Secondly, a completely new approach was taken to evaluate the effect of the neuropsychological intervention. This involved a procedure which has proved its merits in evidence-based pharmacotherapeutic trials in psychiatric or neuropsychiatric patients (MartinezMartin, Rodriguez-Blazquez, Forjaz, \& de Pedro, 2009; Quinn et al., 2002; Schneider et al., 1997). In short, an experienced clinician blinded to the actual intervention, which each individual received, assessed the patient on various aspects of psychological and neuropsychological functioning. This clinician used a standardized clinical rating scale in order to evaluate change in cognitive and global functioning in the subjects with adult ADHD. The clinical rating scale used here was based on the Clinician's Interview Based Impression of Severity and Change (CIBIS and CIBIC), which was originally used in, and is a familiar element of, pharmacological studies (Schneider et al., 1997). 


\section{Methods}

\section{Procedure}

A baseline assessment ( $\left.T_{1}\right)$ and two follow-up assessments ( $\left.T_{2}, T_{3}\right)$ were used. The follow-up assessments were carried out after 12 weeks ( $T_{2}$ ), and again after 24 weeks (T3). All participants were screened for cognitive complaints, expectations of the programme and prior treatments. Demographic variables, medication and complaints of cognitive functioning were obtained. After screening, participants were randomly assigned to the intervention group (GMT+) or the psycho-education only group (psycho-education). As stated before, the current study was completed in a controlled manner using two active interventions.

\section{Participants}

Participants were referred for treatment of cognitive problems from the outpatient facility for adults with ADHD at Mondriaan Zorg Groep, location Vijverdal in Maastricht, The Netherlands. All participants had a diagnosis of ADHD (this diagnosis was made by a physician experienced in ADHD) and were 18 years of age or older. Major comorbid disorders according to the Diagnostic and Statistical Manual of Mental Disorders (DSM-IV-TR) (both axis I and axis 2, (APA, 2000)) were excluded from the treatment programme. The use of psychostimulants was not an exclusion criterion because of ethical considerations. In our sample 89 per cent of the participants used psychostimulants. Three participants did not use psycho stimulants (two participants in the experimental group and one participant in the control group). Every participant was screened by a certified psychologist on their motivation before the start of the training. None of the subjects had participated previously in a neuropsychological treatment/research programme. All participants gave informed consent. They were randomly assigned to the Goal Management Training and psycho-education group (GMT+ group) or the psycho-education only group. In total, four groups (two GMT+ groups and two psycho-education only groups) were evaluated.

Two participants of the experimental group dropped out; one because of health issues (severe migraine) and the other participant because of comorbid depressive disorder. In the second assessment, two participants were unable to participate; one because of house renovation/work and the other participant did not show up at several appointments. One participant was unable to take part in the clinical interview at $\mathrm{T}_{3}$ (because of annual leave) and one participant was unable to fill in the SCL-9o and CFQ, because of other responsibilities (work).

See Table 1 for information on the participants. Participants in the two groups did not differ according to age, sex and level of education. Twelve participants 
were included in the experimental group; the control group comprised fifteen participants. At baseline there were group differences on the clinical rating subscales (cognition and general). The control group displayed less interference in daily activities through subjective cognitive complaints. However, the Symptom Check List (SCL-90) score was high for both the experimental and the control group compared to Dutch norm groups. Also, the Cognitive Failure Questionnaire (CFQ) total score was high in both groups compared to Dutch norm groups, as expected.

\section{Treatment programme}

\section{Goal Management Training plus psycho-education for ADHD patients}

The aim of GMT is to teach patients a strategy to improve planning activities and to structure intentions. The training manual was previously translated into Dutch for use by older adults (Levine, 2000; Robertson, 2001; van Hooren et al., 2007). Van Hooren et al. have shown previously that a combination of psycho-education and training had the potential to change the attitude of older patients towards their functioning (van Hooren et al., 2007). One major addition to GMT for ADHD patients concerns the nature of 'psycho-education', i.e. an explanation of the various cognitive functions and the clinical picture of ADHD in adults in general. Furthermore, specific examples of cognitive failures in ADHD were discussed in the group. These examples were based on examples from GMT used by van Hooren et al. (van Hooren et al., 2007). Because of the addition of psycho-education, the programme was adapted to consist of twelve sessions, one individual session and eleven group sessions. The content of each session and the order in which the topics were addressed were structured in a protocol (See Box 1). The group session was co-ordinated by two clinical neuropsychologists: a trainer and an assistant. At the start of the programme, each group comprised a minimum of 6 and a maximum of 8 persons to ensure that the training group could function optimally. There were 2-hour sessions for 11 consecutive weeks. A manual containing the full text and tasks used by the trainer was available. The trainer included examples put forward by the participants in the session. All sessions were structured (see also for an extensive overview: van Hooren et al., 2007). In the group sessions the participants discussed their cognitive problems with peers and had the opportunity to support each other. At the end of each session, participants received homework exercises as well as hand-outs containing a summary of the session. All topics were illustrated with practical examples or exercises. The goal of the first session was to get acquainted with the trainers and other participants as well as with 
the goals of the programme. The expectations of the programme and increasing insight into the complaints about executive functioning were discussed. Psychoeducation on ADHD in adults was examined and participants were asked to reflect on what ADHD meant to them. In the second, third and fourth sessions, high risk situations were identified, the stop strategy was introduced using an automatic pilot metaphor and a personal catchphrase was chosen, for instance "time-out", "ho!" or "wait a minute". In the fifth session psycho-education with respect to memory functioning was offered. The stop strategy was extended in sessions four and five by means of a relaxation technique; information processing and working memory were also discussed (see Box 1). In the sixth session expectations of

Box 1. Overview of structure of the Goal Management Training (GMT) and psycho-education program

\begin{tabular}{|c|c|c|}
\hline & GMT & psycho-education \\
\hline Session 1 & $\begin{array}{l}\text { Getting acquainted/ } \\
\text { information about training }\end{array}$ & $\begin{array}{l}\text { Getting acquainted/ } \\
\text { information about training }\end{array}$ \\
\hline Session 2 & Identifying high risk situations & What is ADHD? \\
\hline Session 3 & $\begin{array}{l}\text { Identifying high risk situations/ } \\
\text { Choosing a personal catchphrase }\end{array}$ & Attention \\
\hline Session 4 & $\begin{array}{l}\text { Use of stop strategy/ } \\
\text { Relaxation technique }\end{array}$ & $\begin{array}{l}\text { Automatic versus non-automatic } \\
\text { tasks }\end{array}$ \\
\hline Session 5 & Stop! & Memory functioning \\
\hline Session 6 & Individual session: own goals & Individual sessions: own goals \\
\hline Session 7 & State! Decision making & Prioritizing \\
\hline Session 8 & State! Decision making & Planning \\
\hline Session 9 & Make subtasks (split) & $\begin{array}{l}\text { Making a week plan/ } \\
\text { Terms for an adequate planning }\end{array}$ \\
\hline Session 10 & Check and monitor & $\begin{array}{l}\text { Doing one thing at once/ } \\
\text { adapting structure }\end{array}$ \\
\hline Session 11 & Check and monitor & Work/Relationships/Finances \\
\hline Session 12 & Overview strategy & Overview psycho-education \\
\hline
\end{tabular}

Box 2. Structure of Goal Management Training (GMT) and psycho-education program

\begin{tabular}{|l|l|}
\hline Group conversation (how was your week?) & 15 minutes \\
\hline Discussion of homework & 15 minutes \\
\hline GMT & 30 minutes \\
\hline Break & 15 minutes \\
\hline Psycho-education & 30 minutes \\
\hline Round off and explanation homework & 15 minutes \\
\hline
\end{tabular}


the course, (individual) personal problems, and goals were discussed. Sessions seven and eight focussed on setting a goal. In sessions seven and eight, also psycho-education on prioritizing and planning was discussed. Session nine was used to discuss splitting a complex task into subtasks and then to prioritise these subtasks. In this session psycho-education on planning and organisation were presented. The main theme of sessions ten and eleven was to check current behaviour, for instance to check whether the goals set were still adequate. Psycho-education for this session was "doing one thing at the time". In the final session an overview was given and participants received an assignment in which they had to use the strategies learned and translate those to their daily lives. This assignment was then discussed in the group.

\section{Psycho-education only}

For the control group 'Psycho-education only', the psycho-education in every session did not contain the strategy training. In the control group, conversation was allowed and homework was discussed. The psycho-education was structured and presented in exactly the same order and in a similar manner as to the GMT+ group. Therefore, the sessions of the psycho-education only group (from T1 until T2) lasted one and a half hours, instead of the two hours for the GMT plus psycho-education group. In the final session (session 12) an overview of the psychoeducation was given. After the psycho-education programme had finished, the participants of the control group were given the strategy training.

\section{Outcome measures}

\section{Subjective functioning}

Cognitive Failure Questionnaire (CFQ): CFQ was used to evaluate the frequency of everyday cognitive failures, including subjective executive functioning. The scale is validated in Dutch and consists of 25 items measuring the frequency of everyday cognitive failures in the domains of memory, attention, perception and action (Broadbent, Cooper, FitzGerald, \& Parkes, 1982; Ponds, Commissaris, \& Jolles, 1997). Participants were asked to indicate on a 5-point scale how often they experienced particular cognitive failures (very often, quite often, occasionally, very rarely, never). Answers were recoded following Dutch instructions (Ponds, Commissaris, \& Jolles, 1997). A higher score on the CFQ indicates a larger number of cognitive failures.

Symptom Check List-90 (SCL-90): the SCL-90 is a multidimensional, self-reporting inventory of psychopathology (Derogatis, Rickels, \& Rock, 1976). The scores 
for the anxiety, depression and sleep subscales ranged from 0-50, 0-80 and 0-15, respectively. On all three scales, a higher score is considered indicative of a larger number of symptoms. The SCL-90 total score was used as a measure of distress.

\section{Objective executive functioning}

Zoo map from the Behavioural Assessment of the Dysexecutive Syndrome (BADS): the zoo map subtest is a planning test. It provides information about the ability to plan a route to visit six of a possible 12 locations in a zoo. The outcome measure chosen was the time needed to plan a route (unstructured version), since GMT involves teaching participants to stop their ongoing behaviour and take more time to plan (Burgess, Alderman, Evans, Emslie, \& Wilson, 1998; Krabbendam, de Vugt, Derix, \& Jolles, 1999).

\section{Clinical rating scale}

A certified and experienced clinical neuropsychologist who was not involved in the treatment programme and blind to the condition or group (GMT+ or psycho-education only) interviewed the participants. He rated participants at baseline and at the two follow-up meetings (after intervention) with respect to six areas of functioning. This included cognition, everyday functioning, work/social functioning, mood and general functioning according to the Clinician's Interview Based Impression of Severity and Change (CIBIS and CIBIC (Schneider et al., 1997)). Prior to the clinical rating, the neuropsychologist explained to the participants that he was blind to their condition and would not discuss themes from the programme. At baseline participants were rated on a 7-point scale: $1=$ no cognitive disorders, $2=$ subjective complaints, no interference in daily life, $3=$ subjective complaints and moderate interference in daily life, 4=subjective complaints and severe interference in daily life, $5=$ mild disorders, $6=$ moderate disorders; $7=$ severe disorders.

At the two follow-up assessments, participants were again rated on a 7-pointscale: $1=$ very much improved, $2=$ much improved, $3=$ minimally improved, $4=$ no change, 5 =minimal worsening; $6=$ moderate worsening, $7=$ severe worsening. The aspects most interesting in this study were the ratings of everyday functioning in general and cognition in particular as GMT was developed to teach patients a strategy for improving planning activities and to structure intentions and therefore diminish cognitive complaints. 


\section{Other measures}

Age was used as a continuous variable. Level of education was indexed on a 8point ordinal scale, ranging from primary to university education (De Bie, 1987).

\section{Statistical analyses}

Although the participants were randomly assigned to the two groups, possible differences could exist between these groups by chance. We first examined whether there were important demographic differences between the experimental and control groups. Using independent t-tests we compared age and level of education between the two groups. We also compared the level of distress (as measured by the SCL-90), cognitive failures, planning time and CIBIS at baseline between the two groups. See Table 1. A chi-square test was used to analyse group differences with respect to sex. General Linear Model (GLM) with repeated measures analysis of variance was applied to examine the effect of intervention. Analyses were carried out with group (two levels: experimental and control group) as between-subject factor and time (three levels: baseline, first-follow up and second follow- up) as the within-subject factor. Secondly, as we were primarily interested in differences between the two groups at T2, difference scores were calculated for all outcome measures (T2-T1), except for the ratings on the clinical rating scale (as 'change' was already measured in the clinical rating). To examine the effects of intervention on cognitive complaints as well as planning

Table 1. Participant characteristics

\begin{tabular}{|r|c|c|c|}
\hline Age & $\begin{array}{c}\text { Experimental } \\
\mathbf{n = 1 2}\end{array}$ & $\begin{array}{c}\text { Control } \\
\mathbf{n}=15\end{array}$ & p-value \\
\hline Sex (m/f) & 35.5 & 37.9 & 0.57 \\
\hline Education & $(7 / 5)$ & $(10 / 5)$ & 0.48 \\
\hline SCL-90 & 5.75 & 5.13 & 0.42 \\
\hline CFQ & 65.5 & 182.2 & 0.26 \\
\hline Zoo map (BADS) & 107.8 & 67.9 & 0.87 \\
\hline CIBIS cog & 4.0 & 87.7 & 0.60 \\
\hline CIBIS general & 3.9 & 3.3 & $0.05^{*}$ \\
\hline
\end{tabular}

Note: independent $\mathrm{t}$-tests were used for age and education.

Sex was analysed using Chi-square test

SCL-90= Symptom Check List-90; CFQ= Cognitive Failures Questionnaire; CIBIS= Clinician's Interview Based Impression of Severity. 
Figure 1. CFQ total score for the GMT+ group and psycho-education group only at baseline (1), follow up after 12 weeks (2), and follow up after 24 weeks (3).



Figure 2. SCL-9o total score for the GMT+ group and psycho-education group only at baseline (1), follow up after 12 weeks (2), and follow up after 24 weeks (3).

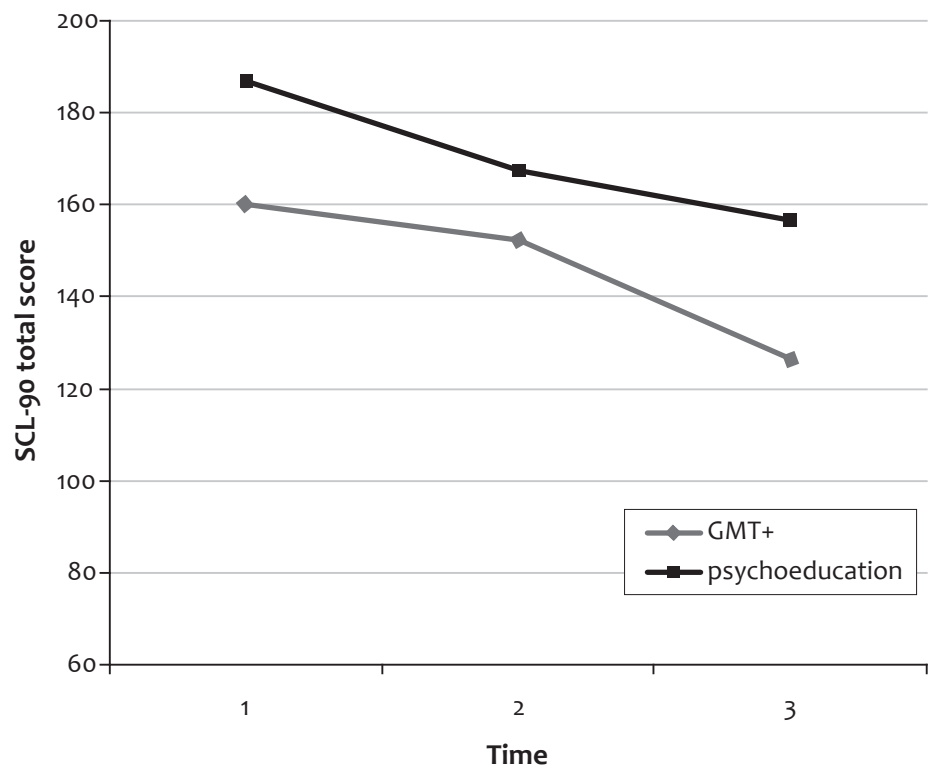


time at assessment two (T2) and three (T3), independent t-tests were carried out in both groups. The $15^{\text {th }}$ version of the Statistical Package for the Social Sciences (SPSS) for Windows was used for the statistical analyses (SPSS-Inc., Chicago), with $\mathrm{p}=0.05$ as significance level.

\section{Results}

\section{Effects of Goal Management Training (GMT) plus psycho-education for ADHD patients}

In assessment two, a significant effect was found between the two groups on the clinical rating scale for the domain 'cognition' $(F(1,22)=0.656, p=0.024)$. See Table 2/Figure 3. The clinician rated the participants in the experimental group as cognitively more improved between baseline (T1) and first follow-up (T2). The two groups did not differ on the clinical rating scale for the domain 'general functioning' $(F(1,22)=0.028, p=0.438)$. Secondly, GLM showed an effect of time for SCL90 total score, CFQ total score and Zoo planning time $(F(1,21)=11.86, p=0.002)$, $F(1,20)=35.66, p=0.000, F(1,22)=6.99, p=0.015)$. See Figures 1 and 2 . There were no interaction effects between group and time on any of the measures.

Figure 3. Clinical rating with respect to 'cognition' for the GMT+ group and psycho-education group only at follow up after 12 weeks (2), and follow up after 24 weeks (3). Clinical rating: $1=$ very much improved, $2=$ much improved, $3=$ =minimally improved, $4=$ no change, $5=$ minimal worsening; 6=moderate worsening, $7=$ =severe worsening

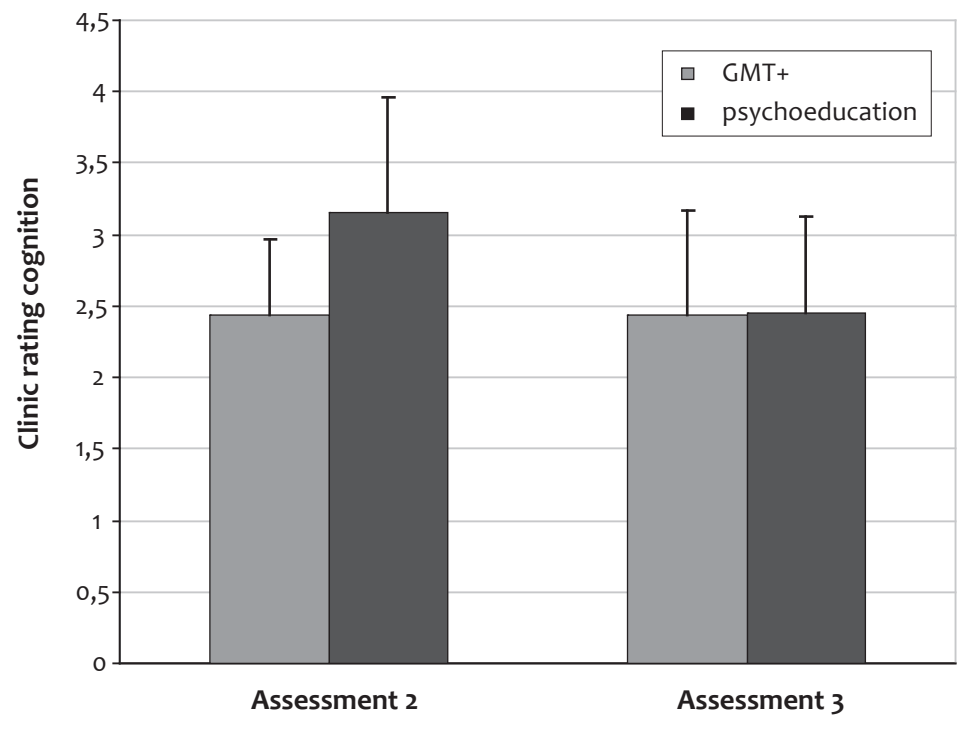


No significant effect was found with respect to the difference scores between follow-up one (T2) and follow-up two (T3) on level of distress as measured by the $\mathrm{SCL}-90(F(1,21)=0.000, p=0.983)$. Also, no significant effect was found with respect to the difference scores between follow-up one (T2) and follow-up two (T3) on cognitive failures $(F(1,21)=0.064, p=0.434$ Finally, no significant differences were found with respect to the planning time (Zoo Map subtest from the BADS) at follow-up one $(\mathrm{T} 2)(\mathrm{F}(1,22)=0.882, p=0.781)$.

\section{Discussion}

The aim of this investigation was to establish whether patients with ADHD would benefit from a structured course based on neuropsychological insights and including several aspects of executive functioning. A new research tool was used to evaluate the possible effect of the intervention in this controlled clini-

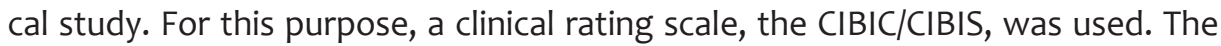
main hypothesis was that patients who were taught an executive strategy would be able to cope better with cognitive failures and would have fewer cognitive complaints compared to patients who received psycho-education only. The first finding in this study was that there were no significant differences between the two groups (experimental and control) with respect to age, level of education of level of distress. The clinician, however, rated that there was more interference in daily life activities for the experimental group. Both groups scored high on measures of distress and frequency of cognitive failures. Although participants with severe comorbidity were excluded from the intervention, the mean level of distress and complaints in several domains like depression, anxiety and sleep was overall high. There was also a great variance between individuals with respect to level of distress. Although comorbid psychiatric disorders were described as an exclusion criterion, the level of distress between participants in both groups strongly varied. For instance, the range of the SCL-90 total score was between 110 and 289.

A second finding of the present study was the significant effect of time on subjective and objective test measures in both groups. On the CIBIC, the experimental group improved more in the domain of cognitive functioning. This was in line with our hypothesis. In the current study the CIBIC was used for the first time in a controlled neuropsychological intervention study. The rating procedure carried out by a health professional blind to the protocal and who uses the CIBIC has potential in detecting changes over time. The present study proves that this is true not only for pharmacological treatment, but also for non-pharmacological 
Table 2. Means, Standard Deviation (SD), difference scores (T2-T1) and p-values of the independent T-tests.

\begin{tabular}{|c|c|c|c|c|}
\hline & T2 & T3 & T2-T1 & \\
\hline & $M(S D)$ & & & $p$-value \\
\hline \multicolumn{5}{|l|}{ CFQ } \\
\hline Exp & $50.7(13.6)$ & $48.9(10.1)$ & $-8.8(8.7)$ & 0.439 \\
\hline Control & $51.3(16.7)$ & $45.3(15.3)$ & $-5.7(9.4)$ & \\
\hline \multicolumn{5}{|l|}{ SCL-90 } \\
\hline Exp & $152.3(50.3)$ & 130.8 (23.9) & $-15.0(40.8)$ & 0.983 \\
\hline Control & $167.5(55.7)$ & $151.9(38.5)$ & $-14.6(42.6)$ & \\
\hline \multicolumn{5}{|c|}{ Zoo map } \\
\hline Exp & $62.3(48.6)$ & $71.1(73.6)$ & $-45.5(84.9)$ & 0.781 \\
\hline Control & $52.1(41.7)$ & $39.9(35.4)$ & $-35.6(83.7)$ & \\
\hline \multicolumn{5}{|c|}{ CIBIC cognition } \\
\hline Exp & $2.5(0.5)$ & & & $0.024 *$ \\
\hline Control & $3.1(0.8)$ & & & \\
\hline \multicolumn{5}{|c|}{ CIBIC general } \\
\hline Exp & $2.7(0.7)$ & & & 0.438 \\
\hline Control & $2.9(0.8)$ & & & \\
\hline
\end{tabular}

Note SCL-90 = Symptom Checklist-90 total score; CFQ = Cognitive Failures Questionnaire Total score; Zoo map = planning time in seconds (BADS); CIBIC = Clinician's Interview Based Impression of Change.

treatment. Interestingly, the present study showed that the CIBIC was sensitive to detecting clinical changes, whereas regular measurements, such as the level of complaints and objective test measures were not. Furthermore, an important advantage of the CIBIC is that the clinician is blinded to the condition and that the rating is based on a clinical interview.

As stated before, on other subjective and objective test measures no group differences were found. Our hypothesis that participants involved in GMT would display less distress and fewer cognitive complaints could only partly be confirmed (by using the CIBIC). Our research was aimed at investigating whether GMT would have an additional effect on psycho-education. The present study has not found very strong evidence for this. One explanation is that, in hindsight, our control group was given a full intervention ('active' control), which included peer interaction and providing information, which could have a positive treatment effect on increasing awareness of cognitive problems in itself. 
Therefore, our 'control' group was not in all respects an actual control group, but was in fact another active treatment programme. The fact that peers interacted with each other about their complaints and discussed factors like personality, coping styles and cognitive problems seems to have had an effect on the results. Another factor that needs to be considered is the fact that the group of participants was very heterogeneous. The diagnosis ADHD is based upon the DSM-IV criteria for children (APA, 2000). The main symptoms are: inattentiveness, hyperactivity and impulsivity. Participants in the current study were heterogeneous with respect to ADHD symptoms.

Qualitative information showed that some participants improved a lot after the GMT programme whereas as other participants did not benefit from the training. Future research should be aimed at gaining insight into what type of participants are "sensitive" to GMT and what factors contribute to this.

Qualitative information showed that the experimental group improved 12 weeks after the intervention programme stopped (T3). This is very promising information as it could be possible that the effects of the strategy training need time to become a new automatic process. Because of ethical reasons, the control group received the strategy training between $\mathrm{T}_{2}$ and $\mathrm{T}_{3}$. Therefore, we were unable to measure actual long-term effects of GMT in adults with ADHD. Future research could include investigating GMT in adults with ADHD compared to a waiting list control group. In this study, it was ethically not allowed to make the 'control' group wait, because of the high level of distress it could cause and need of care of participants. It could be assumed that because the 'control' group had the advantage of "distributed practice", the "control' group would in fact improve more over time (Wilson, 2003).

The present study found an effect of GMT over and above psycho-education for adults with ADHD in a clinical interview. The CIBIC was sensitive to detect clinical change and has potential in the contribution to the evaluation of neuropsychological intervention. Future research should include larger groups and a waiting list control group. 


\section{References}

Adler, L. A. (2008). Neurobiology, pharmacology, and emerging treatment. CNS Spectrum, 13(9 Suppl 13), 4, 1.

APA. (2000). Diagnostic and Statistical Manual of Mental Disorders (4th Edition-Text Revision). Washington D.C.: American Psychiatric Association.

Barkley, R. A. (1997). Behavioral inhibition, sustained attention, and executive functions: constructing a unifying theory of ADHD. Psychological Bulletin, 121(1), 65-94.

Barkley, R. A., Edwards, G., Laneri, M., Fletcher, K., \& Metevia, L. (2001). Executive functioning, temporal discounting, and sense of time in adolescents with attention deficit hyperactivity disorder (ADHD) and oppositional defiant disorder (ODD). Journal of Abnormal Child Psychology, 29(6), 541-556.

Boonstra, A. M., Oosterlaan, J., Sergeant, J. A., \& Buitelaar, J. K. (2005). Executive functioning in adult ADHD: a meta-analytic review. Psychological Medicine, 35(8), 1097-1108.

Broadbent, D. E., Cooper, P. F., FitzGerald, P., \& Parkes, K. R. (1982). The Cognitive Failures Questionnaire (CFQ) and its correlates. British Journal of Clinical Psychology, 21 (Pt 1), 1-16.

Burgess, P. W., Alderman, N., Evans, J., Emslie, H., \& Wilson, B. A. (1998). The ecological validity of tests of executive function. Journal of International Neuropsychological Society, 4(6), 547-558.

Davidson, M. A. (2008). ADHD in adults: a review of the literature. Journal of Attention Disorders, 11(6), 628-641.

De Bie, S. E. (1987). Standaardvragen 1987: Voorstellen voor uniformering van vraagstellingen naar achtergrondkenmerken en interviews [Standard questions 1987: Proposal for uniformisation of questions regarding background variables]. (2nd ed. ed.). Leiden, The Netherlands: Leiden University Press.

Derogatis, L. R., Rickels, K., \& Rock, A. F. (1976). The SCL-90 and the MMPI: a step in the validation of a new self-report scale. British Journal of Psychiatry, 128, 280-289.

Kooij, J. J., Burger, H., Boonstra, A. M., Van der Linden, P. D., Kalma, L. E., \& Buitelaar, J. K. (2004). Efficacy and safety of methylphenidate in 45 adults with attention-deficit/ hyperactivity disorder. A randomized placebo-controlled double-blind cross-over trial. Psychological Medicine, 34(6), 973-982.

Krabbendam, L., de Vugt, M. E., Derix, M. M., \& Jolles, J. (1999). The behavioural assessment of the dysexecutive syndrome as a tool to assess executive functions in schizophrenia. The Clinical Neuropsychologist, 13(3), 370-375.

Lerner, M., \& Wigal, T. (2008). Long-term safety of stimulant medications used to treat children with ADHD. Journal of psychosocial nursing and mental health services, 46(8), 38-48.

Levine B., R. I. H., Clare L., Carter, G., Hong J., Wilson, B. A., Duncan, J., Stuss D. T. (2000). Rehabilitation of executive functioning: an experimental-clinical validation of goal management training. Journal of International Neuropsychological Society, 6(3), 299-312.

Marchetta, N. D., Hurks, P. P., Krabbendam, L., \& Jolles, J. (2008). Interference control, working memory, concept shifting, and verbal fluency in adults with attention-deficit/ 
hyperactivity disorder (ADHD). Neurospsychology, 22(1), 74-84.

Martinez-Martin, P., Rodriguez-Blazquez, C., Forjaz, M. J., \& de Pedro, J. (2009). The clinical impression of severity index for Parkinson's disease: international validation study. Movement Disorders, 24(2), 211-217.

Ponds, R. W., Commissaris, K. J., \& Jolles, J. (1997). Prevalence and covariates of subjective forgetfulness in a normal population in The Netherlands. International Journal of Aging and Human Development, 45(3), 207-221.

Quinn, J., Moore, M., Benson, D. F., Clark, C. M., Doody, R., Jagust, W., et al. (2002). A videotaped $\mathrm{CIBIC}$ for dementia patients: validity and reliability in a simulated clinical trial. Neurology, 58(3), 433-437.

Robertson, I. H. L., B. (2001). Goal Management Training. Dublin.

Schneider, L. S., Olin, J. T., Doody, R. S., Clark, C. M., Morris, J. C., Reisberg, B., et al. (1997). Validity and reliability of the Alzheimer's Disease Cooperative Study-Clinical Global Impression of Change. The Alzheimer's Disease Cooperative Study. Alzheimer Disease and Associated Disorders, 11 Suppl 2, S22-32.

Shaw, P., Eckstrand, K., Sharp, W., Blumenthal, J., Lerch, J. P., Greenstein, D., et al. (2007). Attention-deficit/hyperactivity disorder is characterized by a delay in cortical maturation. The Proceedings of the National Academy of Sciences USA, 104(49), 19649-19654.

Stein, M. A. (2008). Treating adult ADHD with stimulants. CNS Spectrum, 13(9 Suppl 13), 8-11, 11.

Valentijn, S. A., van Hooren, S. A., Bosma, H., Touw, D. M., Jolles, J., van Boxtel, M. P., et al. (2005). The effect of two types of memory training on subjective and objective memory performance in healthy individuals aged 55 years and older: a randomized controlled trial. Patient Education and Counseling, 57(1), 106-114.

van Hooren, S. A., Valentijn, S. A., Bosma, H., Ponds, R. W., van Boxtel, M. P., Levine, B., et al. (2007). Effect of a structured course involving goal management training in older adults: A randomised controlled trial. Patient Education and Counseling, 65(2), 205-213.

Virta, M., Vedenpaa, A., Gronroos, N., Chydenius, E., Partinen, M., Vataja, R., et al. (2008). Adults with ADHD benefit from cognitive-behaviorally oriented group rehabilitation: a study of 29 participants. Journal of Attention Disorders, 12(3), 218-226.

Wilson, B. A. (2003). Neuropsychological Rehabilitation: theory and practice. Cambridge: Swets and Zeitlinger, BV. 



\section{Chapter Eight}

\section{Concluding remarks}

The main objective of this thesis was threefold. First of all, its aim was to gain insight into attention problems and their relationship with mental health (depression, anxiety) and Quality of Life (QoL) in the general adult population. The second objective was to gain more insight into the clinical picture of adult Attention-Deficit/Hyperactivity Disorder (ADHD). The third, and final, objective was to investigate the effect of a specific intervention programme based on Goal Management Training (GMT).

The results of the different studies, carried out to provide a better insight into these issues, were presented in this thesis. The outcome of these studies has a direct clinical application and gives fundamental insights in the phenomenology of attention dysfunction in adults.

Two of the studies focused on the relationship between attention complaints, or characteristics of ADHD, and cognitive functioning, mental health and QoL in the general adult population. Prevalence figures on attention complaints are important as attention complaints may lead to a larger number of psychiatric and emotional complaints and less QoL, as is suggested in students (Gudjonsson, Sigurdsson, Eyjolfsdottir, Smari, \& Young, 2008). This then would be an indication that there is a relative large group of adults with attention complaints and sub-clinical mental health problems, who may seek help in the future. Insight into the prevalence and character of attention complaints can lead to better understanding of these issues and, if necessary, adequate prevention and specific treatment.

Next, two studies focused on patients referred for a multidisciplinary assessment of ADHD in an out-patient facility. Important issues that were investigated were the differences between patients with and those without the diagnosis ADHD with respect to subjective and objective performance, and the contribution of hetero-anamnestic information in the diagnostic process of adult ADHD. Early recognition of adult ADHD is a necessary step towards adequate prevention programmes and effective treatment programmes.

Thirdly, neuropsychological data and theories were reviewed which has led to some practical implications for clinical neuropsychologists. Finally, a nonpharmacological, neuropsychological intervention programme involving GMT in 
adults with ADHD was evaluated. This chapter will provide some suggestions for further research and potential applications.

\section{A continuum of attention dysfunction/ADHD: clinical applications and fundamental insights}

One main goal of this thesis was to investigate the phenomenology of attention dysfunction/ADHD in adults. This kind of clinical research adds to the present knowledge of adult ADHD.

Every human being will recognise attention problems in varying degrees. Everybody knows someone who 'is often with his head in the clouds', or someone who is more chaotic than others. The person with ADHD will experience that people who do not suffer from ADHD also report attention or executive problems, and that those in their environment often disqualify their problems as something that is normal and nothing to worry about. However, ADHD is a serious, pervasive neurodevelopmental disorder that can affect an individual from childhood to adulthood. ADHD is characterized by symptoms of inattention, hyperactivity and impulsivity, which lead to dysfunction in more than one way. ADHD is also characterized by multiple cognitive deficits with a prominent position for attention and executive dysfunction. Executive functioning refers to higher-order cognitive processes which are responsible for goal-directed and contextually appropriate behaviour (Lezak, 1995; Pennington \& Ozonoff, 1996). Given that there are questions whether there is a continuum of attention complaints in the general and clinical population, we examined the subjective and objective attention/executive dysfunction in a general and clinical (ADHD) adult sample. By examining this, we will be better able to understand the phenomenology of attention/executive dysfunction in the general population as well as in the clinical population of ADHD.

To the best of our knowledge, the research conducted here is the first that has examined the relationship between ADHD characteristics or attention complaints and subjective and objective test measures in the general population.

Chapter two described that attention complaints in the healthy population are relatively common (at least $57.3 \%$ of all healthy participants reporting an attention complaint) and are related to depression, anxiety, sleep and several aspects of QoL, such as problems with social functioning, emotional problems and vitality. The current study shows that attention complaints are related to mental health problems and diminished functioning in daily life. This suggests that persons experiencing attention complaints will also experience other com- 
plaints or comorbid problems, and vice versa, which is in line with research findings in adult ADHD. The risk of development of anxiety and mood disorders, personality problems and substance abuse is significantly elevated (Biederman, 2005; Biederman et al., 1993). In fact, comorbidity is a distinct clinical feature of ADHD (Spencer, Biederman, \& Mick, 2007).

Clinicians should be aware that healthy subjects with complaints of attention and impulsivity/hyperactivity might be at risk of developing psychopathology, including depression and anxiety. Especially problems with response inhibition and impulsivity seem to be responsible for higher rates of psychiatric comorbidity. Another clinical implication is the fact that early recognition and acknowledgement of mild attention/executive dysfunction and comorbid problems can lead to adequate prevention programs.

Our findings indicate that attention complaints apparently do not exist by itself, even in the general population. There are indications that attention complaints are related to mental health and QoL. By examining ADHD characteristics in the general population, this thesis has shown that there is evidence for a continuum of attention complaints in the general population.

Chapter three explains that characteristics of ADHD in healthy subjects are related to diminished QoL and resemble problems seen in clinical samples, although to a lesser extent. This is an important finding and in line with several cognitive theories that consider lack of inhibition to be the 'core' deficit in $A D H D$, which results in more general executive function weaknesses. It is, however, unclear what the causal relationship exactly is between cognitive complaints and mental health or QoL. Strikingly, persons with ADHD often experience problems in several domains, including work and relationships throughout their lives. It is possible that these problems originate from (often sub-clinical) cognitive problems.

One hypothesis is that in ADHD, the cognitive problems are the primary reason for the fact that a person cannot develop adequately with respect to education and work, but these can also lead to problems on a personal level, which in turn can lead secondarily to emotional problems (frustration, low self-esteem). A primary problem in inhibition could lead to inappropriate coping mechanisms, which could account for several practical problems, including organisation of house- or homework, and managing finances.

There is more and more evidence that ADHD is the result of a maturational lag most prominently in prefrontal regions, which is important for control of cognitive processes, including the process of inhibition (Shaw et al., 2007). There is abundant proof that the brain of the person with ADHD develops dif- 
ferently. The brain of an ADHD patient seems to be wired differently, because of this maturational lag. In this sense, the term "growing into deficit" seems applicable in ADHD. In addition, the child with ADHD has different life experiences from the one without ADHD. Persons in their environment react in a different way to a hyperactive/impulsive or distracted child. This implies that in addition to brain differences between those suffering from ADHD and control subjects, the child with ADHD often has more negative experiences, which can lead to other comorbid problems.

Also, even mild attention dysfunction in the general population shows a similar pattern, where attention and executive complaints are related to affective problems and QoL. All in all, our findings support the evidence for the existence of a continuum of symptoms of ADHD in healthy subjects.

Our findings supporting a continuum of symptoms of ADHD in healthy subjects is in line with previous research findings (Frazier, Youngstrom, \& Naugle, 2007; Levy, Hay, McStephen, Wood, \& Waldman, 1997; Slaats-Willemse, SwaabBarneveld, de Sonneville, \& Buitelaar, 2007). Levy (1997) suggested earlier that $A D H D$ is best viewed as the extreme of a behaviour that varies genetically throughout the entire population rather than as a disorder with discrete determinants. Also, Slaats-Willemse (2007) found that family members of adults with ADHD performed intermediate between probands with ADHD and control subjects on attention control tests and tests of mental flexibility, suggesting that these executive functions may be appropriate endophenotypes of ADHD.

On the basis of the findings supporting the idea of a continuum of symptoms in ADHD, some fundamental research questions remain. The idea of the existence of a continuum of attention and executive dysfunction raises fundamental questions about the DSM-IV-TR approach. One option is not to describe ADHD as a category with subtypes, but along a dimension (Thapar, Langley, O'Donovan, \& Owen, 2006). This would, for instance, imply that measuring the severity of attention dysfunction would contribute to a better understanding of disorders along the continuum, with ADHD at one end of the continuum. This would also entail that the person with more or severe ADHD symptoms has a higher risk of e.g. comorbid disorders. Until now, research has paid not much attention to the idea of a continuum in ADHD. In the literature it is described that symptom scores of ADHD in adults are significantly associated with the degree of impairment (Kooij et al., 2005). The idea that a person "suffers somewhat from ADHD" would not be so strange in this respect. The clinician needs a consensus when to speak of pathology and where treatment is indicated. Future research should aim at validating the idea of a continuum of attention dysfunction. 


\section{Other clinical implications}

\section{Instruments for the diagnostic process of adult ADHD: clinical applications}

By examining the differences between an ADHD and a non-ADHD sample, all of which had been clinically referred for multidisciplinary assessment of ADHD, we gained insight into the clinical presentation of adults who were referred for ADHD diagnosis (Chapter 5). Our research led to the important finding that adults with ADHD are characterized primarily by executive problems, not attention problems. These findings gave us some additional tools to identify cases of ADHD correctly.

In our opinion, in the diagnostic interview executive functioning should be specifically addressed. Furthermore, neuropsychological evaluation in adult ADHD must focus on subtle executive problems, including self-monitoring. The studies described here found that adults with ADHD made more errors in a verbal learning task. These findings have to be considered in the diagnostic process of ADHD and correspond with some important cognitive theories on ADHD. Theories like Barkley's inhibition theory (1997) and the cognitive-energetic model of Sergeant, Oosterlaan, and van der Meere (1999) all consider executive problems, and inhibition in particular, as an important deficit in ADHD (Barkley, 1997; Sergeant, 1999). Our current research suggests that more attention should be paid to executive functioning, which advocates an important contribution from the clinical neuropsychologist.

Another finding was that a short parent rating scale, the Wender Utah Parent Rating Scale (WPRS) was sensitive to identify adults with ADHD (Chapter 6). In retrospect, parents scored their children in childhood significantly higher on certain behavioural aspects, such as low frustration tolerance, rapid mood swings, agitation, temper tantrums and impulsivity. In childhood these symptoms seem to be an important part of the clinical picture of ADHD and are reported in retrospect by parents. This study shows that a short parent rating scale on symptoms that go beyond the DSM-IV-TR criteria can be useful in the diagnosis of adult ADHD. In our study, correlates between informants and patients on childhood functioning were moderate at best. Our conclusion is that informants possess valuable information on childhood functioning, which assists in the diagnostic process in adult ADHD. Our idea is that referring clinicians could use the WPRS to guide the process of referral for multidisciplinary assessment. 


\section{Neuropsychological angle on ADHD: \\ the contribution of theoretical knowledge on diagnosis and treatment}

With respect to the contribution of neuropsychology and keeping the idea of a continuum of attention dysfunction/ADHD in mind, one would expect that, with the increase in severity of ADHD symptoms, neuropsychological test performance would decline. In this sense, neuropsychological test performance (in the domain of attention and executive functions) would be able to predict the degree of severity of ADHD symptoms. Also, there is ample evidence that ADHD is a neuropsychological disorder and not only a DSM-IV-TR classification. This implies that there is an important role for the clinical neuropsychologist in the diagnostic process and treatment of adult ADHD. Unfortunately, the role of the neuropsychologist in the diagnostic assessment and treatment of adult ADHD often goes unrecognized. We suggest that the neuropsychologist can contribute to the diagnostic assessment by describing strength and weaknesses and formulating hypotheses about cognitive functioning and underlying problems. The cognitive strengths/weaknesses (including an idea of the severity of cognitive impairment) could lead to better understanding of a person's abilities and indicate what type of intervention is needed. If, for instance, through neuropsychological assessment it becomes clear that there is primarily an inhibition problem, strategy training, involving goal management, may be proposed.

\section{Neuropsychological Intervention in adult ADHD}

Although there is a lot of neuropsychological knowledge of ADHD, this is not used on a regular basis in current treatment programmes. It was challenging to examine whether adults with ADHD would benefit from an intervention directed at executive functions, which are in fact the 'weaker' skills in ADHD (Chapter 7). Therefore, we developed an intervention based on Goal Management Training (GMT) for use in adults with ADHD (Robertson, 2001; van Hooren et al., 2007). GMT involves different aspects of goal management, including defining problems, encoding, retrieval strategies and self-monitoring. We used a clinical rating scale, the Clinician's Interview Based Impression of Severity and Change (CIBIC) CIBIS) to test our hypothesis that patients who learned an executive strategy would be able to cope better with cognitive failures and have fewer cognitive complaints compared to patients who received psycho-education only. On the $\mathrm{CIBIC}$, the experimental group improved more in the domain of cognitive functioning, as rated by an experienced clinician, which was in line with our hypothesis. On other subjective and objective test measures no group differences were 
found. Our hypothesis that participants involved in GMT would display less distress and fewer cognitive complaints could partly be confirmed. All in all, the majority of adults with ADHD who followed the GMT training improved over time on several aspects of functioning, including depression, anxiety, sleep, insufficiency, hostility and agoraphobia as reported in a self-report questionnaire. The intervention study described here was the first to show that a neuropsychological intervention was effective in adults with ADHD. This thesis described a psycho-education and GMT programme designed for adults with ADHD, which has proved to be effective over time. The fact that there was a slightly better performance of GMT on a clinical measuring scale compared to psycho-education only, is a promising result. Nevertheless, psycho-education is also an important aspect of treatment. The psycho-education and strategy training described here both originated from neuropsychological theories and neuropsychological experience. Both active interventions have an effect on functioning measured over time. This may be because strategy training and psycho-education apply directly to everyday functioning. We recommend that every intervention in adult ADHD should include psycho-education on the disorder and cognitive functioning. It should also address the emotions experienced by individuals. If the major problem is one of inhibition, GMT is wanted. Future research should aim to include larger groups and a waiting list control group.

\section{Where to go from here?}

The intention of this thesis was to contribute to a better understanding of attention dysfunction/ADHD in adults. From our studies of healthy persons, our basic suggestion is that attention dysfunction should be regarded as a continuum, ranging from no attention dysfunction until severe attention dysfunction, not as a categorical entity. More research on the validation of this concept is wanted. However, it is clear that the standard ADHD patient does not exist. For the diagnostic process, this means that not only criteria or categories, but also severity of attention dysfunction, neuropsychological profile and comorbid problems need to be considered. This kind of information would help with the adequate selection of treatment for the individual.

The conclusions from this thesis also signify some other consequences for the clinical practice. Since ADHD can be considered a neuropsychological disorder, there should be an important role for the clinical neuropsychologist in the multidisciplinary team of adult ADHD care. The neuropsychologist observes behaviour of the individual directly and can formulate a hypothesis on cognitive 
functioning. The neuropsychologist is also an expert when it comes to the evaluation of coping mechanisms.

The contribution of the neuropsychologist with respect to adults with ADHD lies in the assessment of specific strengths and weaknesses and the severity of cognitive impairment, as well as in psycho-education and strategy training. In the current care programs for ADHD, the role of the neuropsychologist is sometimes absent. This is a loss, as the neuropsychologist can make an important contribution. For instance, neuropsychological assessment should include a thorough examination of executive problems and executive functioning. Psycho-education on ADHD, neuropsychology and strategy training are important neuropsychological tools, but are often neglected in current care programs. Based on the results of our intervention study, we suggest that psycho-education on the important aspects of executive functioning as well as counselling with respect to coping behaviours should be implemented as a treatment option in adult ADHD. This thesis is a starting point for the evaluation of a new kind of neuropsychological treatment programme for adult ADHD. 


\section{References}

Barkley, R. A. (1997). Behavioral inhibition, sustained attention, and executive functions: constructing a unifying theory of ADHD. Psychological Bulletin, 121(1), 65-94.

Biederman, J. (2005). Attention-deficit/hyperactivity disorder: a selective overview. Biological Psychiatry, 57(11), 1215-1220.

Biederman, J., Faraone, S. V., Spencer, T., Wilens, T., Norman, D., Lapey, K. A., et al. (1993). Patterns of psychiatric comorbidity, cognition, and psychosocial functioning in adults with attention deficit hyperactivity disorder. American Journal of Psychiatry, 150(12), 17921798.

Frazier, T. W., Youngstrom, E. A., \& Naugle, R. I. (2007). The latent structure of attentiondeficit/hyperactivity disorder in a clinic-referred sample. Neuropsychology, 21(1), 45-64.

Gudjonsson, G. H., Sigurdsson, J. F., Eyjolfsdottir, G. A., Smari, J., \& Young, S. (2008). The Relationship Between Satisfaction With Life, ADHD Symptoms, and Associated Problems Among University Students. Journal of Attention Disorders.

Kooij, J. J., Buitelaar, J. K., van den Oord, E. J., Furer, J. W., Rijnders, C. A., \& Hodiamont, P. P. (2005). Internal and external validity of attention-deficit hyperactivity disorder in a population-based sample of adults. Psychological Medicine, 35(6), 817-827.

Levy, F., Hay, D. A., McStephen, M., Wood, C., \& Waldman, I. (1997). Attention-deficit hyperactivity disorder: a category or a continuum? Genetic analysis of a large-scale twin study. Journal of the American Academy of Child and Adolescent Psychiatry, 36(6), 737-744.

Lezak, M. D. (1995). Neuropsychological Assessment (3rd ed. ed.). New York: University Press.

Pennington, B. F., \& Ozonoff, S. (1996). Executive functions and developmental psychopathology. Journal of Child Psychology and Psychiatry, 37(1), 51-87.

Robertson, I. H. L., B. (2001). Goal Management Training. Dublin.

Sergeant, J. J., Oosterlaan, J. \& van der Meere, J.J. (1999). Handbook of disruptive behaviour. New York: Cambridge University Press.

Shaw, P., Eckstrand, K., Sharp, W., Blumenthal, J., Lerch, J. P., Greenstein, D., et al. (2007). Attention-deficit/hyperactivity disorder is characterized by a delay in cortical maturation. The Proceedings of the National Academy of Sciences USA, 104(49), 19649-19654.

Slaats-Willemse, D. I., Swaab-Barneveld, H. J., de Sonneville, L. M., \& Buitelaar, J. K. (2007). Family-genetic study of executive functioning in attention-deficit/hyperactivity disorder: Evidence for an endophenotype? Neuropsychology, 21(6), 751-760.

Spencer, T. J., Biederman, J., \& Mick, E. (2007). Attention-deficit/hyperactivity disorder: diagnosis, lifespan, comorbidities, and neurobiology. Journal of Paediatric Psychology, 32(6), 631-642.

Thapar, A., Langley, K., O’Donovan, M., \& Owen, M. (2006). Refining the attention deficit hyperactivity disorder phenotype for molecular genetic studies. Molecular Psychiatry, 11(8), 714-720.

van Hooren, S. A., Valentijn, S. A., Bosma, H., Ponds, R. W., van Boxtel, M. P., Levine, B., et al. (2007). Effect of a structured course involving goal management training in older adults: A randomised controlled trial. Patient Education and Counseling, 65(2), 205-213. 
Attention dysfunction and ADHD in adults: determinants and interventions 



\section{Summary}

Attentional deficits as well as objective impairments in attentional function are frequently found in several clinical conditions in adults, including Attention-Deficit/Hyperactivity Disorder (ADHD). Although more and more research is carried out in clinical ADHD samples, a number of important questions remain. What is the prevalence of attentional problems or characteristics of ADHD in the healthy population? What are the distinctive features of adult ADHD? What should be the role of the clinical neuropsychologist in the diagnostic process and treatment of adult ADHD?

In the first part of the thesis, the prevalence and consequences of attention dysfunction in a healthy sample was investigated. In the second part, we focussed on neuropsychological models, determinants, phenomenology and intervention in adult ADHD.

In Chapter 2, the influence of attentional problems on Quality of Life (QoL) was investigated in healthy subjects, aged 24 to 81 , drawn from a large population study. Attentional complaints appeared to be common over the age range tested. Furthermore, these were related to depressed mood, anxiety, vitality and sleep problems. These can have a serious impact on daily life functioning and QoL. Memory complaints were related to other aspects of health, such as pain and changes in health. We concluded that it is very relevant to recognize attention complaints in the healthy population. This is because these complaints are common and related to depression, anxiety, sleep patterns and several aspects of QoL. Relevant aspects of QoL were problems with social functioning, emotional problems and vitality. Insight into (factors contributing to) specific cognitive complaints in the current sample can lead to a better understanding of these and, in turn, to adequate prevention and specific treatment.

In Chapter 3, we investigated cognitive complaints using the Maastricht Cognitive Questionnaire (MCQ). In addition, QoL and complaints of depression and anxiety were measured using standard questionnaires. A cross-sectional sample was drawn from a large-scale longitudinal study. It was shown that complaints of inattention in combination with impulsivity/hyperactivity were related to a larger number of complaints of depression and anxiety. In addition, there was diminished satisfaction with life in these subjects. Inattention in childhood was not 
related to adult depression or anxiety. We found that characteristics of ADHD in healthy subjects are related to diminished QoL. In addition, they were related to problems of depression and anxiety as seen in clinical samples although to a lesser extent. Healthy adults with attentional problems in combination with impulsivity/ hyperactivity have a higher risk of the development of affective disorders.

In Chapter 4, we reviewed neuropsychological findings and (neuro)cognitive models of ADHD (primarily in adults). The most prominent model considers inhibition to be the primary/core problem in ADHD. This means that a person with $A D H D$ is unable to control their behaviour, to keep information in working memory, to think of the consequences of their behaviour, to set achievable goals or adjust these goals in light of new information ('monitoring'). Thus, problems in the inhibition of behaviour can have serious executive consequences, and in turn, consequences for daily life functioning. This model is applicable to the combined subtype of ADHD (i.e., that with inattention and hyperactivity-impulsivity), but not to the inattentive subtype. Another way of looking at ADHD is in a multidimensional way. Multidimensional models consider a role for both executive dysfunction/inhibitory deficits and delay-aversion in ADHD. Other multidimensional models believe that cognitive,as well as energetic factors influence symptoms seen in ADHD. All these models provide insight into the phenomenology and have a potential contribution to make in understanding the clinical picture of adult ADHD. In Chapter 4, casuistic information was added as the aim of the overview was to try and bridge the gap between theory and clinical practice. Knowledge of neurobiological and neuropsychological factors and models is clearly important in understanding the clinical picture of ADHD and this suggests a significant role for the clinical neuropsychologist.

In Chapter 5, we aimed to gain insight into the clinical presentation (viz. selfreported complaints and neuropsychological functioning) of adults referred for ADHD diagnosis. 42 per cent of all referred patients were diagnosed with adult ADHD. Adults with ADHD made significantly more errors in a verbal learning task than the non-ADHD control group, which indicates an impairment of the self-monitoring function in adult ADHD. The ADHD group reported more problems than the control group in the domains of executive functioning, but not in the domains of attention and hyperactivity. On the basis of these findings, we contend that more attention should be paid to executive complaints and functioning (present and past) when referring adults suspected of ADHD for multidisciplinary assessment. Also, characteristics that are thought to be striking symptoms of adult ADHD, such as problems with concentration and hyperactive behaviour, are in fact not distinctive symptoms of ADHD at all. 
In Chapter 6, we investigated whether specific childhood characteristics would predict adult ADHD by taking a checklist which is frequently employed to determine whether children have ADHD and using it to assess ADHD in the case of adults. The aim was to assess whether childhood functioning can aid the diagnosis of adults with ADHD. Parents scored children who received an ADHD diagnosis in adulthood significantly higher on certain behavioural aspects, such as low frustration tolerance, rapid mood swings, agitation, temper tantrums and impulsivity. In childhood, these complaints seemed to be an important part of the clinical picture of ADHD and they were reported retrospectively by parents. In adulthood, the semi-structured interview on childhood characteristics should take these aspects into account in the diagnostic process of adult ADHD.

In Chapter 7, we investigated whether patients with ADHD would benefit from a structured course involving several aspects of executive functioning (Goal Management Training (GMT)). The present study found a small effect of GMT over and above psycho education for adults with ADHD during a clinical interview. The CIBIC was sensitive to detect clinical cognitive change and has potential in contributing to the evaluation of neuropsychological intervention. Both groups (GMT and psycho-education) showed an improvement in overall functioning on other subjective and objective test measures. These are important findings as neuropsychological intervention in adult ADHD is often neglected and only few studies have investigated nonpharmacological interventions (despite the demand for it).

Chapter 8 represents the general discussion of the results of the studies described in this thesis. Clinical implications are provided and recommendations for future research are made. By examining ADHD characteristics in the general population, our research has shown that there is evidence for a continuum of attention complaints in the general population. Even mild attention dysfunction in the general population is related to affective problems and lower QoL. Early recognition and acknowledgement of mild attention and executive dysfunction and comorbid problems is important, because it can lead to prevention programs. The research carried out for this dissertation led to the important finding that adults with ADHD are characterized primarily by executive problems, not attentional problems. These findings gave us some additional tools for the diagnostic assessment of adult ADHD. Another important suggestion is that there is an important role for the clinical neuropsychologist in the diagnostic assessment and treatment of adult ADHD. Since ADHD can be considered a neuropsychological disorder, there should be an important role for the clinical neuropsychologist in the multidisciplinary team of adult ADHD care. The neu- 
ropsychologist observes behaviour of the individual directly and can formulate a hypothesis on cognitive functioning. The neuropsychologist is also an expert when it comes to the evaluation of coping mechanisms. The contribution of the neuropsychologist with respect to adults with ADHD lies in the assessment of specific strengths and weaknesses and severity of cognitive impairment, and specific neuropsychological treatment. 


\section{Samenvatting}

Aandachtsklachten en aandachtsstoornissen worden geobserveerd in verschillende volwassen klinische populaties, waaronder ook de Aandachtstekortstoornis met hyperactiviteit (ADHD). Ook al wordt er steeds meer onderzoek gedaan naar volwassen klinische ADHD groepen, er blijven een aantal belangrijke onderzoeksvragen bestaan. Wat is de prevalentie van aandachtsklachten of kenmerken van ADHD in de gezonde volwassen populatie? Wat zijn onderscheidende kenmerken van ADHD op volwassen leeftijd? Wat is de rol van de klinisch neuropsycholoog in de diagnostiek en behandeling van volwassenen met ADHD?

Voor het eerste gedeelte van dit proefschrift, worden de prevalentie en consequenties van aandachtsdisfunctioneren in een gezonde volwassen populatie beschreven. In het tweede gedeelte van het proefschrift, ligt de focus op de kliniek, waarbij neuropsychologische modellen, determinanten, fenomenologie en neuropsychologische interventies bij volwassenen met ADHD aan bod zullen komen.

In Hoofdstuk 2, wordt de invloed van aandachtsklachten op kwaliteit van leven beschreven in een groep volwassen deelnemers, in de leeftijd van 24 tot 81 jaar oud. Deze deelnemers zijn onderzocht in het kader van een grootschalige, longitudinale studie. Aandachtsklachten bleken binnen deze groep regelmatig voor te komen. Deze aandachtsklachten zijn gerelateerd aan depressie, angst, vitaliteit en slaapproblemen. Aandachtsklachten kunnen dus serieuze gevolgen hebben voor het dagelijkse functioneren en de kwaliteit van leven. Geheugenklachten blijken, daarentegen, gerelateerd aan andere gezondheidsaspecten, zoals pijn en veranderingen op het gebied van de gezondheid. De conclusie is dat het belangrijk is om aandachtsklachten in een gezonde populatie te herkennen. Ze komen geregeld voor en zijn gerelateerd aan psychische klachten en kwaliteit van leven. Wat betreft kwaliteit van leven zijn aandachtsklachten met name gerelateerd aan sociaal functioneren, emotionele problemen en vitaliteit. Inzicht in (factoren die bijdragen aan) specifieke cognitieve klachten in de onderzochte populatie kan leiden tot een beter begrip van cognitieve problemen, en op zijn beurt, tot adequate preventieprogramma's en specifieke behandeling.

In Hoofdstuk 3, wordt de relatie tussen cognitieve klachten, kwaliteit van leven, depressie en angst gemeten met bekende vragenlijsten en de Maas- 
trichtse Cognitie Vragenlijst voor Volwassenen (MCVV). Hiervoor werd een crosssectionele steekproef getrokken uit een grootschalige longitudinale studie. De resultaten tonen aan dat klachten op het gebied van aandachtstekort in combinatie met impulsiviteit/hyperactiviteit gerelateerd zijn aan een hogere mate van depressie en angst en een lagere kwaliteit van leven. Problemen op het gebied van aandachtstekort in de kindertijd blijken niet gerelateerd aan depressie of angst op volwassen leeftijd. Kenmerken van ADHD in gezonde personen blijken dus gerelateerd aan een lagere kwaliteit van leven. Bovendien zijn deze kenmerken gerelateerd aan depressie en angst, zoals die ook gezien worden in klinische populaties. Al met al, hebben gezonde personen met kenmerken van ADHD een groter risico op angst- en of depressieve klachten.

In Hoofdstuk 4, wordt een overzicht gegeven van de neuropsychologische bevindingen en (neuro-)cognitieve modellen van ADHD (voornamelijk in volwassenen). Het meest prominente model suggereert een rol voor "inhibitie" als een belangrijk probleem in ADHD. Dit betekent dat iemand met ADHD zijn eigen gedrag niet kan inhiberen, waardoor hij/zij ook bijvoorbeeld moeite heeft om informatie in het werkgeheugen te houden, na te denken over de consequenties van gedrag en haalbare doelen vast te stellen of, als dat nodig is, deze bij te stellen ("monitoren"). Inhibitieproblemen kunnen dus leiden tot verschillende (executieve) problemen, en dus tot problemen in het dagelijkse leven. Het inhibitiemodel is enkel van toepassing op het gecombineerde subtype van ADHD (aandachtstekortstoornis met hyperactiviteit/impulsiviteit). Een andere benadering is de multidimensionele benadering. Bepaalde multidimensionele modellen beschouwen, zowel executieve/inhibitieproblemen en vertraging-aversie ('delayaversion'), als belangrijke defecten in ADHD. Andere multidimensionele modellen geloven dat cognitieve en energetische factoren de symptomen van ADHD beïnvloeden. Al deze modellen geven inzicht in de fenomenologie en geven een belangrijke bijdrage in het begrip van het klinische beeld van ADHD op volwassen leeftijd. In Hoofdstuk 4, worden twee casussen beschreven in een poging om de kloof tussen theorie en praktijk te overbruggen. Kennis over de neurobiologie, neuropsychologie en theoretische modellen is belangrijk om het beeld van ADHD te kunnen begrijpen, hetgeen tevens impliceert dat er een belangrijke rol is weg gelegd voor de klinisch neuropsycholoog.

Het doel van Hoofdstuk 5 is om inzicht te geven in de klinische presentatie van ADHD op volwassen leeftijd door te kijken naar klachten en het neuropsychologisch functioneren van volwassenen die verwezen zijn voor ADHD diagnostiek. $42 \%$ van de verwezen patiënten kreeg de diagnose ADHD. Volwassenen met ADHD maakten significant meer fouten op een verbale leertaak dan de vol- 
wassenen zonder de diagnose ADHD, hetgeen mogelijk wijst op een 'self-monitoring'-probleem. De ADHD groep rapporteerde meer problemen dan de controlegroep op het gebied van executief functioneren, maar niet op de gebieden aandacht of hyperactiviteit. Op basis van deze bevindingen concluderen we dat meer aandacht besteed zou moeten worden aan executieve klachten en functioneren (zowel huidige klachten/functioneren als klachten/functioneren in het verleden) als iemand verdacht wordt van ADHD en verwezen wordt voor multidisciplinaire diagnostiek. Ook blijken kenmerken waarvan gedacht wordt dat ze typisch zijn voor ADHD, zoals concentratieproblemen en hyperactiviteit, niet typisch voor ADHD op volwassen leeftijd.

In Hoofdstuk 6, wordt een onderzoek beschreven naar de voorspellende waarde van specifieke kenmerken op de kinderleeftijd voor ADHD op volwassen leeftijd. Hiervoor wordt gebruik gemaakt van een frequent gebruikte heteroanamnestische vragenlijst om te bepalen of bepaalde kenmerken van ADHD op kinderleeftijd iets kunnen zeggen over het beeld op volwassen leeftijd. Het doel was vast te stellen of informatie over het functioneren op kinderleeftijd kan helpen in het diagnostisch proces naar ADHD op volwassen leeftijd. Ouders scoorden kinderen, die op volwassen leeftijd de diagnose ADHD kregen, hoger in op bepaalde gedragskenmerken, te weten lage frustratietolerantie, snelle stemmingswisselingen, agitatie, woedebuien en impulsiviteit. In de kindertijd blijken deze kenmerken een belangrijk deel van het klinische beeld zoals die door ouders worden ervaren. In de volwassenheid is het van belang deze aspecten van de kindertijd mee te nemen in het diagnostisch proces van ADHD.

Hoofdstuk 7 beschrijft de resultaten van een gestructureerde neuropsychologische interventie bij volwassenen met ADHD. Doel is om na te gaan of volwassen patiënten met ADHD profiteren van een gestructureerde interventie die verschillende elementen van executief functioneren omvat. De studie beschrijft een klein significant effect van Goal Management Training (GMT) bovenop psycho educatie bij volwassenen met ADHD, gemeten met een klinisch interview. Het klinisch interview bleek gevoelig om klinische cognitieve veranderingen te meten en kan een belangrijke bijdrage leveren in de evaluaties van neuropsychologische interventies. Beide groepen (GMT en psycho educatie) lieten een algemene verbetering zien op andere subjectieve en objectieve test maten. Dit zijn belangrijke bevindingen, aangezien neuropsychologische interventies in ADHD tot nu toe niet geëvalueerd zijn en er slechts weinig studies naar non-farmacologische interventies hebben gekeken (ondanks het feit dat er wel vraag naar is).

Hoofdstuk 8 presenteert een algemene discussie van resultaten die beschreven zijn in dit proefschrift. Klinische implicaties worden gegeven en verdere aan- 
bevelingen worden gedaan. Door het onderzoek naar kenmerken van ADHD in de algemene populatie, lijkt er bewijs voor een continuüm van aandachts en executieve klachten. Zelfs relatief milde aandachtsklachten zijn gerelateerd aan emotionele problemen en een lagere kwaliteit van leven. Een vroege her- en erkenning van milde aandachts- en executieve problemen en comorbide problemen is van belang, omdat het tot adequate preventieprogramma's kan leiden. Het onderzoek dat hier beschreven wordt geeft tevens aanwijzingen dat volwassenen met ADHD met name gekenmerkt worden door executieve problemen, niet zozeer aandachtsproblemen. Deze bevindingen geven extra handvatten voor het diagnostisch proces van ADHD op volwassen leeftijd. Een andere belangrijke implicatie van dit proefschrift is dat er een substantiële rol ligt weg gelegd voor de klinische neuropsycholoog in de diagnostiek en behandeling van ADHD. Aangezien ADHD gezien kan worden als een neuropsychologische aandoening, zou de neuropsycholoog ene belangrijke positie in moeten nemen in het multidisciplinaire team dat betrokken is bij de zorg voor volwassenen met ADHD. De neuropsycholoog observeert gedrag en kan hypotheses over het cognitief functioneren formuleren. De neuropsycholoog is tevens een expert wat betreft de evaluatie van copingmechanismen. De bijdrage van de neuropsycholoog bij volwassenen met ADHD ligt in het vaststellen van sterke en zwakke kanten, in het beschrijven van de ernst van de cognitieve stoornissen en het geven van specifieke neuropsychologische interventies gericht op executieve functies. 



\section{Dankwoord}

Op deze plek wil ik graag een aantal mensen bedanken die een belangrijke bijdrage hebben geleverd aan de totstandkoming van dit proefschrift.

Allereerst Jelle, dank voor de steun en het vertrouwen dat je me in de afgelopen jaren (al vanaf mijn studie!) hebt gegeven. Je hebt de wetenschapper in me wakker gewaakt. Ik ben je dankbaar voor alle uren overleg (op kantoor of aan de van Heylerhoflaan), de mooie metaforen en de bijdrage aan mijn persoonlijke en professionele ontwikkeling.

Jeanette, dank voor je positieve denken, relativerende vermogen en nakijken van al mijn artikels. Met name de laatste jaren zijn dankzij jouw meedenken en positieve bijdragen in een stroomversnelling gekomen.

De leden van de leescommissie en corona dank ik voor het beoordelen van dit proefschrift.

Natalie Marchetta wil ik danken voor de opzet van het ADHD-protocol en al het voorwerk dat zij heeft gedaan.

Petra Hurks, ooit stagebegeleider, nu mede-auteur, wil ik bedanken voor het gebruik van de Maastricht Cognitie Vragenlijst voor Volwassenen en de bijdrage aan maar liefst drie artikels in dit proefschrift. Het overleg was altijd gezellig en constructief.

Martin van Boxtel wil ik bedanken voor zijn co-auteurschap en denkwerk over methodologische kwesties en MAAS-zaken.

Rudolf Ponds wil ik bedanken voor zijn rol als expert in het onderzoek naar neuropsychologische interventies bij ADHD. Ik ben erg blij dat je bereid was om alle ADHD-patiënten op verschillende tijdstippen te beoordelen. Geduld bleek een schone zaak! Dank ook voor de bijdrage aan hoofdstuk 7. 
Uiteraard dank ik alle patiënten van de poli ADHD die wilden deelnemen aan het onderzoek. Tevens dank ik alle betrokken behandelaren van de poli ADHD van Vijverdal voor hun medewerking.

Met veel plezier en enthousiasme heb ik op de poli ADHD van Vijverdal gewerkt. In het bijzonder wil ik hier danken: Brechje-Dandachi-Fitzgerald, Esther Steins, Mery van de Ven, Inge Knuts, Femie Kengen, Lilian Huijnen, Desiree Tap-Op 't Veld, Yindee van Os, Josien Schneiders, Esmeralda Klinkenberg, Climmy van den Nieuwenhof, Elvire Duchateau, Carlein Karimoen, Marielle Wetzels, Theodoor de Kraker, Linda Rooijakkers, Elke de Koning en Loes Weusten.

Daarnaast dank ik alle betrokken AIO's, onderzoekers en medewerkers van DOT 12 voor de interesse en de mogelijkheden voor overleg.

Marjolein de Vugt, mijn huidige kamergenoot, wil ik danken voor haar enthousiasme, haar luisterende oor en de gezellige baby- en kinderkletspraat.

Tevens bedank ik de collega's op de Geheugenpoli/afdeling Psychiatrie voor hun belangstelling en steun, in het bijzonder: Carla Brandts, Heidi Lansdaal, Fleur Prompers, Kirsten Smeets, Inez Ramakers, Pauline Aalten, Annelien Duits, Roos Verkooyen en oud-collega's Floor van Bergen, Femke Dings en Yvonne Bol.

Susan van Hooren en Susanne Valentijn bedank ik voor hun werk op GMT-vlak: de gezellige trip naar Dublin en de vertaling van de GMT zijn de basis voor dit proefschrift.

Elsa Misdom, dank voor alle logistieke bemoeienis bij het afronden van het proefschrift.

Nico Rozendaal, Wim van der Elst en Dick Willems wil ik bedanken voor de ondersteuning bij statistische en methodologische kwesties.

Ook dank ik Krystle en Chelley voor de hulp bij het invoeren van de data.

Maaike van de Reyen, dank voor de medewerking bij de zorgadministratie van Vijverdal en het steeds opnieuw zoeken en aanleveren van dossiers.

Anita Kaemingk, dank voor de mooie lay-out en het oog voor detail. 
Dees, bedankt voor je geweldige dosis humor, enthousiasme en steun. Er ging geen week voorbij zonder dat je vroeg naar het proefschrift (ook al lag er nog niets... ). Fijn dat jij er bij bent als paranimf (met "inhoud"). Het lijkt wel of we het hebben afgesproken! Is niet de eerste keer dat we "in sync" zijn. Fer ook bedankt voor je interesse, vriendschap en 'het genieten': "Wanneer gaan we weer naar Beluga?"

Ghis, "kleine" zus, ben blij dat jij naast me staat. Hoop nog vaker met jou en Etienne naar DVD-tjes te kijken en naar Pinkpop te gaan. Ik ben er trots op dat ik jouw werk voor de omslag van dit proefschrift mocht gebruiken! Ziet er mooi uit!

Veronique \& Sven, Josien \& Steven. Bedankt voor de gezellige etentjes, afspraakjes en de afleiding. Dat we er nog vaak op uit mogen (met of zonder de kids).

Joep, Susanne, Fia, Karel: het is af! Dank voor jullie belangstelling en medeleven.

Mam, dank voor het meeleven en de stimulans; zonder jouw en paps investeringen was dit niet mogelijk geweest.

Lieve Bart, zonder jou lag dit proefschrift er niet. Dank voor al je liefde. Je mag dan wel alleen opgenomen zijn in de "acknowledgements", maar je staat voor mij op nummer 1 !

Isabel, lieve meid, ik ben gek op je! 
Attention dysfunction and ADHD in adults: determinants and interventions

158 


\section{Curriculum vitae}

Dymphie Mathilde Joseph Maria Scholtissen-In de Braek werd geboren op 23 september 1977 in Maastricht. In 1994 behaalde ze haar HAVO-diploma en in 1996 haar VWO-diploma aan het Stella Maris College te Meerssen. Daarna ging ze Psychologie studeren aan de Universiteit Maastricht. Zij koos voor de biologische richting met als afstudeervariant Neuropsychologie. Haar onderzoeksstage richtte zich op de woordvlotheid van kinderen met ADHD en maakte deel uit van een longitudinale studie, de Study of Attention Disorders Maastricht (SAM). $\mathrm{Na}$ haar afstuderen, in september 2000, startte zij als onderzoeker/psycholoog op de Academische Afdeling voor Neuropsychologie (AAN) en de afdeling NietAangeboren Hersenletsel (NAH)/Ouderenpsychiatrie van Psycho Medisch Streekcentrum (PMS) Vijverdal (inmiddels Mondriaan Zorg Groep). In deze periode maakte ze kennis met de Goal Management Training (beschreven in dit proefschrift). Vervolgens volgde ze in de periode 2003-2004 de opleiding tot Gezondheidszorgpsycholoog aan de afdeling Geheugenpoli/Poli Psychiatrie van het academisch ziekenhuis Maastricht (azM). Na het afronden van de GZ-opleiding startte ze als Gezondheidszorgpsycholoog/coördinator ADHD-team aan de poli ADHD binnen de zorglijn Neuropsychiatrie van PMS Vijverdal. Het onderzoek dat ze hier deed staat beschreven in dit proefschrift. Sinds april 2007 is ze werkzaam op de Geheugenpoli/Poli Psychiatrie van het azM (inmiddels Maastricht Universitair Medisch Centrum (MUMC)), waar ze klinisch werk en onderzoek combineert. 
